SAND94-1706

Unlimited Release

Printed October 1994
Distribution

Category UC-800

\title{
ROBOTIC ALL-TERRAIN LUNAR EXPLORATION ROVER (RATLER) FY93 PROGRAM STATUS REPORT
}

\author{
Wendy A. Amai, Paul R. Klarer, \\ J. Bryan Pletta, and James W. Purvis \\ Sandia National Laboratories \\ Advanced Vehicle Development Department \\ Albuquerque, NM 87185 \\ Roger P. Case \\ Technadyne Engineering Consultants, Inc. \\ Albuquerque, NM 87192
}

\begin{abstract}
The development of a Robotic All-Terrain Lunar Exploration Rover (RATLER) prototype is described. The RATLER Laboratory-Directed Research and Development (LDRD) project was initiated in Fiscal Year 1993 (FY93) for a period of two years. This document reports on the project's activities during the first year of development and briefly discusses plans for the second year's work. Details include analysis of the rover's performance requirements for expected lunar conditions and a description of a point design selected as being representative for an actual rover. Technical information regarding several prototypes constructed and tested during FY93 is included, as is a discussion of weaknesses in the current RATLER design. Plans for addressing these weaknesses in the project's second year are outlined and briefly discussed.
\end{abstract}




\section{ACKNOWLEDGMENTS}

The authors wish to acknowledge their colleagues in the field of robotics for planetary exploration, without whose support and encouragement the RATLER project may never have materialized. Specifically, the Space Exploration Initiative Office at NASA/Langley Research Center, the ARTEMIS Project Office at NASA/Johnson Space Center, the Telerobotics Program Office at NASA Headquarters, and the NASA TeleRobotics Intercenter Working Group were instrumental in their critiques and evaluations of the RATLER design concept, which provided significant input to the RATLER project and helped to drive the design in important areas. A special acknowledgment of the work of Dr. James Purvis (Sandia National Laboratories, Department 9204) is appropriate since the RATLER design concept originated with him. The entire RATLER project team appreciates his thoughtful insights and ideas, which provided a theoretical basis for the work, and his generosity in sharing those ideas for the benefit of the team and the project. 


\section{DISCLAIMER}

This report was prepared as an account of work sponsored by an agency of the United States Government. Neither the United States Government nor any agency thereof, nor any of their employees, make any warranty, express or implied, or assumes any legal liability or responsibility for the accuracy, completeness, or usefulness of any information, apparatus, product, or process disclosed, or represents that its use would not infringe privately owned rights. Reference herein to any specific commercial product, process, or service by trade name, trademark, manufacturer, or otherwise does not necessarily constitute or imply its endorsement, recommendation, or favoring by the United States Government or any agency thereof. The views and opinions of authors expressed herein do not necessarily state or reflect those of the United States Government or any agency thereof. 


\section{DISCLAIMER}

\section{Portions of this document may be illegible in electronic image products. Images are produced from the best available original document.}




\section{CONTENTS}

$1.0 \quad$ INTRODUCTION

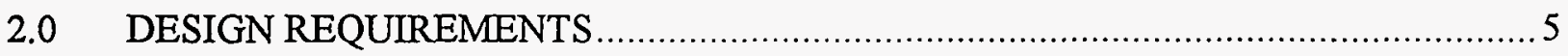

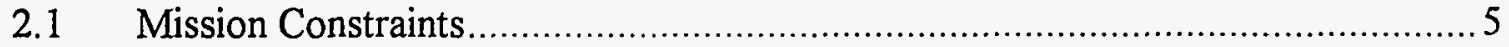

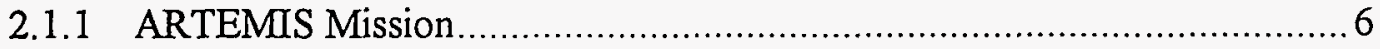

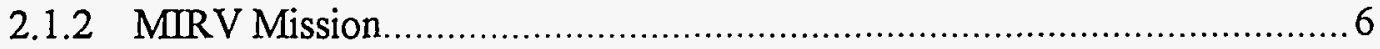

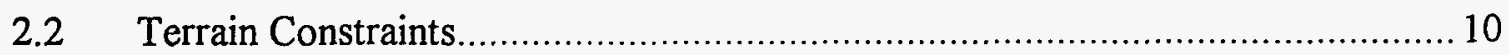

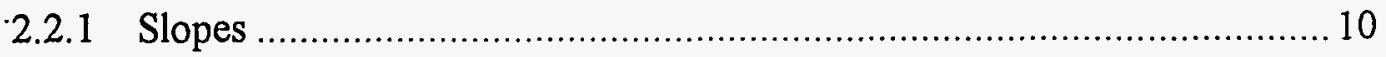

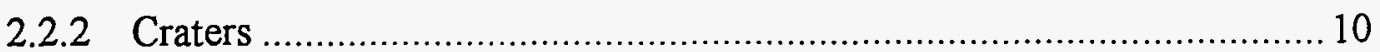

2.2.3 Boulders/Obstacles .......................................................... 11

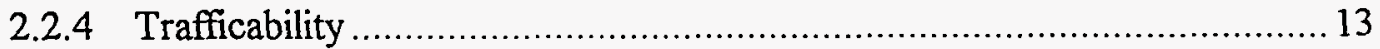

2.3 RATLER Functional Requirements ....................................................... 13

2.4 Conclusions from Analysis ........................................................... 16

3.0 KINEMATICS ANALYSIS OF RATLER MECHANISM ................................. 18

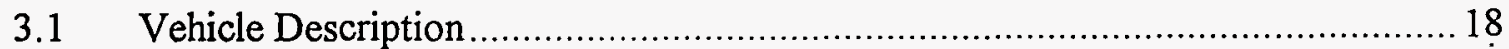

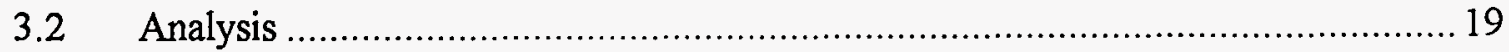

4.0 RATLER SCALE MODELS AND PATHFINDER .............................................2 27

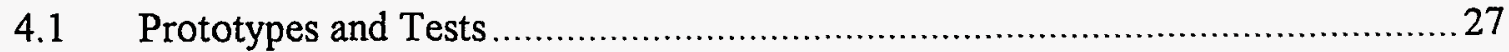

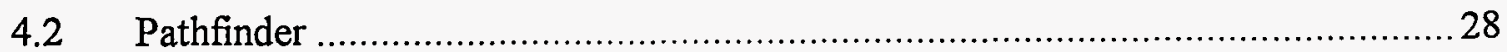

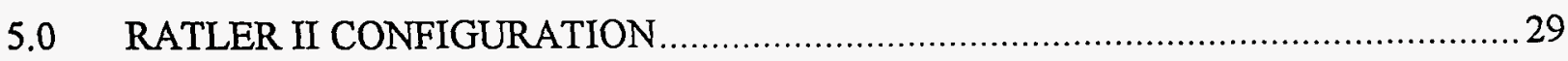

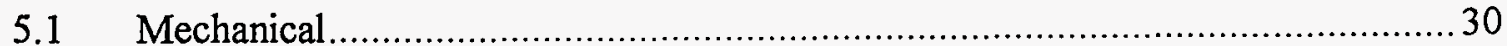

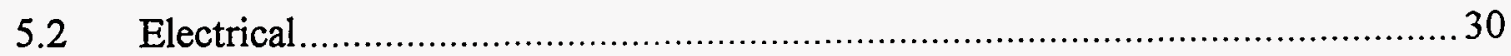

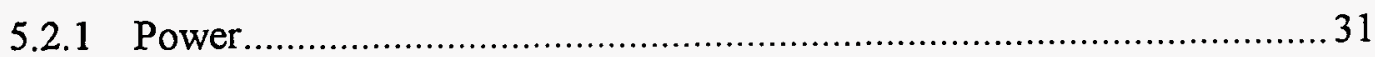

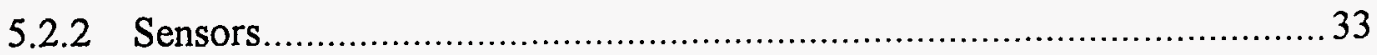

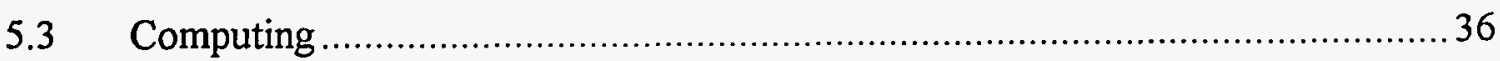

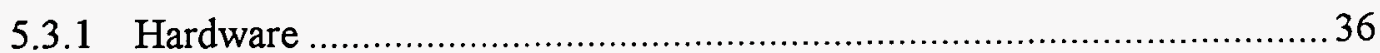


6.0 CONTROL DRIVING STATIONS (CDS)

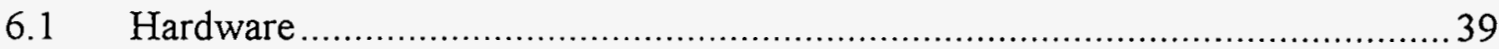

6.1.1 Mechanical System .............................................................. 40

6.1 .2 Electrical ...................................................................... 41

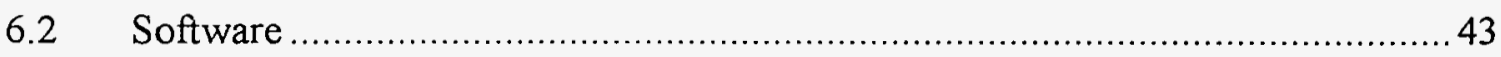

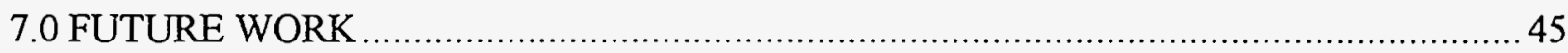

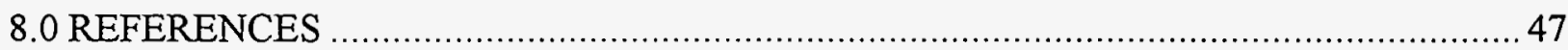

APPENDIX A: RATLER TECHNICAL INFORMATION

\section{FIGURES}

1. RATLER Testing at Death Valley .................................................................. 2

2. RATLER-A in Simulated Mars Terrain .............................................................. 3

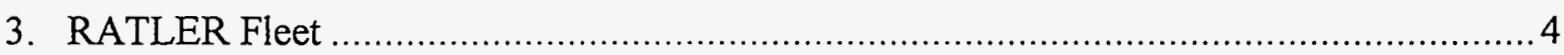

4. RATLER Control Driving Station............................................................... 4

5. ARTEMIS Common Lunar Lander ................................................................... 6

6. ARTEMIS with a 10-ft DELTA Shroud …................................................... 7

7. MIRV Orbital Transfer System ...................................................................... 8

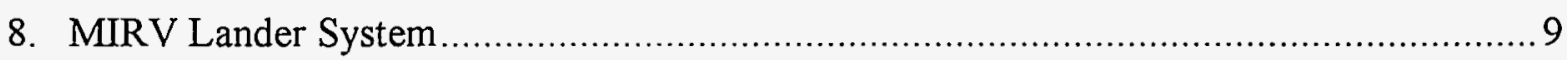

9. Crater Physical Parameters........................................................................... 12

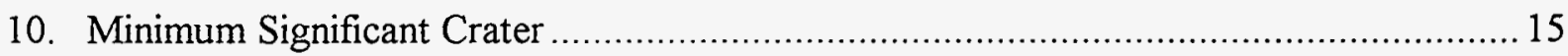

11. Maximum Significant Crater ................................................................... 15

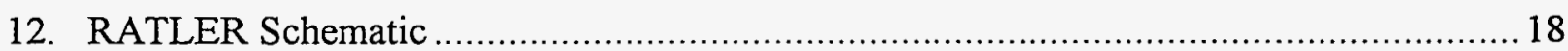

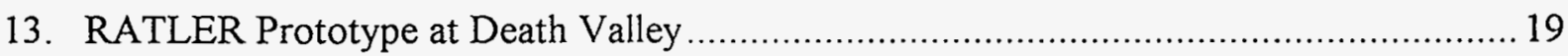

14. Maximum Step Clearance Geometry ............................................................... 20

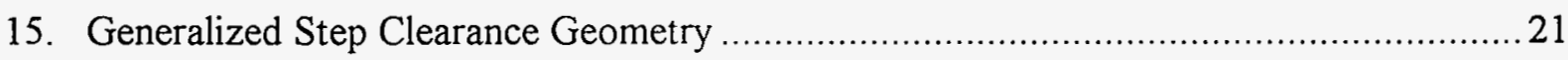

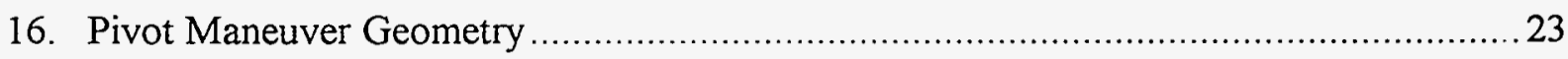

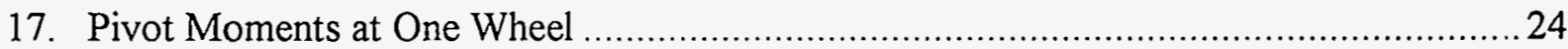




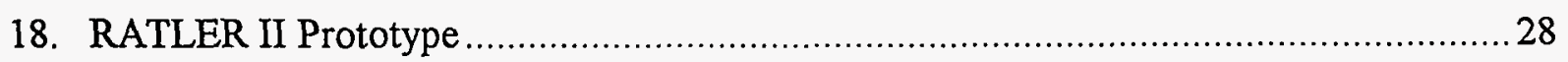

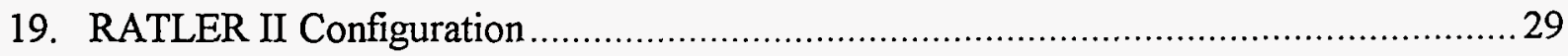

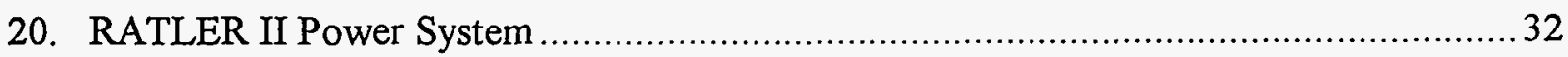

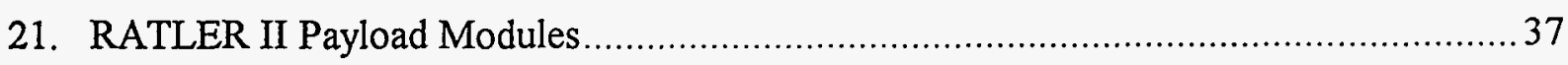

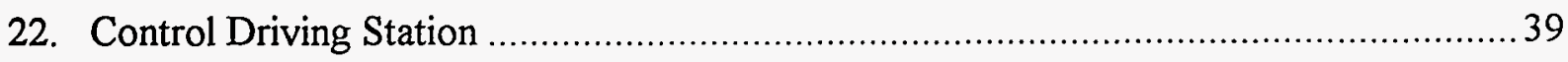

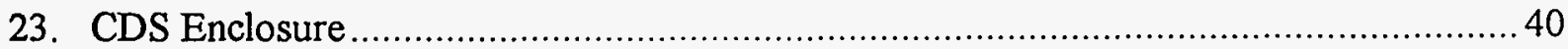

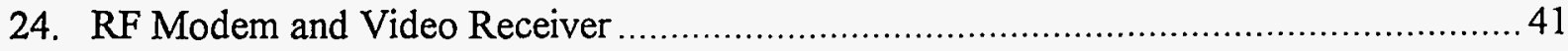

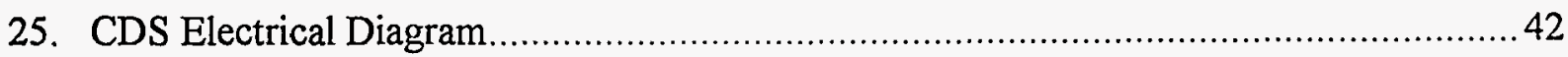

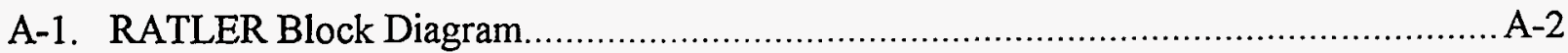

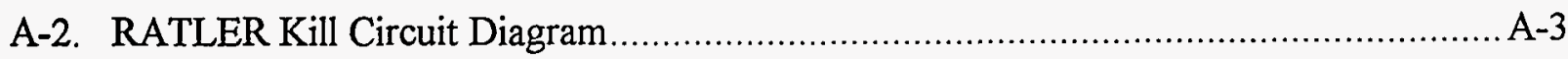




\section{TABLES}

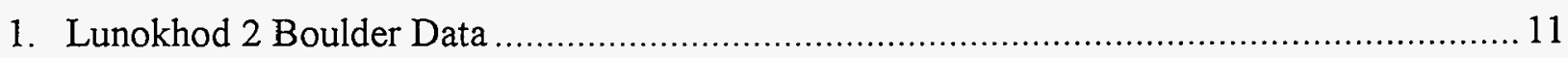

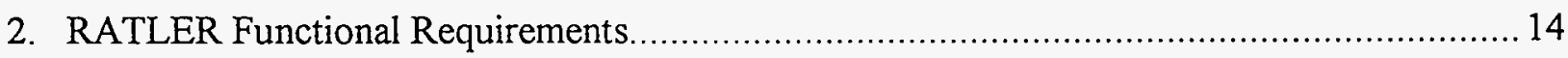

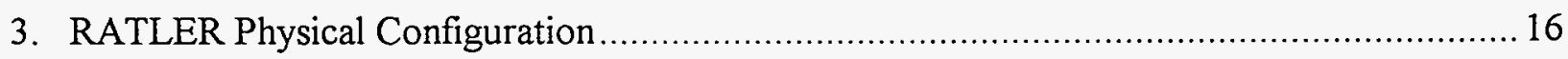

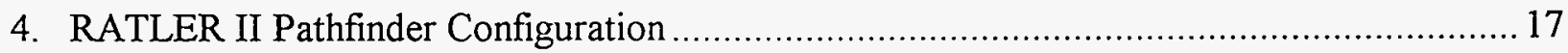

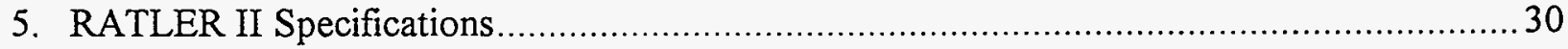

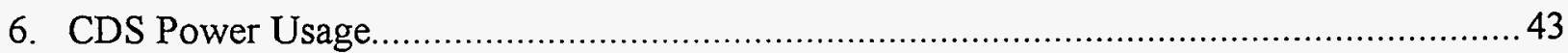




\subsection{INTRODUCTION}

In 1989 President George Bush called for the establishment of a U.S. Space Exploration Initiative (SEI) with the goals of returning to the Moon to stay and a manned mission to Mars. Subsequent national studies such as the National Aeronautics and Space Administration's (NASA) 90-Day Study' and the Synthesis Report ${ }^{2}$ led to significant renewed interest in robotic precursor missions for exploration of the Moon. In response to the President's call, engineers at Sandia National Laboratories (SNL) developed an innovative concept for a robotic rover vehicle designed for use in the exploration of the lunar surface. The design configuration, mobility parameters, and performance of several prototypes of this vehicle are the subject of this report.

Sandia National Laboratories' Robotic Vehicle Range (SNL/RVR) has been developing mobile robotic systems for a variety of Department of Energy (DOE) and Department of Defense (DoD) applications since 1984. Beginning in 1989, the SNL/RVR began exploring civil space applications that could make use of the existing technology base, particularly in lunar exploration missions. A philosophy that stresses simplicity in the design and implementation of a rover system wherever possible has been the basic tenet of the SNL/RVR's approach to the problem of lunar exploration. In line with this philosophy and without official funding, an innovative concept for a simple, agile lunar rover vehicle was developed and evaluated in the form of several scale models.3,4 The Soviet Union's space program successfully operated two lunar rovers ${ }^{5,6}$ in the early 1970s using very simple technology. These efforts demonstrated that teleoperation is a viable technique despite the inherent Earth-Moon communication time delay, and that relatively simple mechanisms can provide a useful level of capability to perform meaningful science through telerobotics. Figure 1 shows one of the early models of SNL's Robotic All-Terrain Lunar Exploration Rover (RATLER) - the focus of Sandia's lunar exploration efforts-during field testing at Death Valley National Monument in the late spring of 1992.

Over the summer of 1992, two summer-hire students employed at SNL/RVR designed, constructed, and tested a more robust version of the RATLER scale model, called RATLER-A. RATLER-A and the original models provided additional testing opportunities at the White Sands National Monument, where the RATLER design concept showed promise for very good mobility and agility characteristics in very dry, loose gypsum sand. Two additional models were built to demonstrate the concept to NASA, DOE, and the public at the National Air and Space Museum's Planetary Rover EXPO in September 1992. Figure 2 shows the RATLER-A being operated over simulated Mars terrain at the Planetary Rover EXPO. 


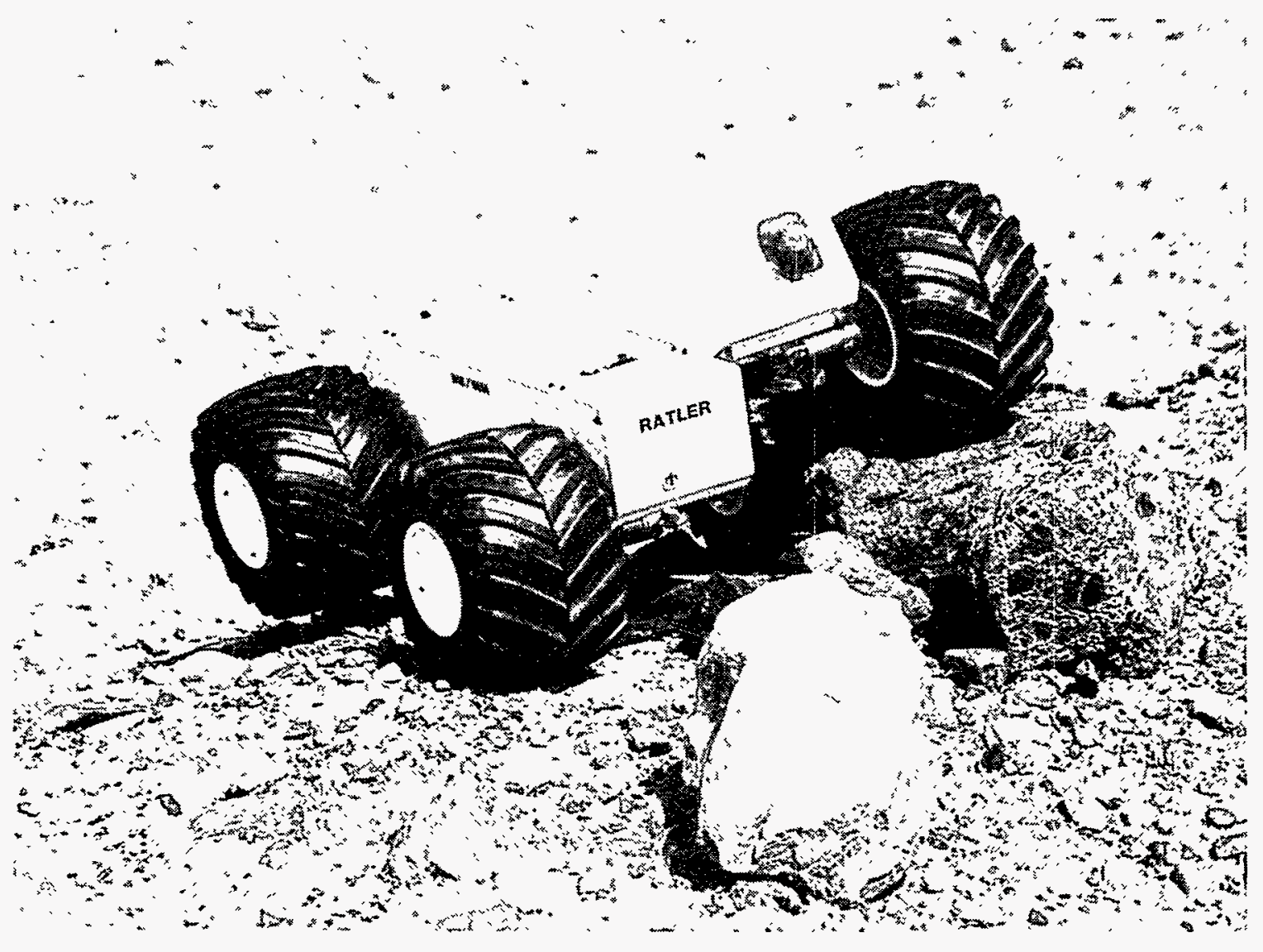

Figure 1. RATLER Testing at Death Valley.

As a result of the work with the scale models, a Laboratory-Directed Research and Development (LDRD) program was initiated to develop a full-scale RATLER vehicle. The LDRD project was originally proposed for a period of two years, beginning in October 1992, and was recently approved for further development in Fiscal Year 1994 (FY94). The remainder of this report focuses on the LDRD program for development and testing of the full-scale RATLER, called RATLER II. The program's goals for FY93 were to determine what constraints existed in the lunar rover mission scenario that would tend to drive vehicle requirements, and then to determine those requirements in terms of vehicle functionality and design. After determining constraints and deriving requirements for the rover, a design and prototyping activity of a fullscale, representative lunar rover vehicle was to be initiated. The prototype design was to be capable of satisfying the requirements derived earlier, as well as providing a capacity to extend capabilities beyond those originally scoped into the design. As a secondary design goal, any opportunities to exploit possible "dual use" aspects of the prototype for terrestrial applications were to be pursued, or allowed, as long as they did not adversely impact the primary design goal of a lunar surface exploration rover prototype. The specific deliverable for FY93 was to be a 


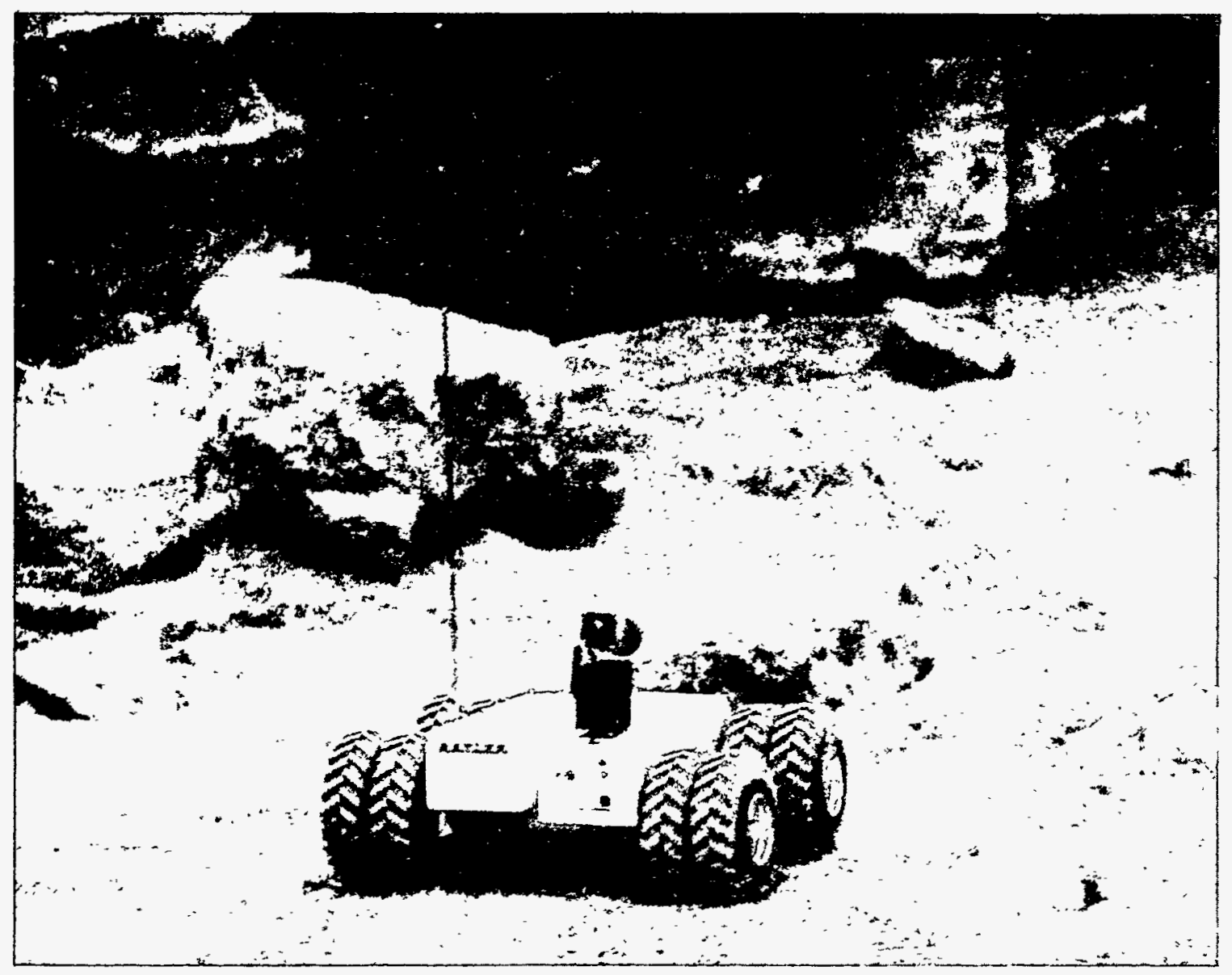

Figure 2. RATLER-A in Simulated Mars Terrain.

functional, teleoperated lunar rover prototype system, and the end-of-year milestone was a demonstration of teleoperation functionality. In summary, the goals for the RATLER II development program were to develop a one-meter scale RATLER vehicle using off-the-shelf technology and to demonstrate a capability commensurate with stated or inferred requirements for a lunar exploration rover vehicle. In conjunction with the actual vehicle platform, a compact, portable Control Driving Station (CDS) was also developed to support field operations. Figures 3 and 4 show several RATLER versions, including the full scale RATLER II, and the CDS. 


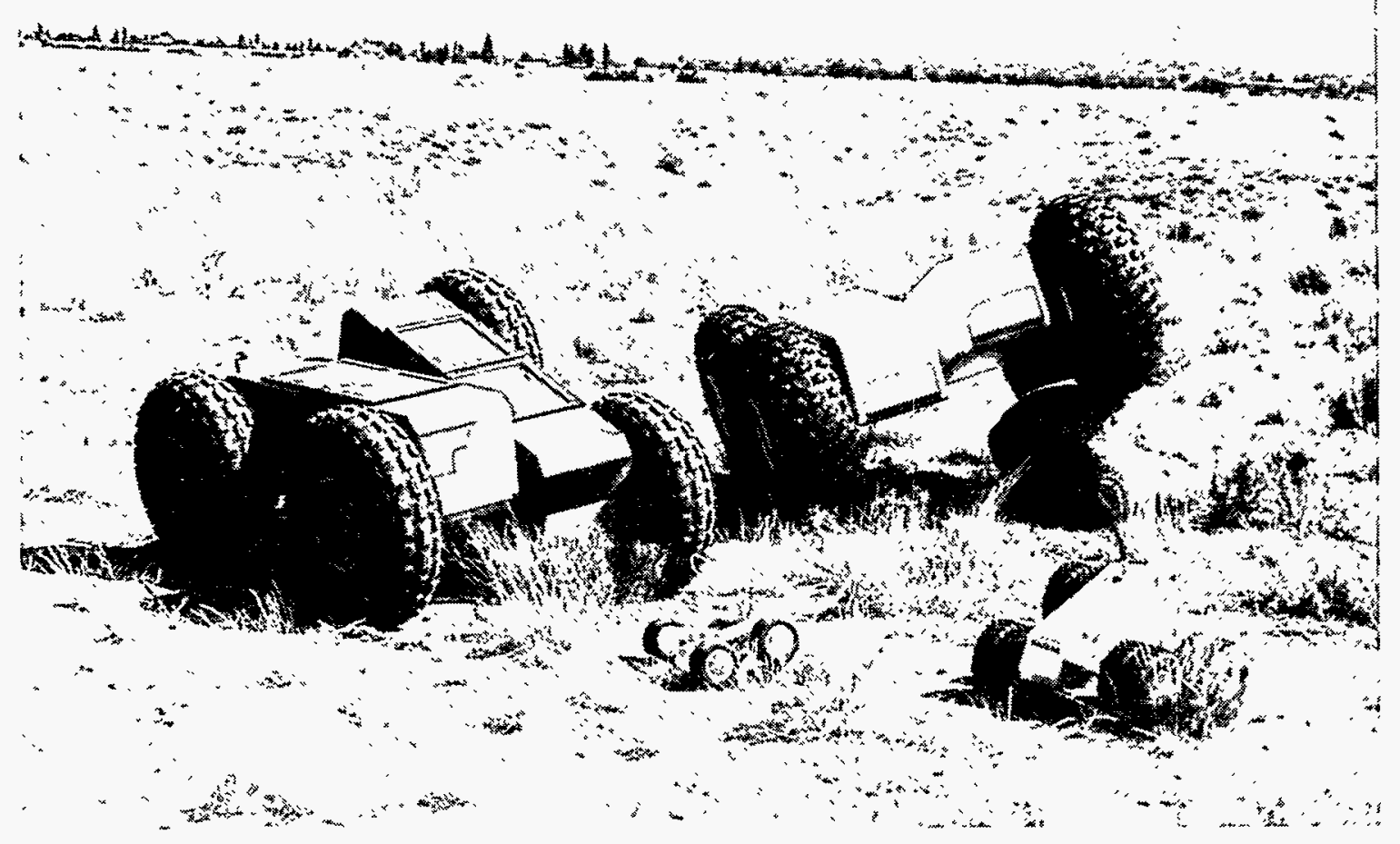

Figure 3. RATLER Fleet.

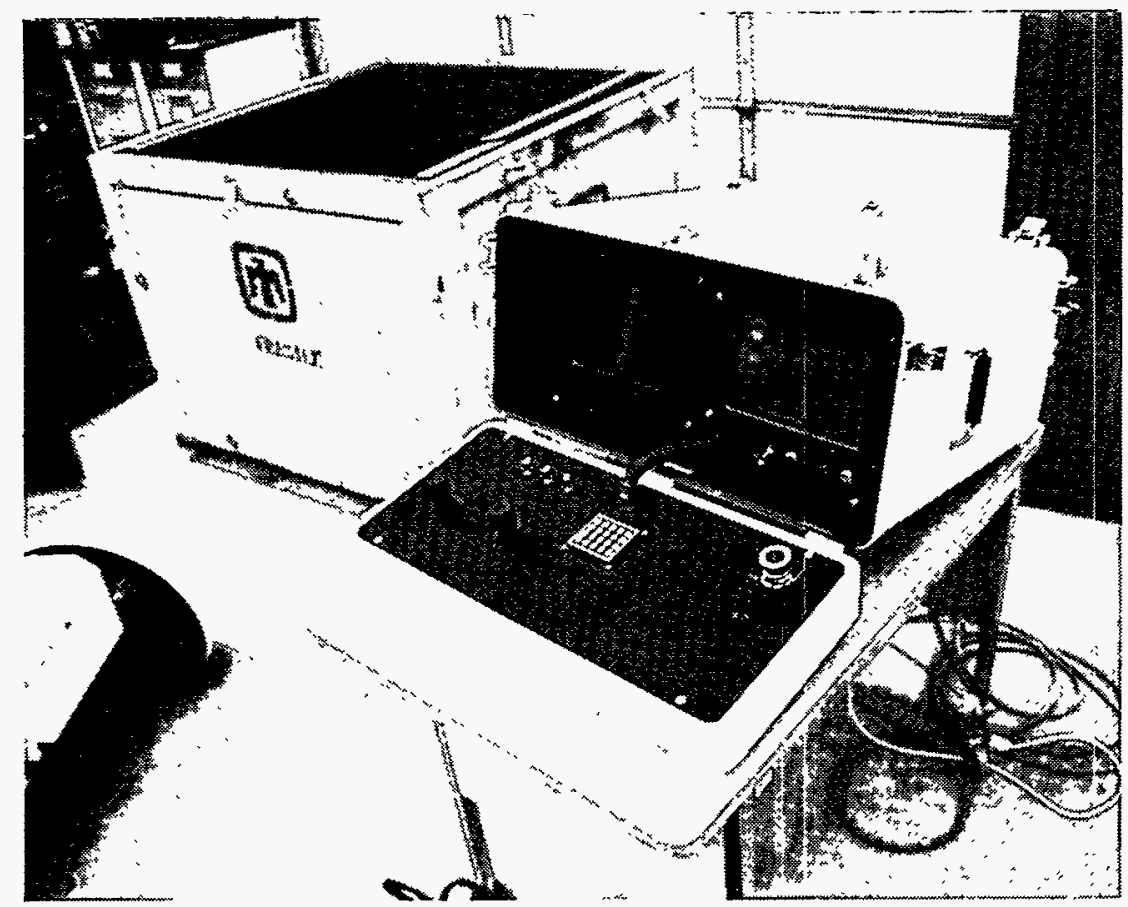

Figure 4. RATLER Control Driving Station. 


\subsection{DESIGN REQUIREMENTS}

The FY93 LDRD RATLER project plan required a trade-off analysis to be performed so that a design configuration for the RATLER vehicle could be optimized for the envisioned mission scenario and for the expected terrain. First, the analysis established the constraints imposed on the rover hardware configuration by mission considerations, such as available launch mass/volume, mission goals, and rover deployment parameters. Next, the analysis established the constraints imposed on the rover hardware configuration by the expected lunar terrain in terms of the soil's mechanical characteristics and of the size and frequency distributions of positive obstacle types (boulders, escarpments) and negative obstacle types (craters, rilles). From these constraints, a set of functional requirements for the rover were derived that were used to define a baseline hardware configuration.

\subsection{Mission Constraints}

Constraints imposed on the RATLER configuration by mission considerations include launch mass and volume and the lander-driven rover deployment requirements after landing on the lunar surface. Another important constraint is the "longest single dimension" of the rover configuration, which is directly related to the launch volume constraint and is highly dependent on the actual launch vehicle configuration. Mission goals for lunar robotic precursors had not yet been completely defined at the time (Fall 1992), but generally included such items as a minimum rover operational lifetime of from 9 to 14 Earth days and a payload capacity of from 10 to $30 \mathrm{~kg}^{7}$ to allow geology instruments to be carried and operated. Further definition of mission and rover requirements have proceeded over the past year, and a draft set of requirements is currently available from NASA8. Two different mission launch scenarios were contemplated for a lunar rover. The first scenario envisioned using the ARTEMIS Common Lunar Lander9 as the final stage in a soft landing. The second scenario envisioned a converted military Multiple Independently targeted Reentry Vehicle (MIRV) bus that carries several rover lander packages.10 The lander packages are fitted with airbags and are designed to survive a semi-hard landing after having been ejected from the orbiting bus. 


\subsubsection{ARTEMIS Mission}

The ARTEMIS Common Lunar Lander has been under development at NASA's Johnson Space Center for several years. As illustrated in Figure 5, the lander is designed to accommodate a variety of possible payloads by providing a single, large flat area on top of the lander for the payload interface. ARTEMIS is expected to have an initial minimum payload capacity of $65 \mathrm{~kg}$. This capacity may grow to as much as $200 \mathrm{~kg}$ in follow-on development. The payload bay on ARTEMIS is essentially a cylindrical volume $1.83 \mathrm{~m}$ in diameter and approximately $2.8 \mathrm{~m}$ high. This space is based on the outer bolt circle on the ARTEMIS Payload Interface Panel and a Delta launch vehicle fitted with a "10-foot" Shroud, as shown in Figure 6. The ARTEMIS Payload Interface Panel will be approximately $1.4 \mathrm{~m}$ above the surface after the legs are deployed and the lander has touched down.

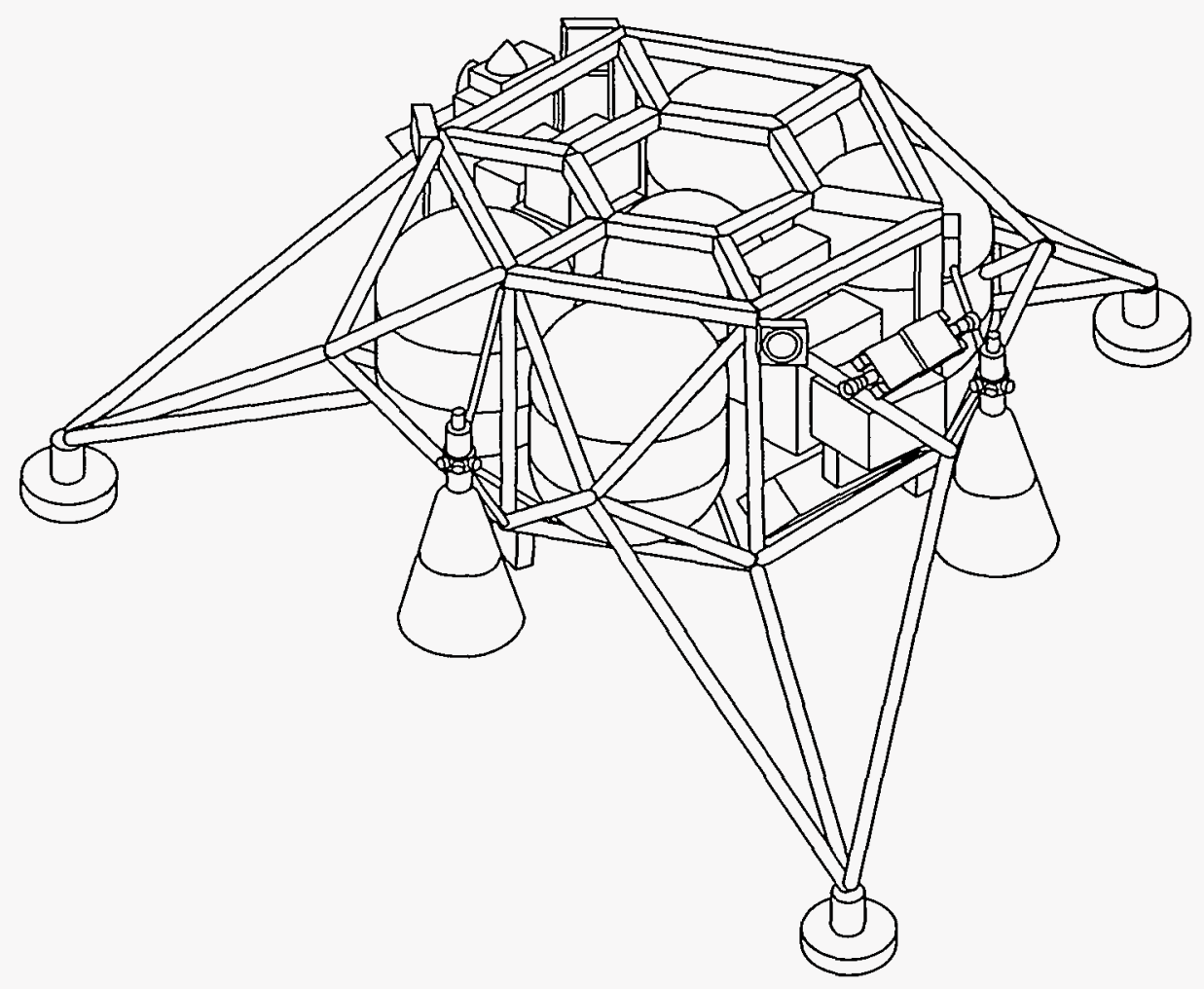

Figure 5. ARTEMIS Common Lunar Lander.

Illustration courtesy of ARTEMIS Project Office, NASA Johnson Space Center

\subsubsection{MIRV Mission}

The MIRV mission scenario is illustrated in Figures 7 and 8. An existing expendable launch vehicle is envisioned. The vehicle carries a modified military MIRV bus fitted with (1) a rocket engine for Lunar Orbital Insertion, (2) communications and orbital science equipment for 


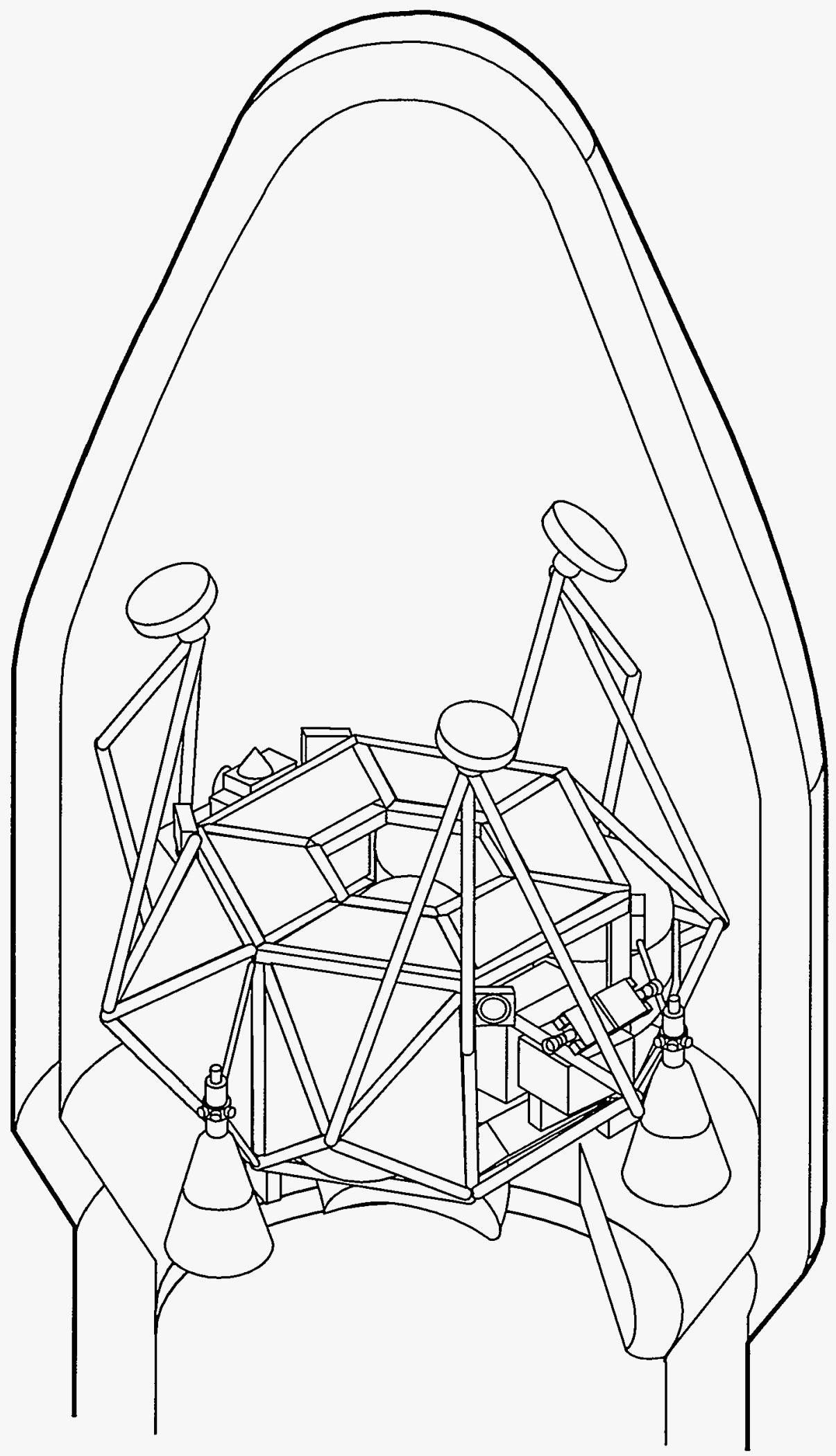

Figure 6. ARTEMIS with a 10-Foot DELTA Shroud.

Illustration courtesy of ARTEMIS Project Office, NASA Johnson Space Center 


\section{Bus dispenses rover garages.}

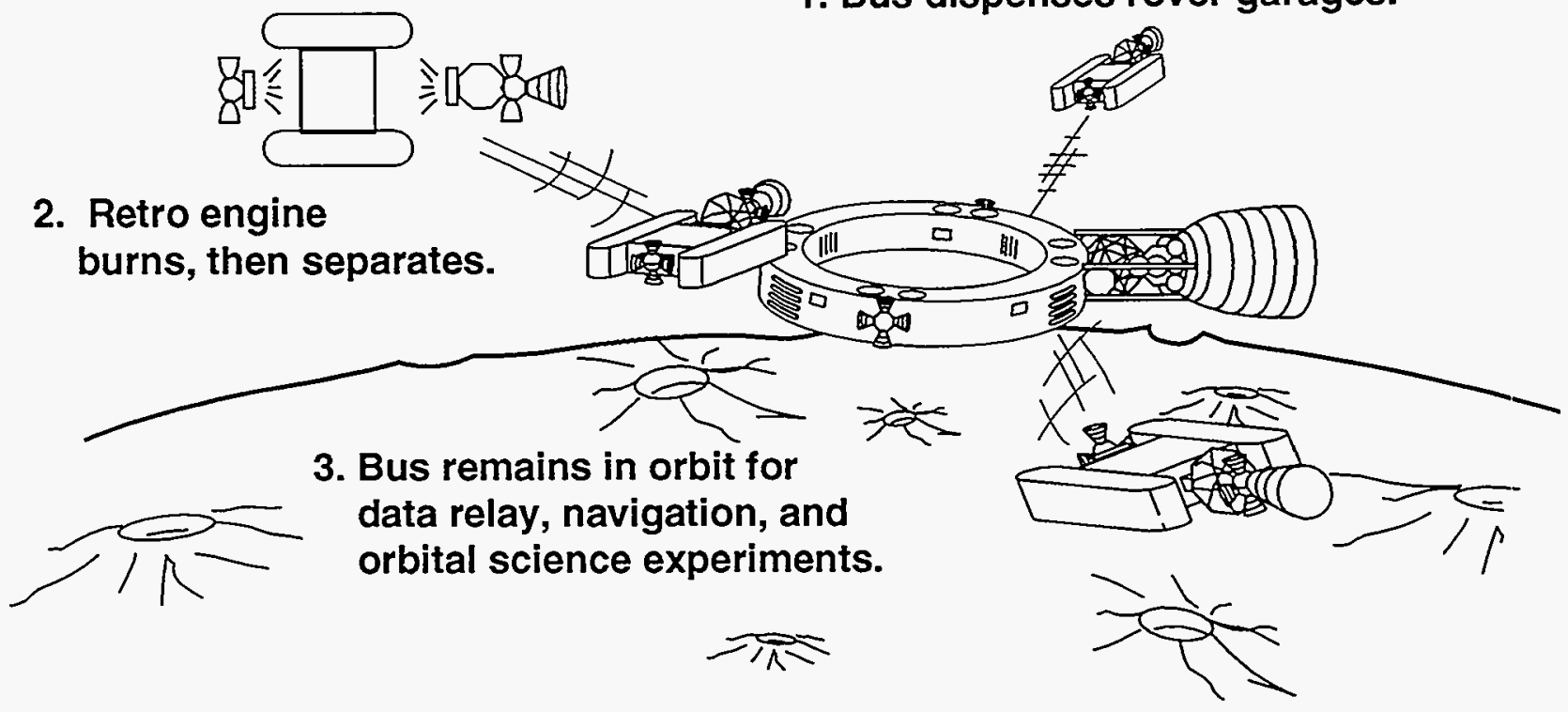

Figure 7. MIRV Orbital Transfer System.

Illustration courtesy of J. Purvis, Civil Space Programs Department 9204, Sandia National

Laboratories, $N M$

use in Lunar orbit, and (3) several self-contained rover lander packages. Each rover package is fitted with (1) a small rocket motor to deorbit the unit, (2) an airbag system for terminal impact protection, (3) communications and surface science equipment, and (4) a small rover vehicle. It must be pointed out that a detailed study of this mission scenario has not yet been performed, so the numbers assumed below for mass and volume are only very rough estimates. Rovers to be used on the MIRV mission are constrained by the MIRV bus design in terms of available volume and total payload mass. If the original unmodified MIRV bus is designed to carry ten reentry vehicles, and some of that space and mass is taken up by communications, reaction motors, and interface equipment on a modified bus, as many as six rover lander packages could be launched on a single booster. The mass of each package will be approximately $55 \mathrm{~kg}$, of which approximately $15 \mathrm{~kg}$ is the rover itself. Each package will provide approximately $1.0 \mathrm{~m}^{3}$ of volume internally, of which approximately $0.75 \mathrm{~m}^{3}$ is available for the rover itself. The remaining mass and volume attributed to each package will be taken up by auxiliary equipment and subsystems. The rover will be only a few centimeters above the surface after the package has jettisoned the airbags and opened the cover to allow deployment of the rover. 


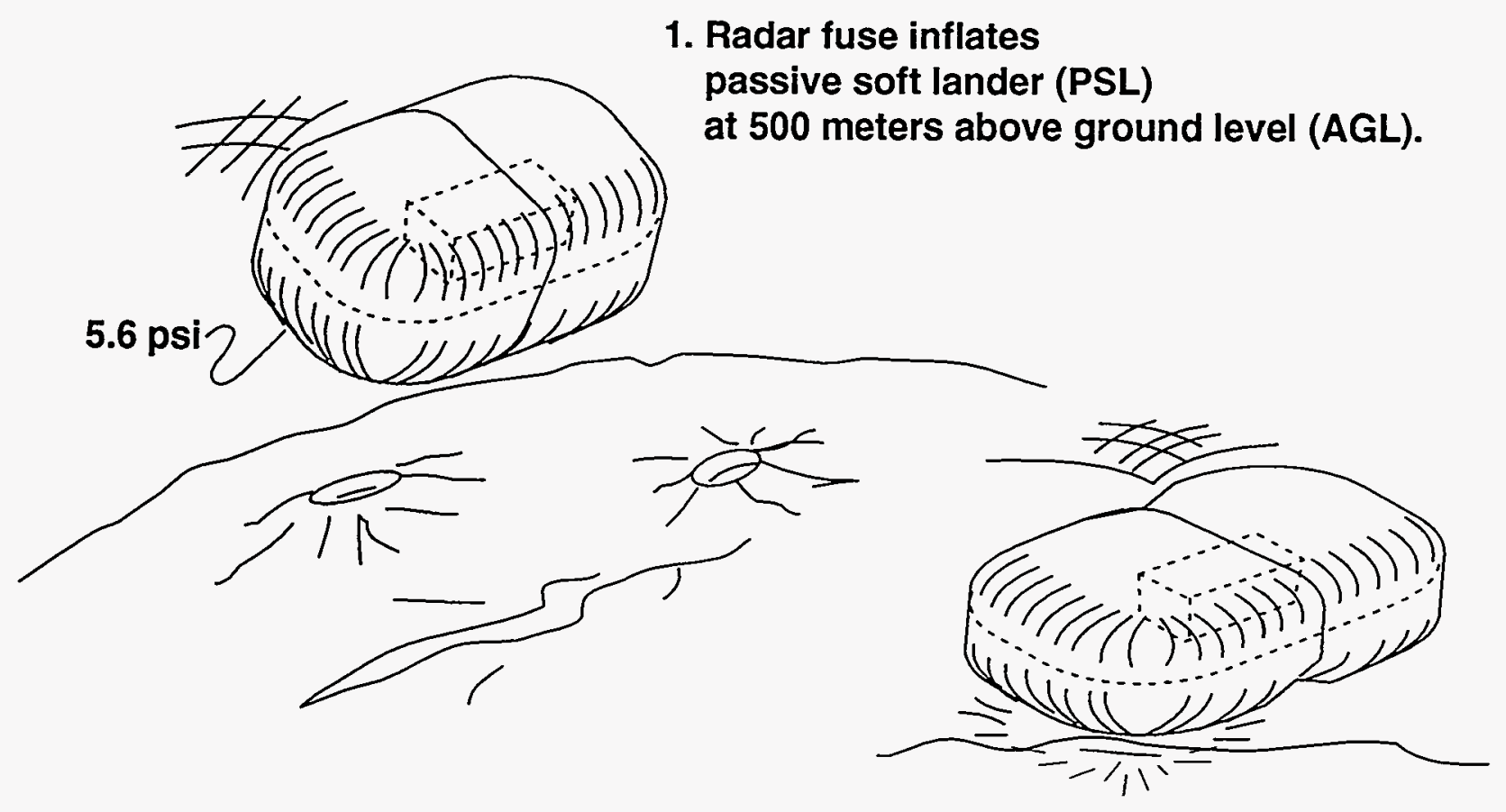

2. Soft landing at $50 \mathrm{~m} / \mathrm{s}$.

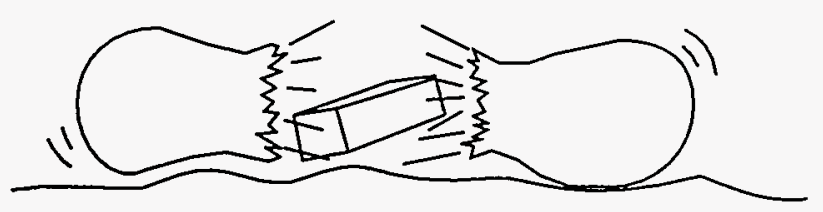

3. PSL separates from rover garage.
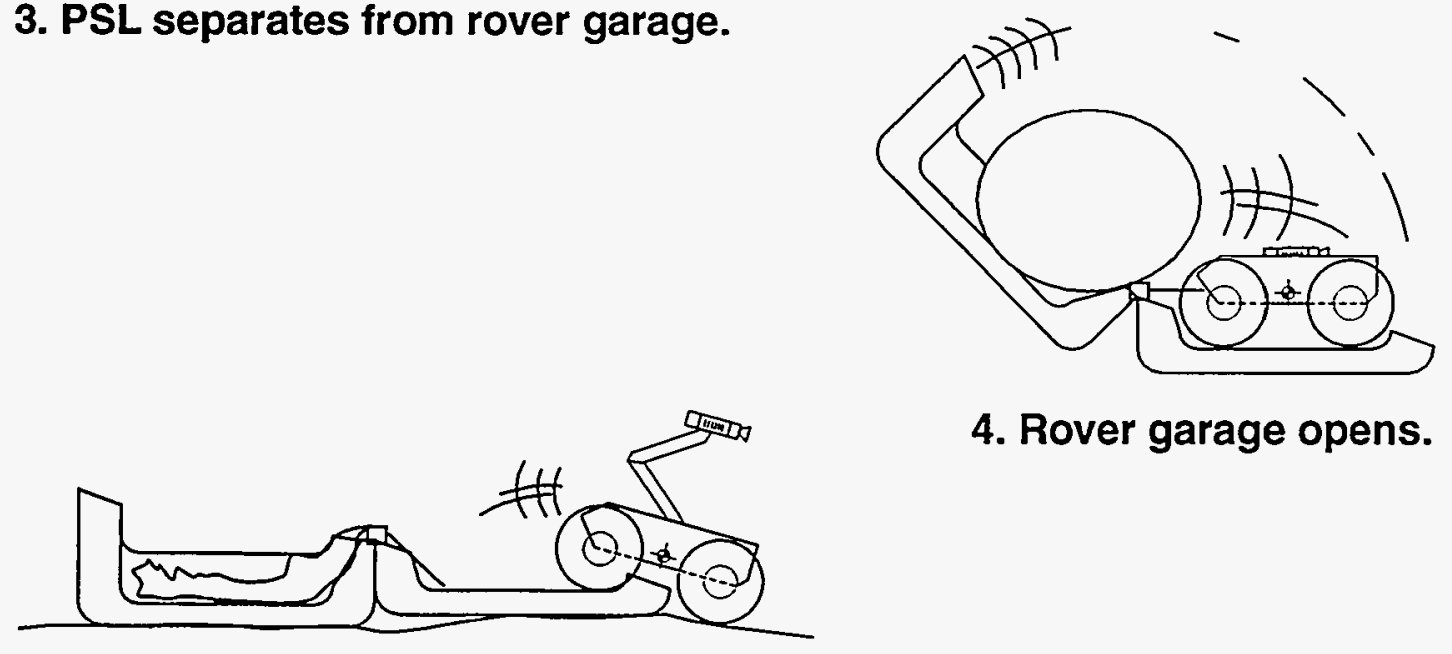

4. Rover garage opens.

5. Rover mission begins.

(Garage functions as science package.)

Figure 8. MIRV Lander System.

Illustration courtesy of J. Purvis, Civil Space Programs, Department 9204, Sandia National Laboratories, NM 


\subsection{Terrain Constraints}

Constraints imposed upon vehicles by the operating terrain are primarily a matter of physical scale. What constitutes an "obstacle" for a particular vehicle is entirely dependent on the method of locomotion and the physical size of the obstacle in relation to the vehicle's locomotion hardware. Since the RATLER is a wheeled vehicle, wheeled locomotion is assumed for the purposes of this discussion. For wheeled vehicles, the important physical parameters to consider are the wheel diameter, the wheelbase, and the stance. The important obstacle parameters include their horizontal extent (diameter or width), their vertical extent (height or depth measured from the surrounding surface, assumed as a plane), and their frequency distribution characteristics; that is, how often they appear and their typical spacing within a given area. Obstacles such as craters and boulders are of primary concern in local vehicle navigation, whereas larger scale terrain features such as extended slopes and escarpments, tend to be more important in long distance or "global" navigation planning. Unfortunately, the lunar surface has not yet been completely mapped at a scale that is fine enough to allow detailed planning for lunar rover vehicle traverses. In fact, the only data that exists at a resolution scale of a meter or less comes from the Soviet's Luna sites and the U.S. Apollo and Surveyor landing sites, which constitute only a few square kilometers in total area. The following sections rely on data from the Lunar Source Book, which is a compilation of work from U.S., U.S.S.R., and European lunar scientists.

\subsubsection{Slopes ${ }^{11}$}

Extended slopes range from nearly flat ( $1^{\circ}$ of rise) in valley floors to as steep as $40^{\circ}$ on some mountainsides. Slopes inside craters have been observed to be as steep as $40^{\circ}$ to $45^{\circ}$ in the fresh ones, but typically they are in the range of $10^{\circ}$ to $30^{\circ}$, excluding the large craters that penetrate the underlying bedrock. These large craters can exhibit vertical cliffs within the crater wall or around the central peak formations. The sinuous collapsed lava tubes, known as rilles, could be quite steep-sided, but the Apollo 15 crew at Hadley Rille measured the side slopes to be only $25^{\circ}$ to $30^{\circ}$.

\subsubsection{Craters ${ }^{6,12,13}$}

Crater sizes on the lunar surface range from micrometers to hundreds of kilometers in diameter. The craters span a range of relative ages from young craters with sharp rims to old craters that have been eroded to mere shallow depressions. Crater erosion is primarily the result of ballistic deposition of ejecta from nearby impacts. The lunar surface appears to have attained a state of equilibrium where craters are created at the same rate at which they are destroyed or eroded. For the crater size range of interest for rover mobility considerations ( $<500 \mathrm{~m}$ diameter), 
the implication is that approximately $90 \%$ of the craters in this size class will be of the "degraded" type, with smooth rounded rims and a layer of fine material in the crater floor, and only approximately $10 \%$ of the craters will have sharp rims. Data from the Lunokhod 2 mission to Le Monier crater ${ }^{6}$ suggest that the figure for fresh, sharp-rimmed craters may be as high as $15 \%$ to $30 \%$ of the population. The sharp-rimmed craters represent a more significant hazard for rover mobility since the abrupt transition from the rim to the crater interior is similar in some ways to boulder- or escarpment-type obstacles. However, the older, "degraded" craters may present mobility problems associated with high accumulations of fine dust. What little data that exists on crater size-frequency distributions tend to show that for the crater size of interest, typical values are between 100 and 1,000 craters per square kilometer. To determine a crater's potential for obstructing rover mobility, various aspects of crater geometry become significant factors. Crater depth versus rim diameter is one of the more obvious of these factors. Observations made from Lunokhod data established a simple ratio of 10:1 for diameter versus depth of small craters. In addition, Figure 9 illustrates the basic geometry of so-called "simple" craters and provides a model for predicting the dimensions of various crater features.

\subsubsection{Boulders / Obstacles ${ }^{11,12}$}

Obstacles such as boulders, steps, or similar above-ground (positive) discontinuities in the surface vary in size from micrometers to tens of meters. Observations made from orbital data and at the various Luna, Apollo, and Surveyor landing sites tend to show that cratering is the primary surface-forming process on the Moon, and that the primary source of rocks and boulders on the lunar surface is from impacts and the resultant crater ejecta formation. Micro-impacts over the last several hundred million years have produced a very fine-grained dust that seems to cover everything. Larger rocks and boulders are scattered over the surface and appear in large fields concurrent with observed ejecta rays from the larger craters. The Lunokhod 2 data (Table 1) show the approximate average frequency distribution of boulders on the surface based on a very limited set of observations.

Table 1. Lunokhod 2 Boulder Data ${ }^{13}$

\begin{tabular}{|c|c|c|}
\hline Boulder Size, $S_{b}$ & Number Observed & Unit Area \\
\hline$S_{b}>1$ meter & 0 & $100 \mathrm{~m}^{2}$ \\
\hline $20 \mathrm{~cm}>S_{b}<1$ meter & 3 & $100 \mathrm{~m}^{2}$ \\
\hline $10 \mathrm{~cm}<S_{b}<20 \mathrm{~cm}$ & 10 & $100 \mathrm{~m}^{2}$ \\
\hline
\end{tabular}




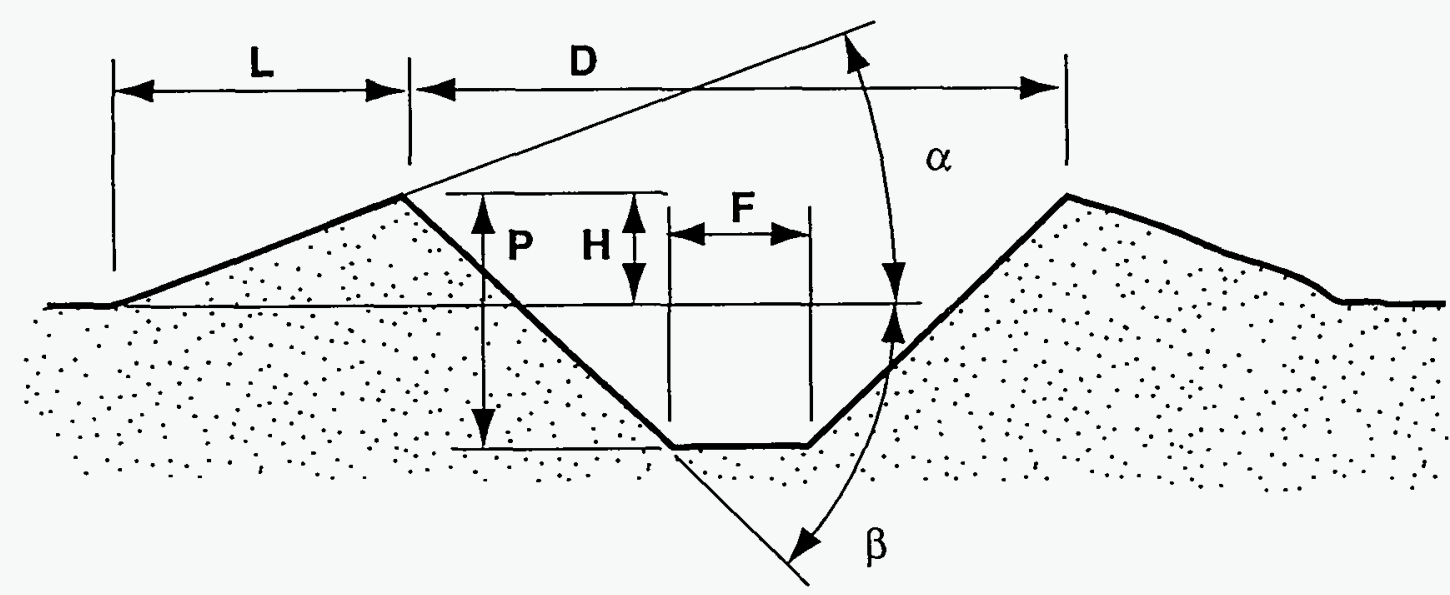

Schematic Cross Section of a Simple Crater

\section{Simple Crater Geometry}

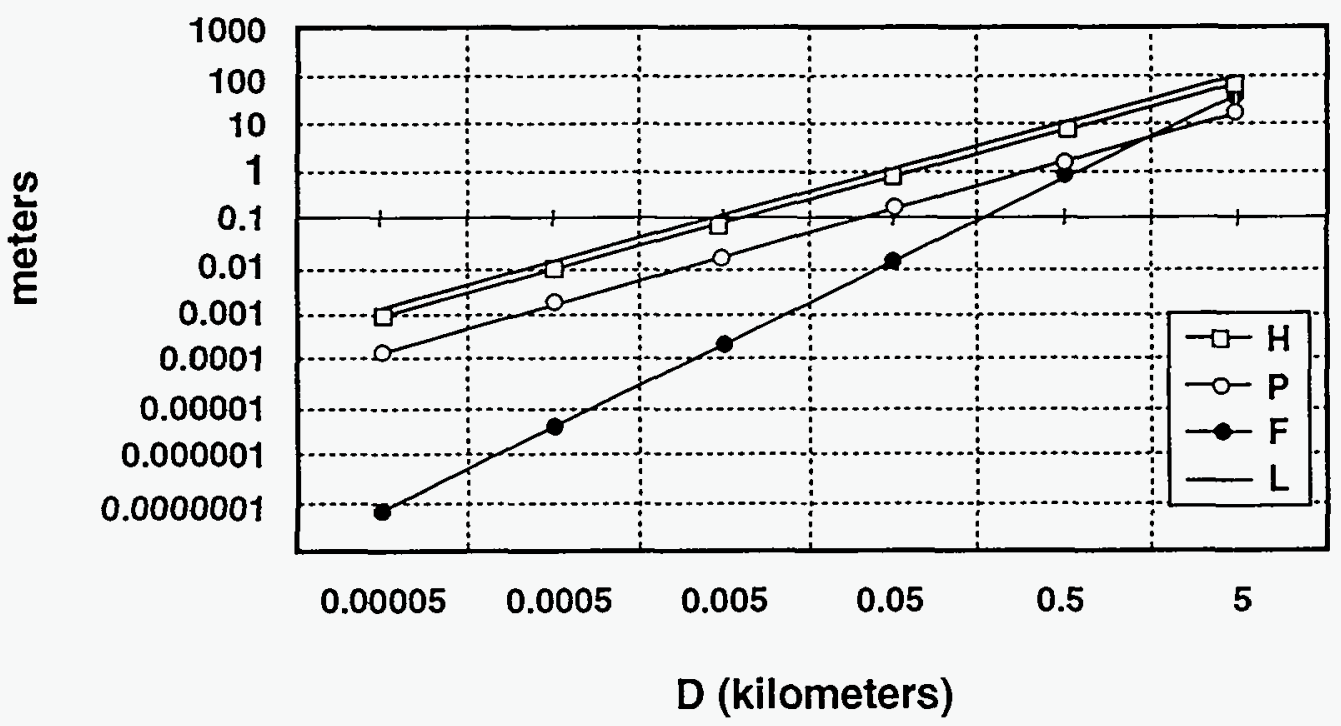

\begin{tabular}{|c|c|c|c|c|c|c|}
\hline $\mathrm{D}$ & $\mathrm{H}$ & $\mathbf{P}$ & $\mathrm{F}$ & $\mathrm{L}$ & $\beta$ & $\alpha$ \\
\hline kilometer & meters & meters & meters & meters & degrees & degrees \\
\hline & & & & & & \\
\hline 0.00005 & 0.001567 & 0.008876 & $7.94 \mathrm{E}-07$ & 0.011524 & 7.744002 & 19.54856 \\
\hline 0.0005 & 0.016183 & 0.090827 & $4.62 \mathrm{E}-05$ & 0.118193 & 7.797023 & 19.96969 \\
\hline 0.005 & 0.167131 & 0.929428 & 0.002692 & 1.212249 & 7.850398 & 20.40527 \\
\hline 0.05 & 1.726069 & 9.510772 & 0.156691 & 12.43345 & 7.904129 & 20.88974 \\
\hline 0.5 & 17.82617 & 97.32306 & 9.121027 & 127.524 & 7.958218 & 21.63119 \\
\hline 5 & 184.1018 & 995.9001 & 530.9379 & 1307.952 & 8.012668 & 24.02365 \\
\hline
\end{tabular}

Figure 9. Crater Physical Parameters.

Derived from diagrams, equations, and parameters given in the Lunar Source Book, pp. 64-6 


\subsubsection{Trafficability $14,15,16,17,18$}

Trafficability is defined as the capacity of a soil to support a vehicle and to provide sufficient traction for movement. Experience gained from the Apollo manned Lunar Rover Vehicle (LRV), Modular Equipment Transporter (MET), and the Soviet Lunokhod robotic rover vehicles, shows that almost any vehicle with round wheels will perform satisfactorily on the lunar surface, provided the ground contact pressure is no greater than 7 to $10 \mathrm{kPa}$ (approximately 1.0 to $1.4 \mathrm{psi}$ ). Other detailed information gained from these missions indicates that wheel slip in the fine-grained soil was approximately $2 \%$ to $3 \%$, and that the energy consumed by the wheel's compaction of the soil as it rolled was roughly equivalent to the energy expended in continuously climbing a smooth, rigid $1.5^{\circ}$ slope. Observations from the Lunokhod 2 mission noted that the soft dust, present as the uppermost few centimeters on flat terrain, became as deep as $20 \mathrm{~cm}$ or more near the toe of slopes both inside and outside crater rims. This condition resulted in some mobility problems for the rover because of the softness of the material and the resultant high wheel sinkage. A set of empirical equations developed by Bekker allows the trafficability of a wheel in a well-characterized soil to be estimated. Unfortunately, Bekker's work was based on empirical results from terrestrial vehicles of a scale significantly larger than that currently contemplated for lunar rovers. As a result, the question has arisen as to whether or not the equations are relevant to this particular application. A computerized version of Bekker's equations has been released by an expert in this field, and preliminary results from that software indicate that vehicles significantly smaller than the LRV or Lunokhod may have difficulty moving in the soft lunar soil. These questions are currently under review by researchers in the field of planetary robotics, including SNL.

\subsection{RATLER Functional Requirements}

Considering the uncertainty about the actual mission scenario that will be used and the dearth of detailed information regarding the lunar surface at fine resolutions, defining a firm hardware configuration for the flight version of the RATLER will be difficult. However, there is sufficient information to at least bound the physical parameters of the RATLER so its configuration is close to that which would eventually be qualified for flight.

The design considerations for the RATLER regarding slopes include both climbing capability and stability parameters. The RATLER should be dynamically stable on the maximum slope climbable, both laterally and longitudinally. This degree of stability will ensure that the vehicle will not tip over if a turn or pivot maneuver must be executed on a slope. This requirement would be necessary when performing a cross-slope traverse or in climbing a very 
steep slope at a series of oblique angles in "switch-back" fashion. A high confidence of dynamic stability can be assured if the rover is statically stable on slopes of approximately $45^{\circ}$ or more.

For a RATLER type rover with a wheel diameter of a nominal size, $W D$, the significant crater size range is bounded by the following practical considerations as illustrated in Figures 10 and 11 . The minimum crater depth of significance will be approximately $1 / 5$ of the wheel diameter, WD, since any smaller craters will begin to appear less as an obstacle or "pothole" and more as a simple undulation in the surface. Using the crater geometry relationships illustrated in Figures 9, 10, and 11 , the diameter of such a crater is determined to be approximately $1.1 \times W D$.

The maximum crater depth of significance will be approximately one wheel diameter, WD, since anything larger will begin to appear as a series of whole-vehicle attitude changes through varied terrain rather than a single encounter with an obstacle. Again using data from Figure 9, the diameter of such a crater is found to be approximately $5 \times W D$.

The RATLER design has been shown to be theoretically capable of overcoming obstacles on the order of 1.3 wheel diameters in size, ${ }^{4}$ thus defining the upper bound of traversable positive obstacles as $1.3 \times W D$ in height. Larger obstacles must be avoided by traversing around them rather than attempting to surmount them directly. The lower bound for significant positive obstacles will be on the order of approximately $1 / 10$ of the wheel diameter, $W D$, as anything smaller will simply deflect the tire or cone-wheel rather than cause the body articulation joint to flex significantly.

Based on the above information, Table 2 summarizes the upper and lower bounds of the RATLER's functional requirements.

Table 2. RATLER Functional Requirements

\begin{tabular}{|c|c|c|c|}
\hline Parameter & Upper Bound & Lower Bound & Units \\
\hline Slope Climbing \& Stability & 45 & 0 & degrees \\
\hline Crater Depth (traversable) & $W D$ & $W D / 5$ & wheel diameters (m) \\
\hline Boulder Height (traversable) & $1.3 \times W D$ & $W D / 10$ & wheel diameters (m) \\
\hline Lander Deployment Height & 1.4 & approximately 0.1 & $\mathrm{~m}$ \\
\hline Ground Contact Pressure & 7 & unknown & $\mathrm{kPa}$ \\
\hline Total Mass & 65 & approximately 15 & $\mathrm{~kg}$ \\
\hline Total Volume & 5.1 & approximately 0.75 & $\mathrm{~m}^{3}$ \\
\hline Maximum Dimension & 2.8 & approximately 0.9 & $\mathrm{~m}$ \\
\hline
\end{tabular}




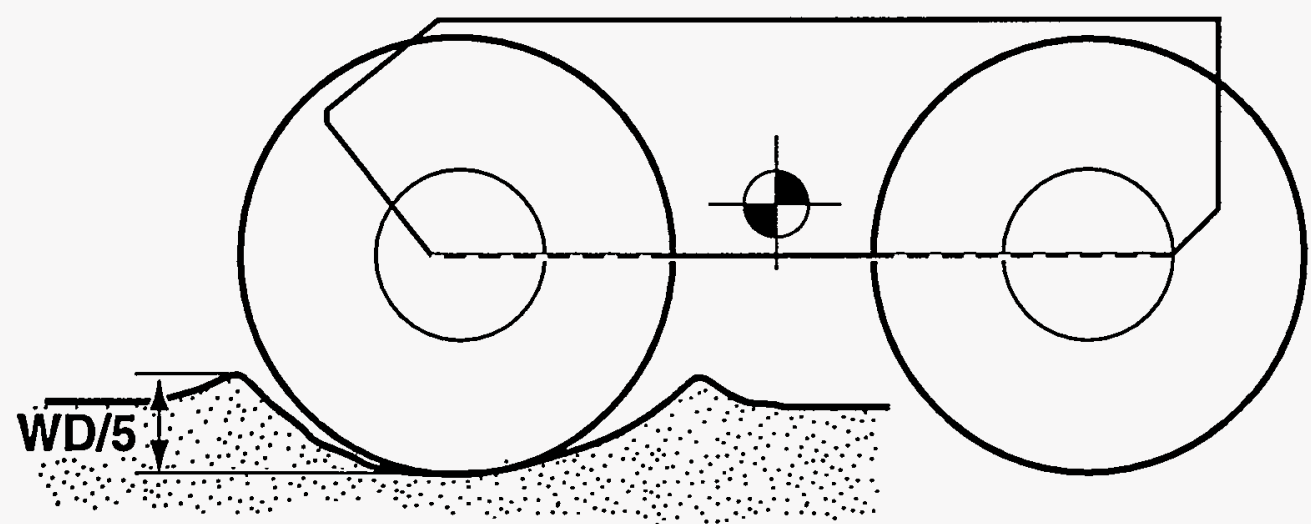

Figure 10. Minimum Significant Crater.

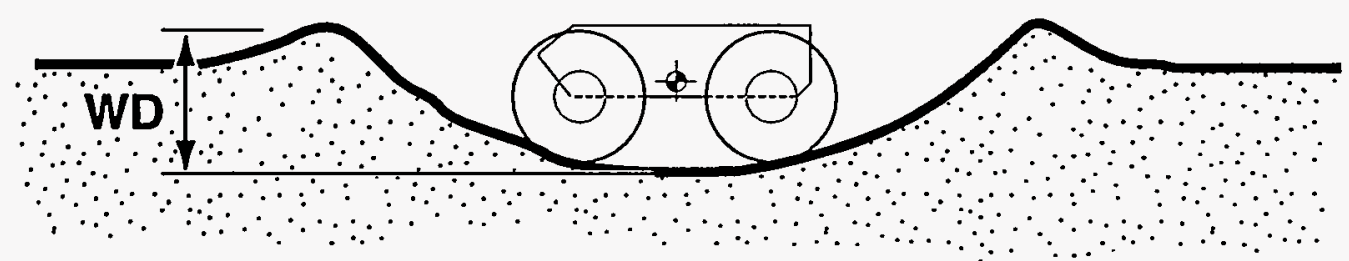

Figure 11. Maximum Significant Crater. 
Of the two sets of constraints on the rover's configuration, namely mission constraints and terrain constraints, the mission constraints will tend to drive the rover's actual configuration. This is a result of the limited payload bay volume on the launch vehicle and its maximum mass lift capability. In contrast, it can be generally said of the terrain constraints that for terrain mobility, the bigger the rover is, the better it can handle terrain and the more extreme the terrain can be before mobility becomes a serious concern. Based on the above requirements and the known physical characteristics of the RATLER design 4 as they relate to performance, Table 3 summarizes the upper and lower bounds of the RATLER's physical configuration. The values for the upper bounds assume the RATLER is mounted vertically on ARTEMIS inside the DELTA fitted with the 10-foot Shroud. The lower bounds assume that the RATLER is mounted in a MIRV canister with a maximum single dimension of $0.9 \mathrm{~m}$.

\section{Table 3. RATLER Physical Configuration}

\begin{tabular}{|c|c|c|c|}
\hline Parameter & Upper Bound & Lower Bound & Units \\
\hline Wheel Radius & 52 & 17 & $\mathrm{~cm}$ \\
\hline Wheel Width (minimum) ${ }^{*}$ & 6.2 & 2.9 & $\mathrm{~cm}$ \\
\hline Wheelbase & 147 & 47 & $\mathrm{~cm}$ \\
\hline Stance & 154 & 50 & $\mathrm{~cm}$ \\
\hline
\end{tabular}

*The minimum wheel width assumes a maximum allowed ground contact pressure of $7 \mathrm{kPa}(1.0$ psi) in lunar gravity, and a ground contact patch that is one wheel-width square.

\subsection{Conclusions from Analysis}

Considering the current lack of hard data on mission requirements, launch vehicle, specific science instruments, and lunar terrain details, a firm design configuration for the RATLER would be premature. However, for the purposes of the LDRD project, which is to expand the RATLER concept from the scale model stage to a full-scale version complete with computing and sensing systems, the information collated in the preparation of this document does provide some limited guidance for the RATLER II prototype's design configuration. A pathfnder unit for the RATLER II project was constructed at SNL/RVR in mid-November 1992. The unit is sized to represent a version of the RATLER that lies within the range of configurations listed in Table 3 , and to allow the LDRD project to advance without the need for mission specific constraint criteria that, at present, either do not exist or are in a state of flux. Table 4 lists the RATLER II pathfinder's configuration parameters. 
Table 4. RATLER II Pathfinder Configuration

\begin{tabular}{lcccc}
\hline \multicolumn{1}{c}{ Parameter } & & Value & & Units \\
\cline { 1 - 1 } Wheel Radius & 25.4 & & $\mathrm{~cm}$ \\
Wheel Width & & 20.32 & & $\mathrm{~cm}$ \\
Wheelbase & 73.6 & & $\mathrm{~cm}$ \\
Stance & 100.4 & & $\mathrm{~cm}$ \\
Total Mass & 70 & & $\mathrm{~kg}$ \\
Total Stored Volume & & 0.6 & & $\mathrm{~m}^{3}$ \\
Maximum Single Dimension & 174 & & $\mathrm{~cm}$ \\
Slope Stability & $>45$ & & degrees \\
Slope Climbing & 22 & & degrees \\
Crater Depth (traversable) & 50 & & $\mathrm{~cm}$ \\
Boulder Height (traversable) & 66 & & $\mathrm{~cm}$ \\
\hline
\end{tabular}

Further work remains to be done in terms of analysis for the RATLER LDRD project. Specifics that will be looked at in the future include drive torque, power budget, and the wheel/soil interaction. In particular, the wheel/soil interaction and trafficability parameters for small rovers in the lunar environment are of major concern. A former SNL/RVR summer-hire student, who is continuing his work over the 1993-94 school year, will be looking at the Bekker trafficability equations in detail to determine their implications for small planetary rovers in low ambient gravity fields. 


\subsection{KINEMATIC ANALYSIS OF RATLER MECHANISM}

\subsection{Vehicle Description}

The RATLER is a four-wheeled, all-wheel-drive platform with a body constructed of twin left and right compartments connected by a hollow central pivot. A three-view schematic of the dual-body, central-pivot design is shown in Figure 12. A patent disclosure has been made for the mobility chassis.
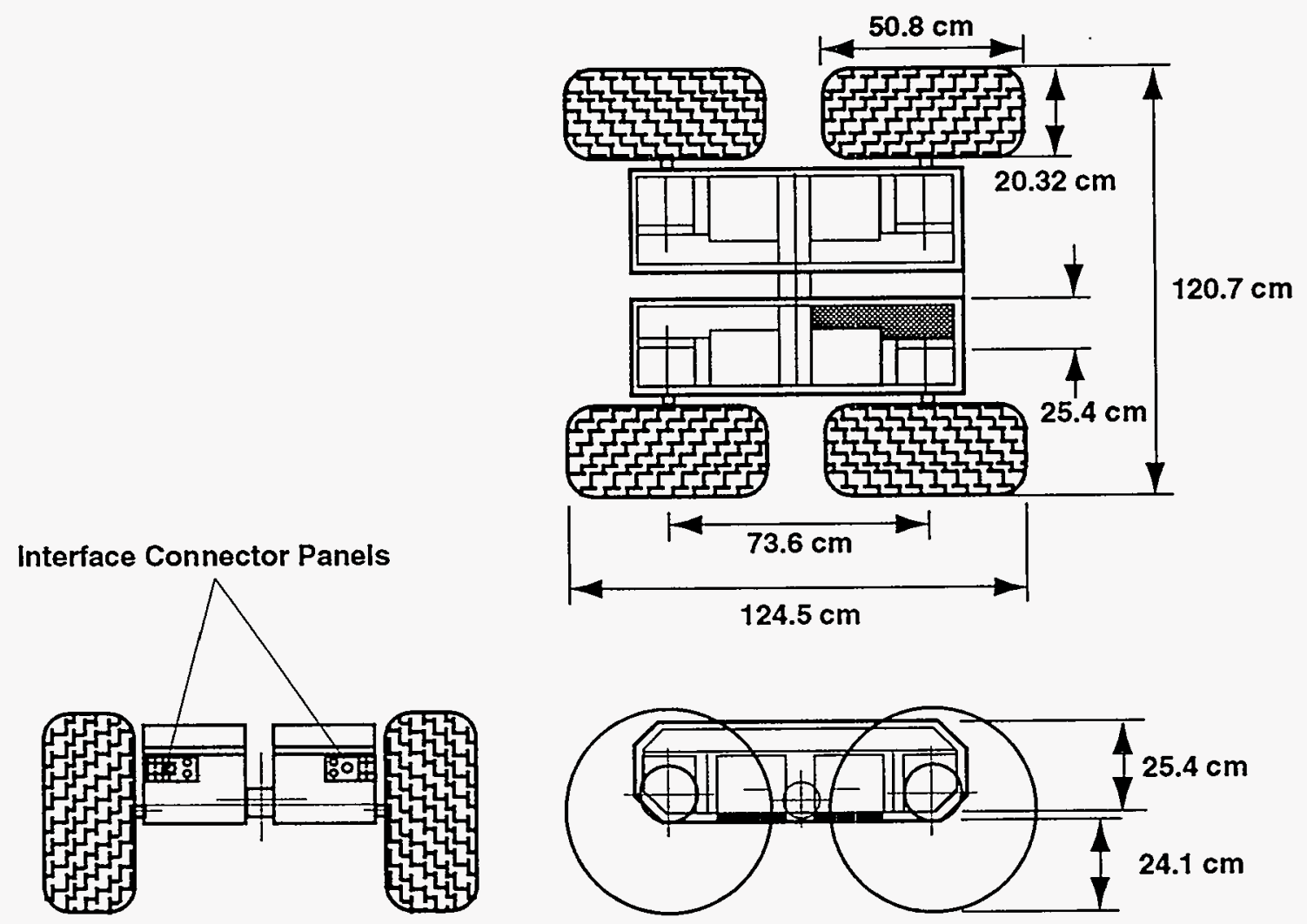

Figure 12. RATLER Schematic.

The uniquely simple method of chassis articulation, using a hollow central pivot between the two compartments, is employed to allow all four wheels to remain in contact with the ground while traversing uneven terrain. This central pivot, as well as the vehicle center of mass, is located as close to the axle line and the geometric center of the vehicle as possible to ensure maximum stability while climbing over large obstacles. The articulating action of the twocompartment, central-pivot design is illustrated in Figure 13. This photograph depicts the first remotely controlled prototype being driven over loose, dry sand dunes in Death Valley, California. 


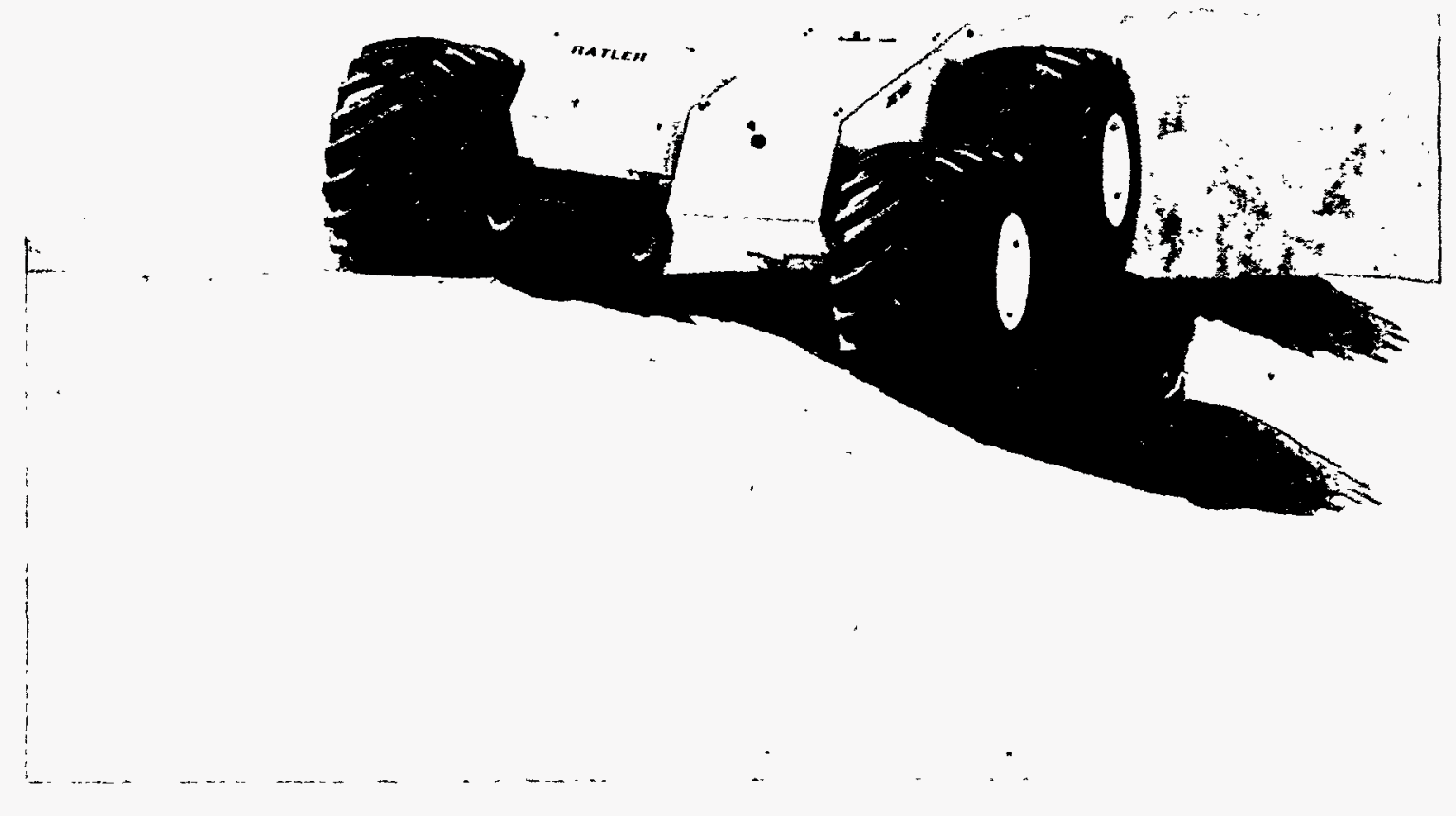

Figure 13. RATLER Prototype at Death Valley.

\subsection{Analysis}

The following four important design and operational aspects of the RATLER have been analyzed to date: (1) the maximum-height vertical step that can be cleared, (2) the optimum wheelbase for a given wheel radius, (3) the optimum stance for a given wheel radius and wheel width, and (4) the traction advantage of the two-compartment, central-pivot design over a conventional four-wheeled platform. These characteristics will be discussed below.

Figure 14 illustrates the maximum step height problem. From the geometry, the maximum step height, $\boldsymbol{H}$, that can be climbed is

$$
H_{\max }=\sqrt{B^{2}-R^{2}}
$$




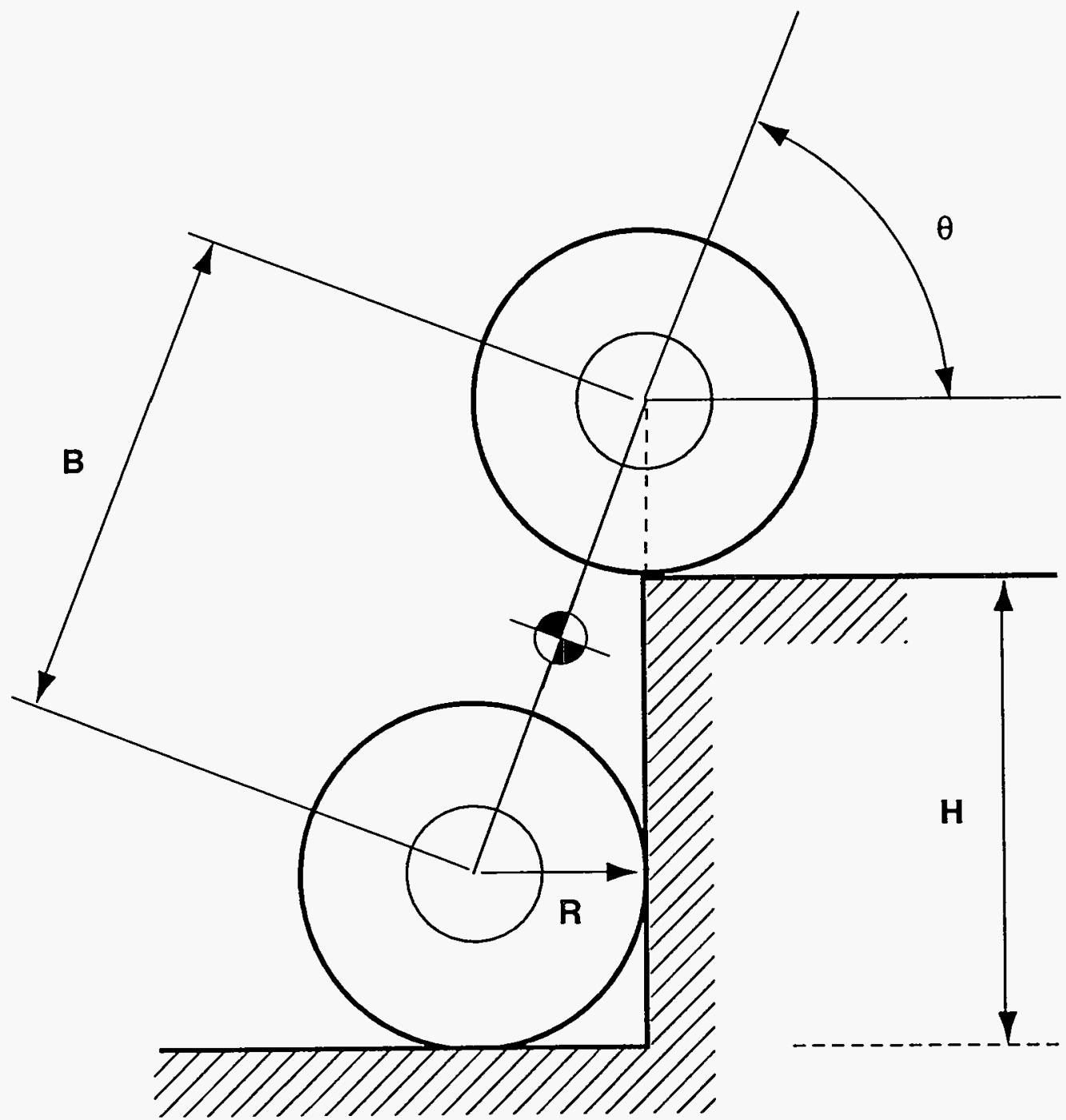

Figure 14. Maximum Step Clearance Geometry.

where $B$ is the wheelbase and $R$ is the wheel radius. The ground clearance is assumed to be equal to the wheel radius, and the center of mass is assumed to be located along a line between the axles so that the vehicle will not tip over backwards.

Constructing Figure 15 similar to Figure 14 but without the rear wheel touching the vertical face of the step, it can be shown that for any angle, $\theta$, there is a minimum height,

$$
H_{\min }=R(1+\tan \theta)
$$

such that the vehicle bottom will scrape on all steps with height $\boldsymbol{H}$ if 


$$
H_{\text {min }}<H<H_{\text {max }}
$$

In terms of the geometry

$$
H=B \sin \theta,
$$

and therefore no scraping will occur as long as

$$
B \sin \theta<R(1+\tan \theta)
$$

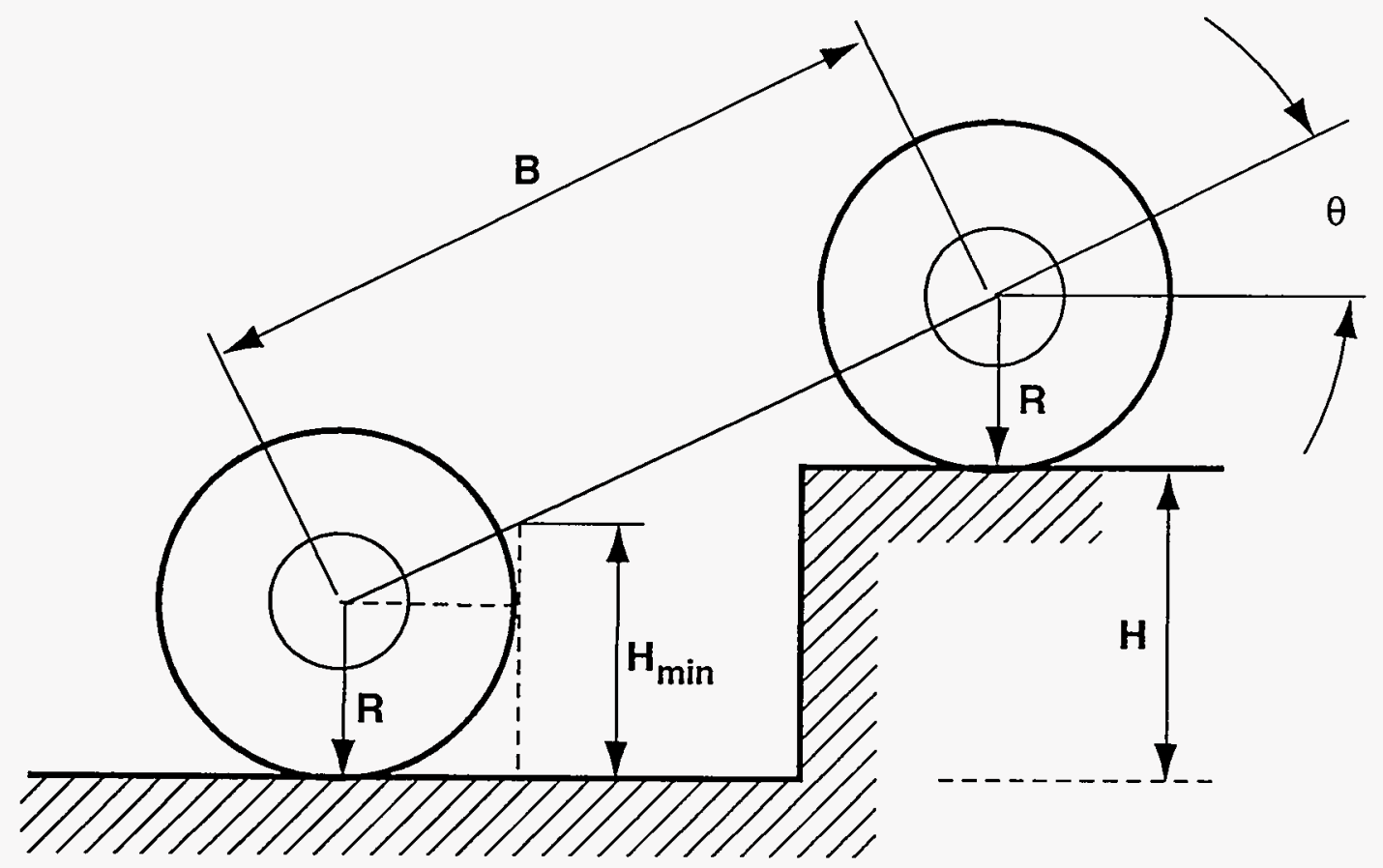

Figure 15. Generalized Step Clearance Geometry.

The bottom of the vehicle will just touch the point of the step if the inequality in Equation (5) is instead an equality. Assuming the equality and differentiating with respect to $\theta$, it can be shown that a minimum occurs when

$$
\sin \theta=\cos \theta
$$

The optimum value of $\boldsymbol{B}$ for no bottom scraping is then 


$$
B=2 \sqrt{2} R
$$

Using the above result in Equation (1), the maximum step height that a vehicle with an optimized wheelbase can possibly climb is

$$
H_{\max }=\sqrt{7} R
$$

or 1.32 wheel diameters.

A similar analysis using Equation (8), assuming hemispherical boulders and neglecting wheel width, shows that, for climbing or straddling obstacles, the optimum stance $S$ must be in the range

$$
S<3.74 R \text {. }
$$

This equation defines the upper bound for the stance $S$ in terms of the wheel radius $R$.

The stance also directly affects the vehicle's ability to perform a pivot maneuver, where the vehicle turns about its own centroid as illustrated in Figure 16. By analyzing the forces at each wheel where $F_{t}$ is the force applied for pivoting the vehicle, a summation of the moments about the center of rotation yields the relationship between the stance, $S$, and the wheelbase, $B$.

Since the forces and moments about the centroid are identical at each wheel, it is sufficient to analyze the moments for one wheel as shown in Figure 17. The force $\boldsymbol{F}_{\boldsymbol{a}}$ is the resultant applied force in the direction of the pivot maneuver and results from the drive motors' applied tractive forces, $F_{\boldsymbol{t}}$, in opposite directions on either side of the vehicle. $\boldsymbol{F}_{\boldsymbol{a}}$ acts at the center of the wheel's contact patch, located a distance, $D$, from the vehicle's centroid. The opposing frictional force, $f_{o}$, can be resolved into its pure rolling friction, $f_{r}$, and the pure sliding friction, $f_{S}$, components. The force $f_{r}$ is defined as the product of the coefficient of rolling friction, $\mu_{r}$, and one fourth of the normal force, $N$, in Figure 16, expressed as

$$
f_{r} \equiv \frac{\mu_{r} N}{4}
$$




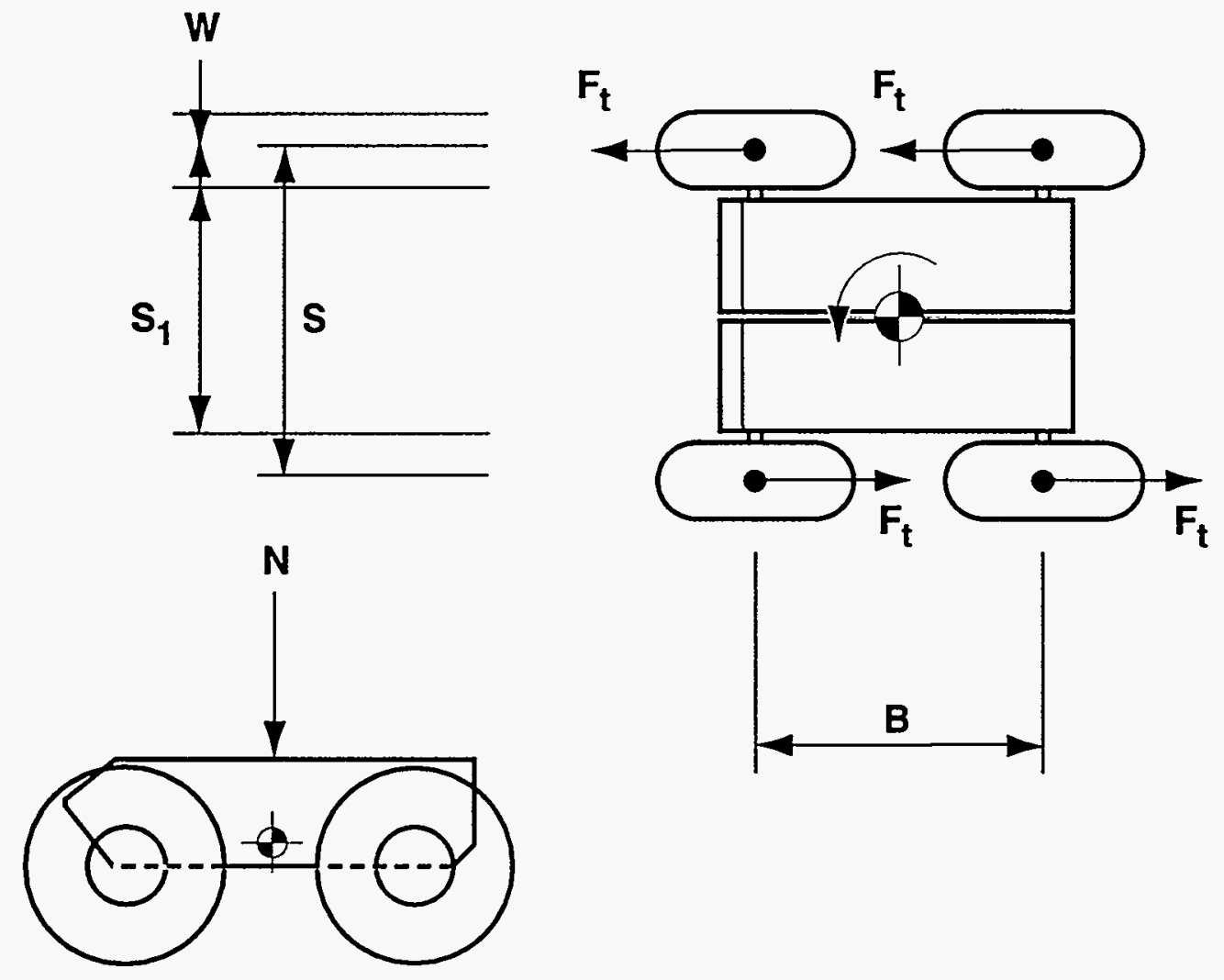

Figure 16. Pivot Maneuver Geometry.

The force $f_{S}$ is defined as the product of the coefficient of sliding friction, $\mu_{s}$, and one fourth of the normal force, $N$, expressed as

$$
f_{s} \equiv \frac{\mu_{s} N}{4}
$$




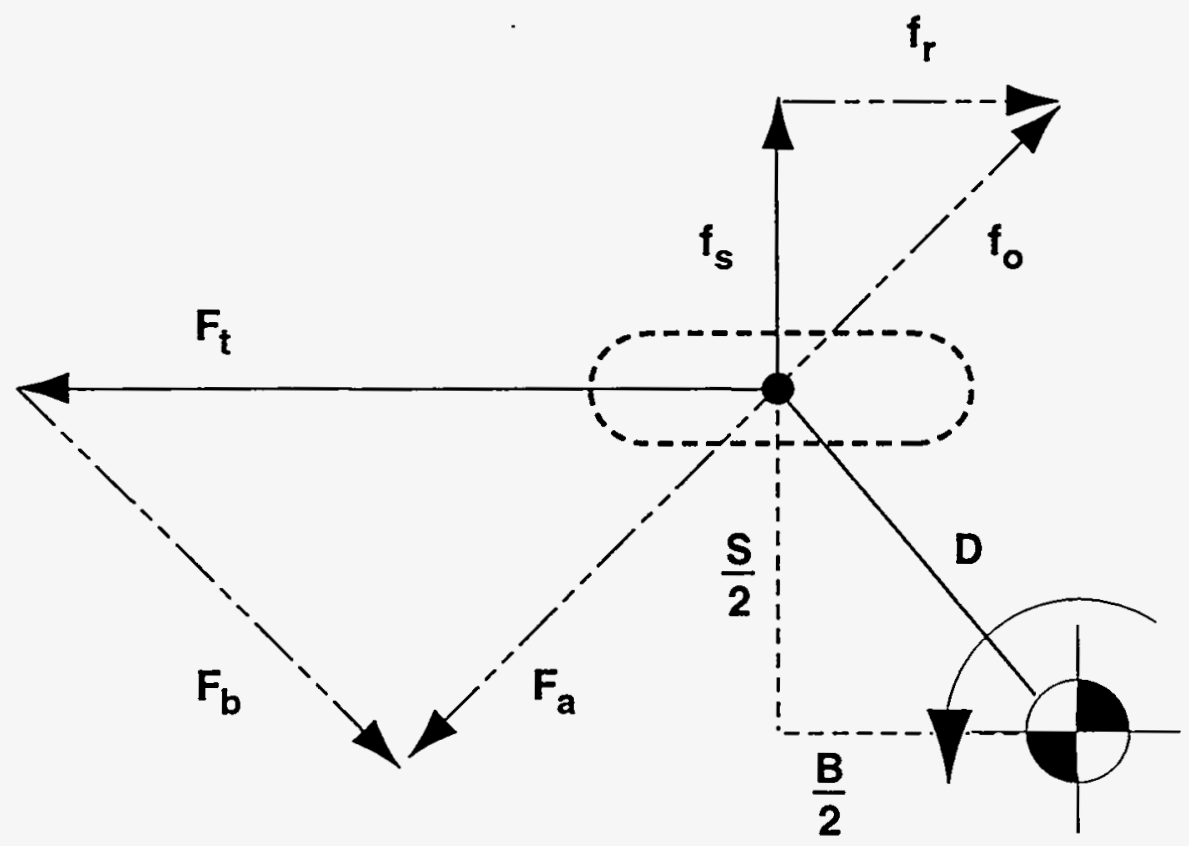

Figure 17. Pivot Moments at One Wheel.

By analyzing the moments as they relate only to the frictional forces, the influence of applied motor torque can be isolated from the analysis, and a representation of the inherent geometric relationship between stance and wheelbase in this case may be obtained. In order to accomplish this, the applied tractive force, $F_{t}$, is defined to be the product of the traction friction, $\mu_{t}$, and one fourth of the normal force, $N$, expressed as

$$
F_{t} \equiv \frac{\mu_{t} N}{4}
$$

Furthermore, $F_{t}$ is assumed to be just slightly greater than $f_{r}$ in order for motion to occur. The moment, $M_{t}$, is defined as the product of the force $F_{t}$ and the distance from the centroid $S / 2$ expressed as

$$
M_{t} \equiv \frac{F_{t} S}{2}
$$


The moment $M_{\boldsymbol{S}}$ is defined to be the product of the force $f_{S}$ and the distance from the centroid $B / 2$ expressed as

$$
M_{s} \equiv \frac{f_{s} B}{2}
$$

When the two moments are in a state of equilibrium, $M_{t}$ equals $M_{S}$ and no motion occurs. For rotation about the centroid to occur, $M_{t}$ must be greater than $M_{s}$, and therefore, $M_{t}$ must always be greater than or equal to $M_{S}$ expressed as

$$
M_{t} \geq M_{s}
$$

By assuming the equality in Equation (15), substituting the values in Equations (11), (12), (13), and (14), and then solving for $S$, the following relationship between the stance, $S$, and the wheelbase, $B$, is true when the system is in a state of equilibrium:

$$
S=B \cdot \frac{\mu_{s}}{\mu_{t}}
$$

The relationship of $S$ and $B$ must be as follows in order for rotation to occur:

$$
S>B \cdot \frac{\mu_{s}}{\mu_{t}}
$$

Therefore the stance, $S$, is related to the wheelbase, $B$, such that

$$
S \geq B \cdot \frac{\mu_{s}}{\mu_{t}}
$$

In order to simplify the analysis of the RATLER's geometry, it is convenient to redefine the stance, $S$, as the sum of the inner spacing between the wheels, $S_{1}$, and the wheel width, $W$, (see Figure 16), expressed as

$$
S=S_{1}+W
$$


By substituting the above expression for $S$ and the relation for $B$ found in Equation (7) into Equation (18), the lateral geometry of the vehicle can be completely described in terms of the wheel radius, $R$, the wheel width, $W$, and the inner spacing between the wheels, $S_{1}$, as follows:

$$
S_{1} \geq\left(\frac{2 \sqrt{2} R \mu_{s}}{\mu_{t}}\right)-W .
$$

In summary, the above analysis shows that the maximum step, $H_{\max }$, and the optimal wheelbase, $B$, for the RATLER design can be defined purely in terms of the wheel radius, $R$, and that the inner stance clearance, $S_{1}$, is a function of the wheel radius, $R$, and the wheel width, $W$. Defining the vehicle's geometry in these terms is useful when attempting to predict the vehicle's performance using models for the wheel/soil interface such as those found in Bekker's equations. ${ }^{16}$

A much more complicated analysis of the step problem, not included here, shows that when only one side of the vehicle climbs a step, the leverage advantage of the articulating RATLER design requires only half as much torque to climb the step as a conventional fourwheeled platform. This result is intuitively obvious since only "half" of the RATLER vehicle is traversing the obstacle. Alternatively, if the two vehicles have equal torque, the RATLER design can climb steps that are slicker by almost a factor of two (the coefficient of friction equations are not linear). 


\subsection{RATLER SCALE MODELS AND PATHFINDER}

\subsection{Prototypes and Tests}

The original RATLER was a small, unpowered balsa model about six inches long that was used to verify that the two-compartment, central-pivot concept would traverse large obstacles and had some advantages over conventional platforms. The major advantages observed included comparable performance with simpler control and fewer moving parts than a similarly sized sixwheeled rover design and considerably better performance than conventional four-wheeled rover designs. Several other models were then constructed to investigate conventional steering versus skid steering, body shapes, composite structures, tethered controls, remote radio frequency (RF) controls, embedded computing, and the incorporation of solar power into the design.

The first motorized scale prototype, incorporating the best ideas from all of the early models, is about 15 inches long with a balsa, mylar, and plastic-tubing chassis. The drive system consists of four small constant-speed DC electric motors, reclaimed from the DOE weapons program, and incorporates a skid steering control methodology. The control system is a commercial radio control set coupled to microswitches for motor control and standard servo setups for the internal tilt of the miniature charge coupled device (CCD) on-board camera. The entire system, including the remote video transmitter, is powered by a series of nine-volt (9V) transistor batteries. This prototype was tested extensively for obstacle and slope climbing abilities at SNL/RVR, the White Sands National Monument, and the Death Valley National Monument. The model was recently donated by SNL to the Space Museum and Space Hall of Fame in Alamogordo, New Mexico, where it is currently on display to the public.

Several subsequent prototypes, all using skid steering, have been constructed and are now undergoing extensive testing at SNL/RVR and on the dunes at the White Sands National Monument. They include an 11-pound aluminum replica of the original balsa RATLER; two 8inch Pygmy RATLERs with a variable speed drive system for the wheels, and a flat-plate body testbed with a variable speed drive system designed so that the stance, ground clearance, pivot height, and pivot limits can be easily changed. A one-meter scale design that incorporates onboard computing and a carbon/epoxy composite construction has also undergone preliminary testing using tether control at White Sands and SNL. It is currently under advanced development at SNL. All of the prototype systems have been tested in damp gypsum sand at White Sands and can climb $18^{\circ}$ to $22^{\circ}$ slopes. A dry, powdery sand test with the Pygmy RATLER showed the potential for climbing even steeper slopes, but further tests are needed to verify this observation. 
All of the prototypes, with the exception of the first 15 -inch balsa version and the latest one-meter scale carbon/epoxy composite version, were built and tested by summer-hire students with the assistance and direction of SNL's technical staff.

\subsection{Pathfinder}

Based on the trade-off study results, a RATLER II pathfinder test article was constructed and tested under tethered control at both SNL/RVR and at the White Sands Missile Range (WSMR) during November and December of 1992. Those field trials and additional analysis led to a few minor changes in the vehicle's configuration and resulted in improved mobility and an increase in mechanical strength of the structure. The changes included the addition of aluminum skid plates to protect the undersides of the carbon composite chassis, larger wheels, increased drive motor torque, and a slight increase in the vehicle's lateral stance. The RATLER II pathfinder prototype is shown in Figure 18.

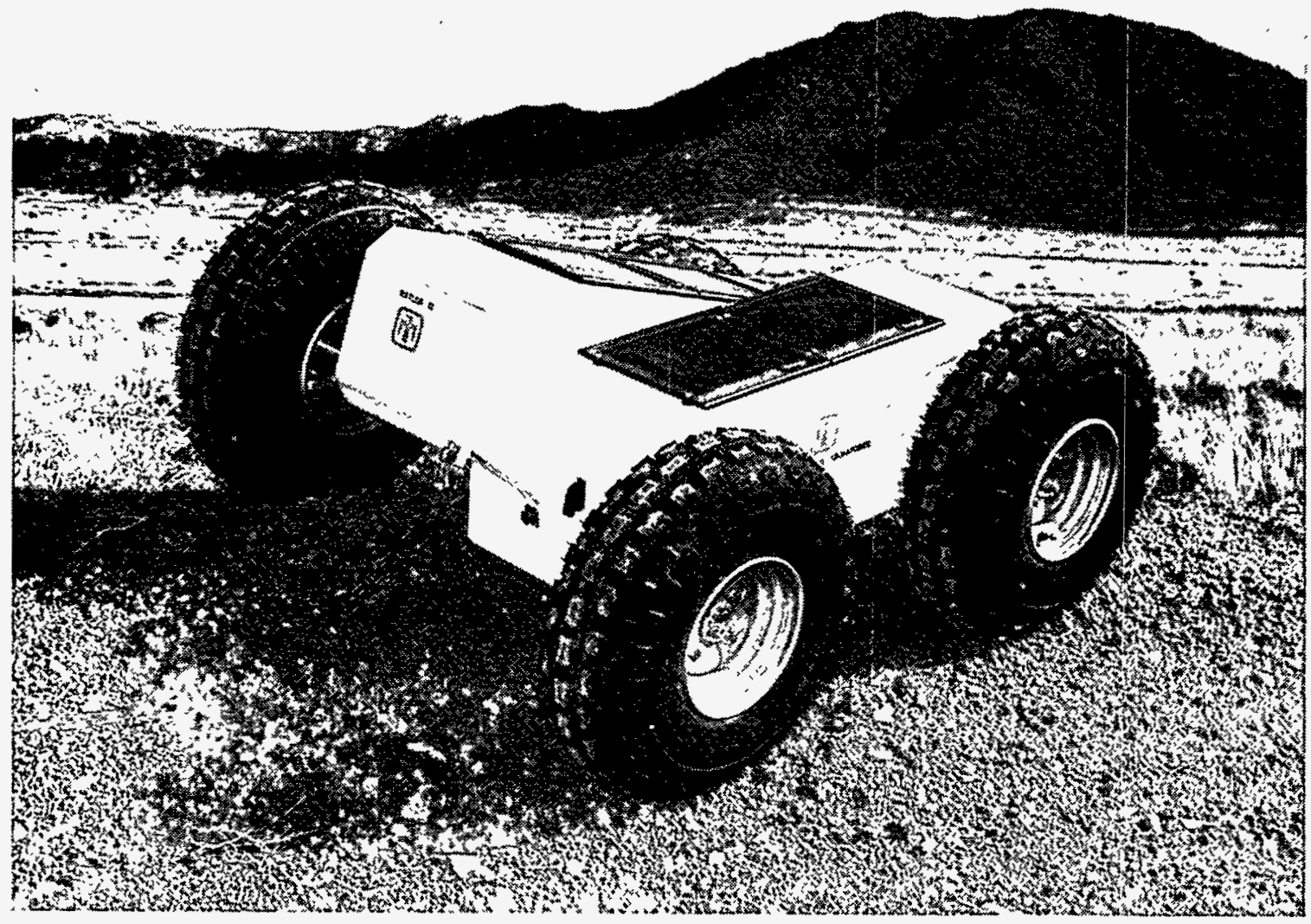

Figure 18. RATLER II Pathfinder Prototype. 


\subsection{RATLER II CONFIGURATION}

When the RATLER II program was initiated in October 1992, the first task was to determine what performance requirements or specifications existed in the literature for a lunar exploration rover. Although examples of lunar roving vehicles were found, a contemporary set of requirements for future missions by rovers to the Moon was not found. Next, a trade-off study was performed in an attempt to derive requirements that could be used by the project team to design and build the RATLER II. The results of that study led to a RATLER II design that could be constructed using off-the-shelf technology. The design was expected to meet a reasonable set of performance criteria in terms of mobility and payload capacity. The current RATLER II configuration was sized to meet the mass and volume constraints imposed by the ARTEMIS Common Lunar Lander 9 and to provide a significant science payload capacity. Figure 19 shows the current RATLER II configuration.

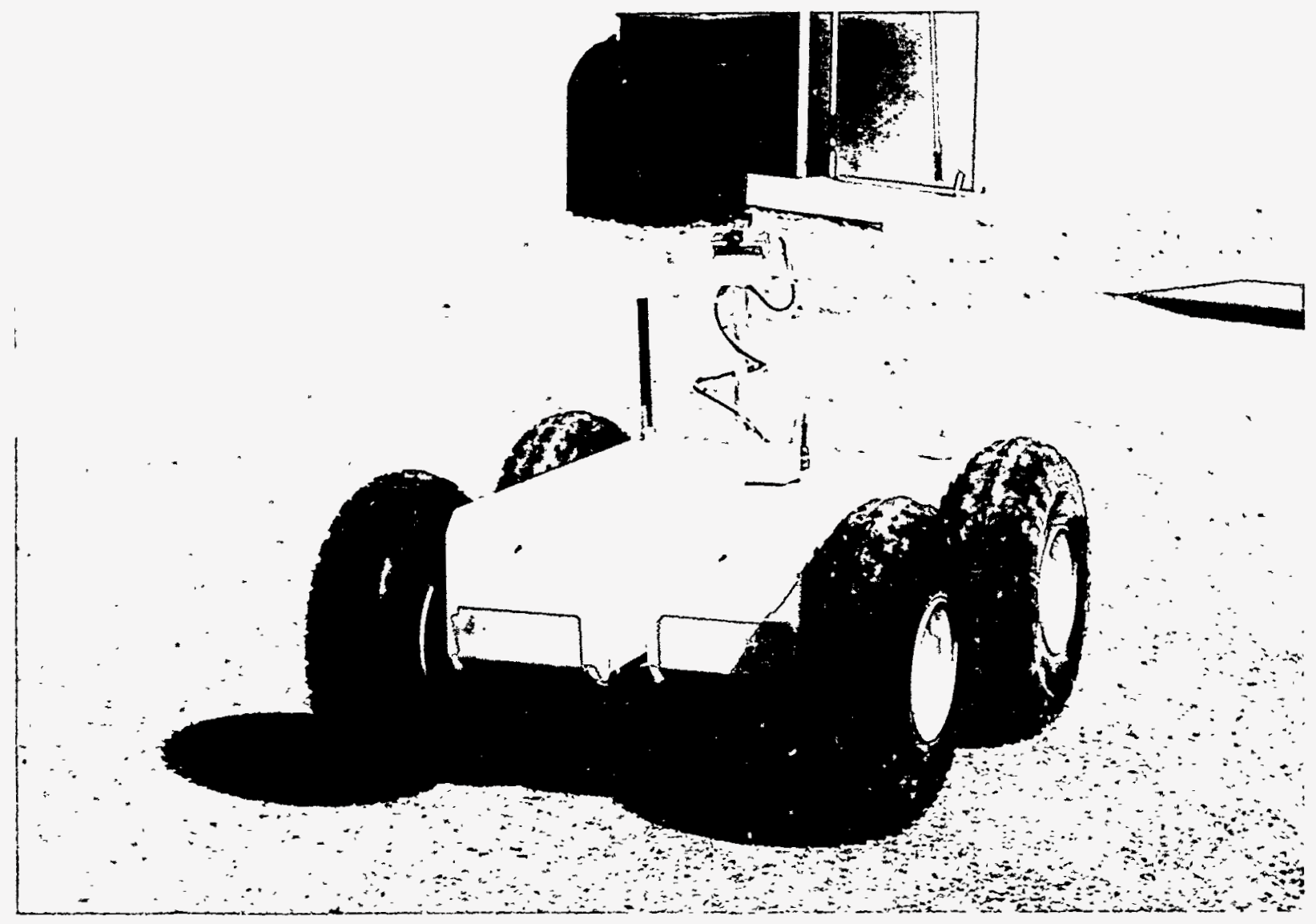

Figure 19. RATLER II Configuration. 


\subsection{Mechanical}

The RATLER II chassis consists of two compartments, left and right, connected by a passive central pivot aligned along the lateral axis of the vehicle. Each compartment is constructed of an inner and outer skin of carbon fibers embedded in an epoxy matrix, laid over a cellulose honeycomb inner core. Each compartment is approximately $25 \mathrm{~cm}$ wide by $25 \mathrm{~cm}$ deep by $92 \mathrm{~cm}$ long, with an empty mass of approximately $3.2 \mathrm{~kg}$. The complete system (not including science instruments) has a mass of about $115 \mathrm{~kg}$ (includes four lead-acid batteries and four custom designed carbon composite wheels). Table 5 lists the RATLER II's specifications and expected performance parameters.

\subsection{Electrical}

The drive system uses four-wheel, independent electric drive from four 24 VDC permanent-magnet gearhead motors, each of which provides approximately $22 \mathrm{~N} / \mathrm{m}$ of torque at a maximum speed of approximately $60 \mathrm{~cm} / \mathrm{s}$. The battery system is augmented with commercial photovoltaic arrays to provide a trickle charge capability. The system is expected to provide about two hours of operation, assuming a $50 \%$ duty cycle on the drive system and derating the batteries for a $0.5^{\circ} \mathrm{C}$ discharge rate at $0^{\circ} \mathrm{C}$. An internal payload space of approximately $9600 \mathrm{~cm}^{3}$ and a maximum of $18 \mathrm{~kg}$ additional mass budget are provided for scientific instruments, which are allowed a total of up to $100 \mathrm{~W}$ of on-board power.

Table 5. RATLER II Specifications

\begin{tabular}{|c|c|c|}
\hline Parameter & Value & Units \\
\hline Wheel Radius & 26 & $\mathrm{~cm}$ \\
\hline Wheel Width & 20 & $\mathrm{~cm}$ \\
\hline Wheelbase & 74 & $\mathrm{~cm}$ \\
\hline Stance (to center of contact patch) & 100 & $\mathrm{~cm}$ \\
\hline Total Vehicle Mass (TVM, no payload) & 115 & $\mathrm{~kg}$ \\
\hline Total Stored Volume (TSV) & 0.6 & $\mathrm{~m}^{3}$ \\
\hline Maximum Single Dimension of TSV & 174 & $\mathrm{~cm}$ \\
\hline Maximum Speed & 0.6 & $\mathrm{~m} / \mathrm{s}$ \\
\hline Slope Stability & $>45$ & degrees \\
\hline Slope Climbing & approximately 30 & degrees \\
\hline Obstacle Climbing & approximately 75 & $\mathrm{~cm}$ \\
\hline Maximum Payload Mass (additional to TVM) & 18 & $\mathrm{~kg}$ \\
\hline Maximum Payload Power (planned) & 100 & W (electric) \\
\hline Maximum Internal Payload Volume & 9600 & $\mathrm{~cm}^{3}$ \\
\hline
\end{tabular}




\subsubsection{Power}

The RATLER II derives its primary power from four $12 \mathrm{~V}, 26 \mathrm{Ah}$, lead-acid gel-cell batteries. A trickle charge is provided by four solar panels with an output total of $20 \mathrm{~W}$. The batteries are configured in two parallel $24 \mathrm{~V}$ banks to supply total of 52 Ah of capacity at $24 \mathrm{~V}$. Motor drive current is supplied directly from the unregulated batteries. Regulated voltages required for the system electronics are obtained from a set of DC-to-DC converters and linear regulators. A diagram of the RATLER power system is shown in Figure 20. Notice that the battery ground is isolated from the output ground of the DC-to-DC converters in the schematic. These two grounds are connected internally at the pulse width modulation (PWM) servo amplifiers. It is desirable to have the computer power supplies completely isolated from the unregulated $24 \mathrm{~V}$ system to eliminate the effects of motor drive current spikes. The internal connection of signal reference and power ground at the PWM servo amplifiers made isolation of the power systems inconvenient. Experience with the RATLER to date has not uncovered any severe electrical noise problems that could be attributed to the common grounds, so no attempt has been made at isolation.

The lead-acid gel-cell batteries were chosen primarily for their relatively low cost and clean operating characteristics. The PowerSonic PS-12260NB batteries used on RATLER II have an energy density of 78.7 watt-hours/liter (Wh/L), a specific energy of 36.8 watthours $/$ kilogram $(\mathrm{Wh} / \mathrm{kg}$ ), and a cost of $\$ 173$ (U.S.) $/ \mathrm{kWh}$. Early in the design phase of the project, a survey of advanced battery technology was conducted to determine power densities that could be expected from new battery designs. Typical performance of these advanced batteries is bracketed by two designs, nickel-iron, which is currently being produced in small quantities, and sodium/sulfur, which is still experimental. Nickel-iron batteries are being manufactured on a limited basis for the electric vehicle market and have an energy density of $118 \mathrm{Wh} / \mathrm{L}$, a specific energy of $51 \mathrm{Wh} / \mathrm{kg}$ and a cost of $\$ 1500$ (U.S.)/kWh. For space applications where weight is the primary concern, perhaps the most promising technology is sodium/sulfur. The sodium/sulfur batteries have an energy density of $83 \mathrm{Wh} / \mathrm{L}$, a specific energy of $81 \mathrm{Wh} / \mathrm{kg}$, and a projected cost of $\$ 110$ (U.S.)/kWh in production.

RATLER II was originally powered by four $40 \mathrm{Ah}$ lead-acid gel-cells. These batteries had a total mass of $56 \mathrm{~kg}$ and provided an estimated operating duration of three hours for a continuous average power consumption of $500 \mathrm{~W}$. Experience has shown that $500 \mathrm{~W}$ is a conservative estimate of the average power consumed during "normal" driving. Initial mobility tests indicated problems when initiating skid turns because of excessive friction of the rubber 


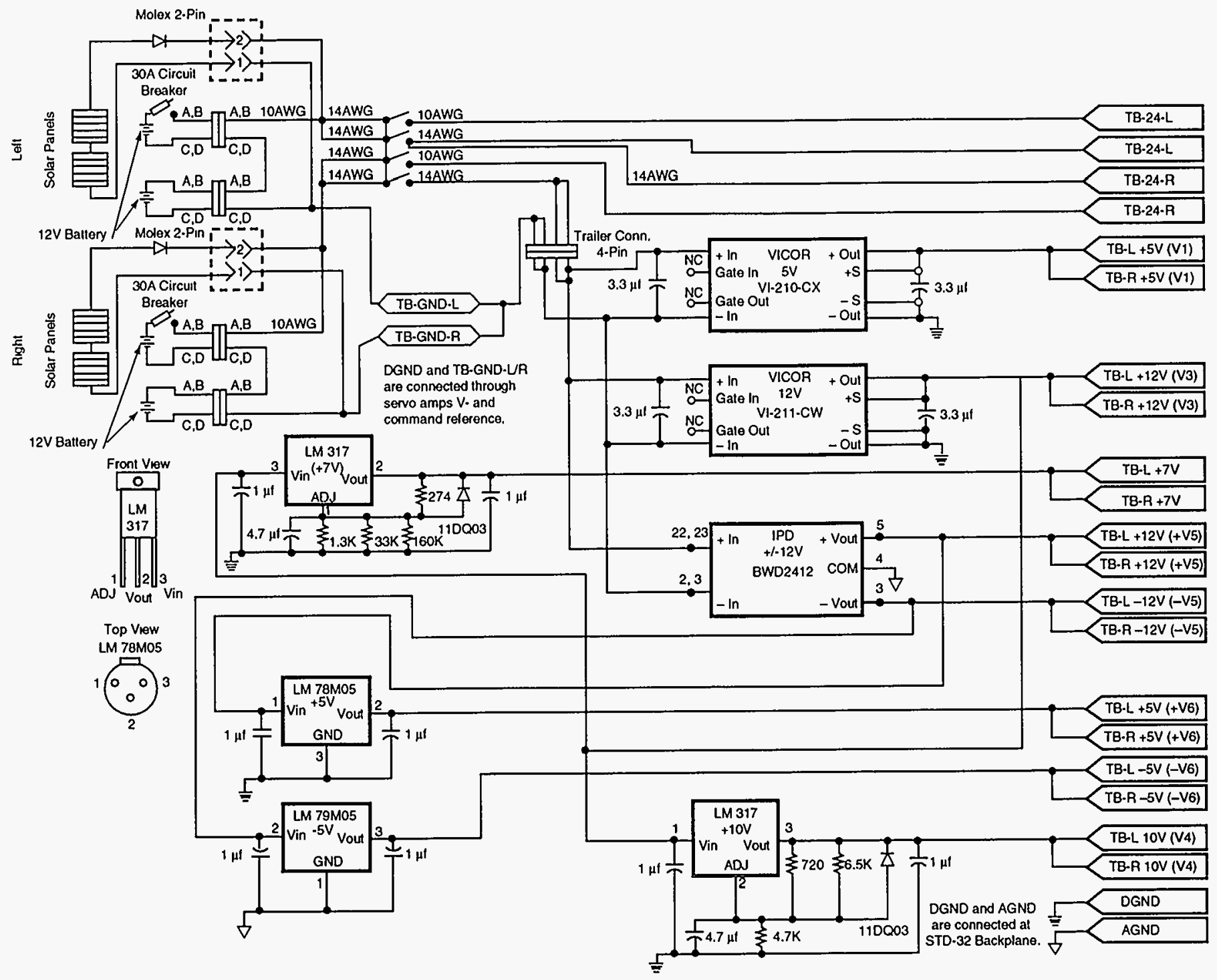

Figure 20. RATLER II Power System. 
tires on asphalt. The $26 \mathrm{Ah}$ batteries were substituted in order to reduce the weight of the vehicle.

These batteries have a total mass of $34 \mathrm{~kg}$ and provide an estimated two hours of operation with the same "normal" driving profile at $20^{\circ} \mathrm{C}$. The $22 \mathrm{~kg}$ weight savings make spin turns possible on dirt or gravel surfaces, but problems are still encountered on pavement and grass. A new wheel design using a carbon/Kevlar composite has reduced the coefficient of friction significantly and has dramatically improved RATLER's turning performance.

The RATLER II design includes plans to incorporate four Siemens M5 solar panels for battery charging. These solar panels have not yet been installed because of time constraints but will be added to the system during the next year. The M5 solar panels each provide $5 \mathrm{~W}$ of power under test conditions of $1,000 \mathrm{~W} / \mathrm{m}^{2}$. These test conditions basically correspond to full midday sun at normal incidence. Typical power consumption of the RATLER II computing system is about $20 \mathrm{~W}$, so these solar cells should keep up with power consumption while the robot is stationary with the communications transmitters turned off.

The Siemens solar panels were chosen based on economics. It was decided that the proofof-principle RATLER was not required to depend upon solar energy for operation but could rely upon rechargeable batteries for developmental and demonstration purposes. Of course the lunar system will have to do a much better job of power management and will require higher efficiency solar cells. The Siemens cells are $11 \%$ efficient on earth, and the entire M5 panel costs less than $\$ 100$ (U.S.). Typical space-qualified cells are $18 \%$ efficient on earth but degrade to $16 \%$ efficiency in space. The highest efficiency cells are manufactured by SunPower and are $20 \%$ to $21 \%$ efficient on earth but are not yet space qualified. Unfortunately, the SunPower cells are very expensive, ranging from $\$ 100$ to $\$ 300$ (U.S.) per cell with an output $0.72 \mathrm{~W}$ each.

\subsubsection{Sensors}

The RATLER II has a variety of navigation and state-of-health sensors built into the system, as well as provisions to interface with various science packages. Navigation sensors are required for the behavioral control system that is planned for future implementation during FY94. Since the RATLER II is a research platform with a unique custom chassis design and electric drive system, state-of-health sensors are extremely important for determining weak points in the design. 
The RATLER II navigation system uses a combination of dead reckoning and Global Positioning System (GPS) sensor data for position location. The dead reckoning routines combine data from a magnetic fluxgate compass, as well as a solid-state angular-rate sensor to determine platform heading. The distance traveled is determined by averaging incremental optical encoder counts from each wheel.

The primary heading sensor is a KVH C100 Compass Engine. The $\mathrm{C} 100$ measures the earth's magnetic field with a toroidal fluxgate. The fluxgate's ring core is free-floating in an inert fluid that allows it to remain horizontal while the platform inclines in any direction up to a maximum of $15^{\circ}$. This ability to passively remain level eliminates the need to compensate for sensor alignment. The $\mathrm{C} 100$ also contains an automatic calibration feature to compensate for magnetic anomalies caused by ferrous materials on the platform. Heading information is communicated to the RATLER II computing system via a 9600 baud serial link at a rate of $10 \mathrm{~Hz}$.

Angular rate is determined with a Systron Donner GyroChip. The GyroChip is a solidstate sensor that uses an oscillating quartz tuning fork to sense angular rate with the Coriolis effect. The angular velocity of the device produces a Coriolis force proportional to the rate of rotation that in turn induces an oscillating signal in a pair of pickup tines. The signal is then amplified and demodulated into a DC voltage proportional to turn rate. The GyroChip has a range of $\pm 50 \mathrm{deg} / \mathrm{s}$, and a full-scale output of $\pm 2.5 \mathrm{VDC}$ that is read directly by the analog/digital $(\mathrm{A} / \mathrm{D})$ board.

Odometry is provided by incremental encoders on each drive motor. The 500 line encoders provide 2,000 quadrature counts for each wheel revolution. These encoder signals are currently read by a four-channel quadrature decoder board. A custom-designed, 14-channel, quadrature decoder board was planned in the original system design to provide sufficient decoder inputs for the wheel, pan/tilt, and arm-joint encoders, but delays in the design have required using the off-the-shelf solution for now. The wheels have a diameter of $56 \mathrm{~cm}$ and a circumference of $176 \mathrm{~cm}$, corresponding to a resolution of less than one $\mathrm{mm}$ in distance traveled. Since the RATLER has no non-driven wheels and is skid steered, wheel slip is a major source of error in the dead reckoning calculations. An average count from all four wheels is used in an attempt to obtain the best estimate of distance traveled. Depending on the magnitude of odometry errors determined from field trials, additional methods of estimating odometry may need to be explored. 
Dead reckoning accumulates errors proportional to distance traveled, so some method of position update must be used to bound these errors to a finite value. A Magnavox GPS engine is used for this purpose on the RATLER II prototype. Obviously GPS navigation is not practical for space applications, and some other type of global position update will be required for lunar missions.

The Magnavox GPS Engine is a six-channel, Clear/Acquisition (C/A) code, single-board GPS receiver intended for embedded applications. Both the code and carrier phase from up to six satellites can be tracked simultaneously to provide robust navigation solutions. Selective Availability (SA) is an intentional degradation of the GPS signals by the U.S. Government for security reasons. Primarily because of the effects of SA, the two-dimensional (2D) accuracy of the GPS Engine in a stand-alone configuration is approximately $100 \mathrm{~m}$ root mean square (RMS). The GPS Engine may also be configured in a differential system. In this configuration, range corrections are broadcast from a stationary receiver at a known location to the mobile receiver. The differential corrections eliminate the effects of SA and greatly reduce other error sources that are common to both receivers. The GPS Engine has a 2D accuracy of 5 to $7 \mathrm{~m}$ RMS in a differential system. Initially, the receiver will be operating in a stand-alone configuration, but future enhancements will implement differential corrections.

The ultimate mission for any lunar rover is to carry science packages for planetary exploration; hence, the RATLER II system has been designed with a variety of spare input/output (I/O) ports to interface with mission payloads. The first mission payload designated to be carried by the RATLER II is a Laser-Induced Breakdown Spectroscopy (LIBS) system developed by Los Alamos National Laboratory.

A variety of state-of-health sensors have been included in the RATLER II design to monitor system parameters that are possible areas of concern. These include motor and computer temperatures, vehicle inclination, battery voltage, and motor currents. Early field trials have shown that the original drive motors have marginal torque output, and overheating of the motors is a concern. This condition is compounded by the difficulty of heat-sinking the motors because of the carbon chassis. Plans are to monitor the temperature of the drive motors with LM35AH centigrade temperature sensors that are calibrated directly in degrees centigrade and output 10 $\mathrm{mV} /{ }^{\circ} \mathrm{C}$ over a range of $-55^{\circ}$ to $150^{\circ} \mathrm{C}$. The $\mathrm{LM} 35 \mathrm{AH}$ will also be used to measure computer temperature. 
Vehicle inclination is measured with three Schaevitz Accustar clinometers. Two clinometers measure pitch angle of each vehicle half, and one clinometer measures roll angle of the entire platform. The Accustar clinometers output an analog voltage signal of $60 \mathrm{mV} / \mathrm{deg}$ ree and have a full-scale range of \pm 60 degrees.

Concern over conservation of energy for the battery-powered vehicle has prompted several measurements of power system state of health. Battery voltage is measured directly from a voltage divider, which scale the 30-volt full-scale value to five volts for input to the A/D board. The largest source of power consumption in the RATLER II system is the drive motors. All other power consumption is either insignificant or a constant drain so that the effect on battery state of health can be estimated. Current consumption from each of the drive motors is monitored so that power consumption can be profiled for normal operations. Each of the servo amplifiers has a current monitor test point that outputs an analog voltage proportional to current. The scale factor of this output is $0.2345 \mathrm{~V} / \mathrm{A}$.

\section{$5.3 \quad$ Computing}

\subsubsection{Hardware}

The computing system implemented on RATLER II is a commercial STD-32 system that is based on the popular STD-80 backplane design but has been expanded to allow 32-bit data transfers. The STD-32 system supports multiple processors using a master/slave arrangement with bus arbitration and peripheral sharing support. The master processor is an Intel 80486-based machine equipped with 3 megabytes $(\mathrm{Mb})$ of RAM and $1 \mathrm{Mb}$ of EEPROM, and the single slave processor is a NEC V53 (80286/80386 clone) equipped with $1 \mathrm{Mb}$ of RAM. Extra card slots have been budgeted to allow additional slave processors for future expansion. Shared peripheral devices on board include a high-speed, 12-bit, 32-channel analog-to-digital converter; a 12-bit, 8channel digital-to-analog converter; Ethernet adapters; and a commercial 4-channel digital quadrature encoder board. Each of the two CPUs have on-board I/O ports which give the system a total of 5 serial (RS-232) ports and 72 Parallel Interface Adapter (PIA) lines, of which 24 are optically isolated. On-board sensors and instrumentation include a magnetic fluxgate compass, a GPS receiver, two pitch-axis and one roll-axis inclinometers, an angular rate sensor for the yaw axis, individual wheel odometers, drive motor tachometers, drive motor temperature sensors, drive motor current monitors, battery voltage sensor, and a computer module temperature sensor. All of the internal components are mounted on removable payload module base plates as shown in Figure 21 to allow easy access for maintenance or repair. Communications with the Control Driving System (CDS) during field operations are handled through a 4800 baud, full-duplex 


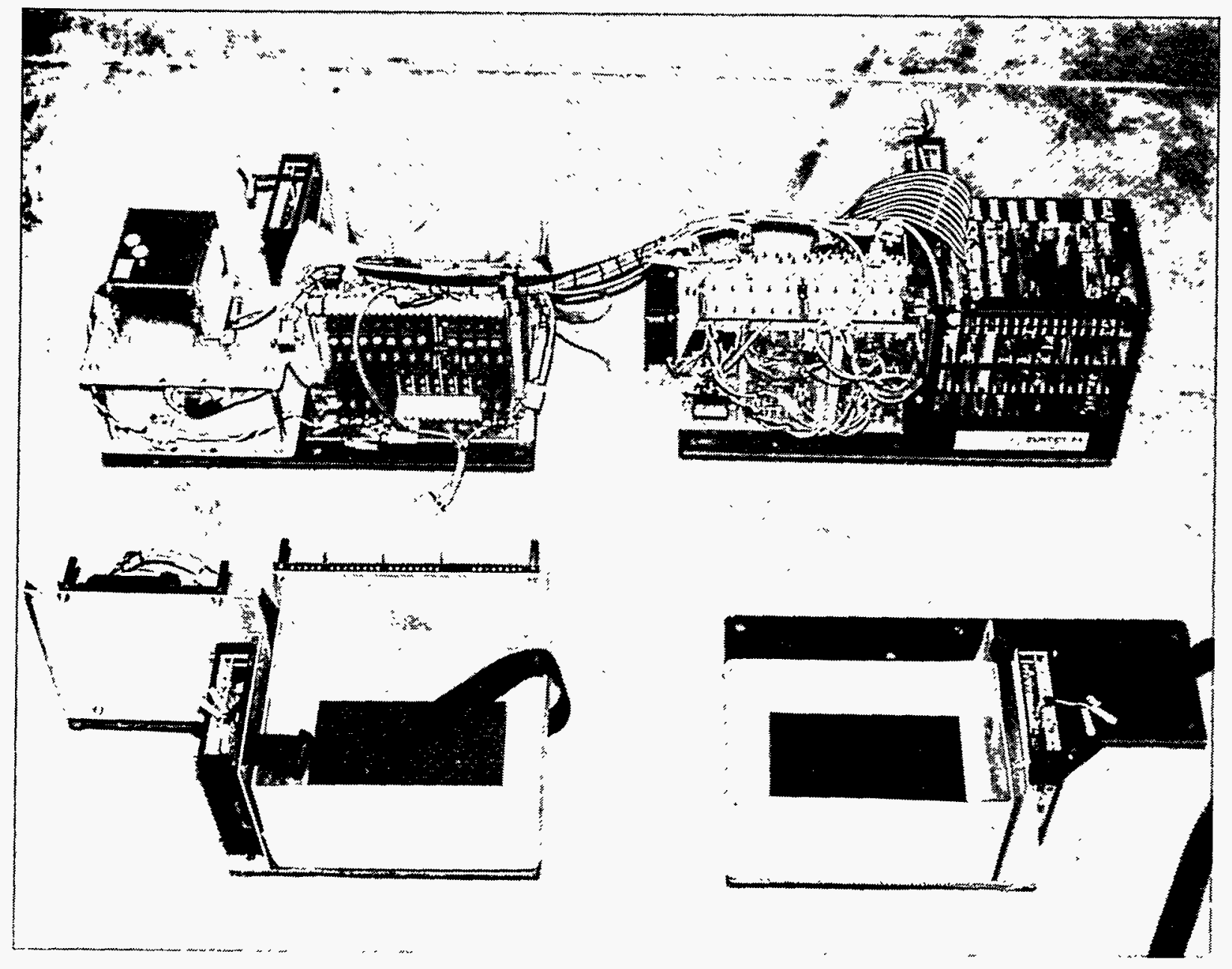

Figure 21. RATLER II Payload Modules.

digital RF modem operating at approximately $400 \mathrm{MHz}$ and a $\mathrm{RF}$ video/audio transmitter operating at approximately $2.3 \mathrm{GHz}$.

\subsubsection{Software}

The RATLER II software operates on a STD-32 dual-processor system, virtually identical to that on the RATLER CDS system. The software that controls the serial communications with the CDS runs on the master 80486 processor, while the vehicle hardware interface software runs on the slave V53 processor. The processors communicate via shared memory and interprocessor messages provided under the Ziatech Star System. As with the CDS, the software is composed of $\mathrm{C}$ language and $\mathrm{C}++$ language modules augmented by a real time, multi-tasking executive and a locally developed communications protocol library. By using similar architectures on both the vehicle and CDS, common software modules can be shared, thus saving development and testing time. An Ethernet port is used for development and accesses a LAN at SNL/RVR for software 
development tools and source code so that code development can be accomplished directly on the target CPUs on board the vehicle. The software system has been designed to allow future expansion of autonomous capabilities and rapid prototyping of new experimental configurations for robotic control.

The slave processor handles all aspects of the vehicle hardware interface, including reading the analog input signals and serial data streams from the on-board sensors and generating the analog output control signals to the drive motors and pan/tilt platform. The slave processor also generates digital output control signals that enable and disable ON/OFF functions on the vehicle for power amplifiers, cameras, transmitters, and various other peripheral devices. Acquired data is converted and stored in common memory for both the slave and master processors to access. When a data query command is received by the master processor from the CDS, the data in common memory is transmitted back to the CDS as a response. Similarly, when commands from the CDS are received by the master processor, they are stored in common memory for the slave processor to use when generating output control signals for the pan/tilt, drive motors, or peripherals. Synchronization between the CPUs is accomplished via the Ziatech Star System message passing and semaphore facilities. Both the slave and master processors incorporate a Local User Interface (LUI) feature that allows a keyboard and display monitor to be attached for development purposes, and control of the keyboard/monitor hardware can be software-switched between CPUs in real time via a simple keystroke. Both CPUs also incorporate self diagnostics and safety monitoring software modules that determine if some problem with either on-board software or hardware has occurred. They will place the vehicle in a safe, nonoperative state to preclude possible injury to people or property if a serious problem is detected. The safety features of the RATLER software are configured in a "fail-safe" manner so that the failure of either hardware or software to actively toggle a "keep alive" circuit will cause that circuit (which is independent of the computer system) to place the vehicle in a safe state.

Following the initial operational capability demonstration of teleoperation in the Fall of 1993, the RATLER II software will be enhanced as needed in the following areas: dead reckoning navigation accuracy, GPS-based navigation, autonomous navigation, multi-vehicle control, serial communication error detection, scientific payload customization, and manipulator control. Additional work will also be done on the communications protocol to support these new functions. 


\subsection{CONTROL DRIVING STATION (CDS)}

\subsection{Hardware}

A portable Control Driving Station (CDS) was designed for the teleoperation of the RATLER II robotic vehicle. This station is the user interface for RATLER II and provides control and monitoring for all vehicle functions. The CDS, shown in Figure 22, consists of a video display from the system camera, a computer display for system status, vehicle control inputs, and audio feedback. The remainder of this section describes the mechanical and electrical systems.

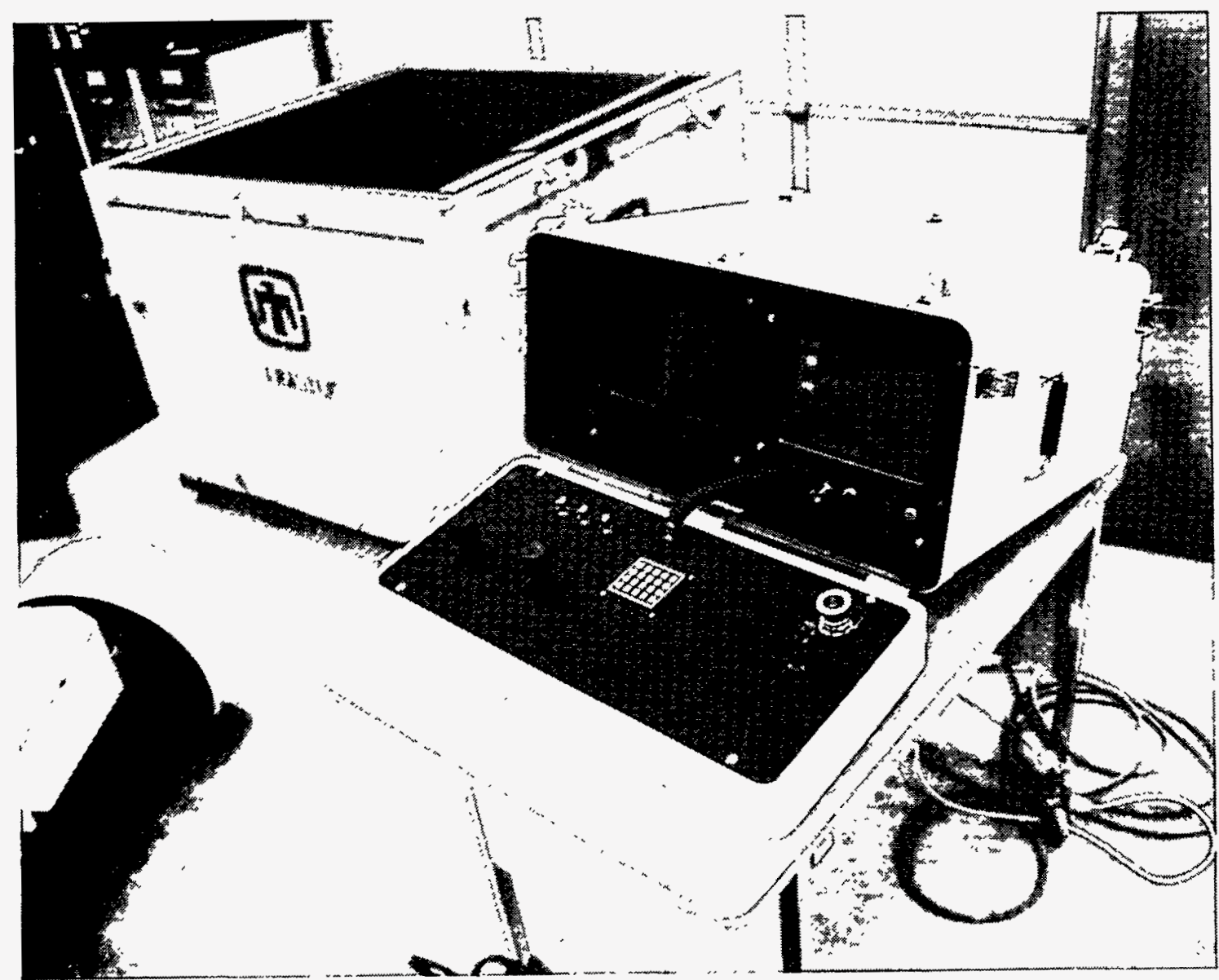

Figure 22. Control Driving Station. 


\subsubsection{Mechanical System}

The most significant design factor for the CDS was portability that, in turn, required components with the latest technology. The basic design was based on the available color liquid crystal display (LCD) monitor for video and the electro-luminescent (EL) enhanced graphics adaptor (EGA) monitor for data. Dimensions of these displays, mounted as physically close to each other as possible, established the minimum height and width of the CDS. The depth of the CDS is based on large-volume components such as the STD-32 computer system and the power supplies. In order to maximize portability, a custom-built enclosure was used (Figure 23). This enclosure is watertight when closed and water-resistant when open for operation.

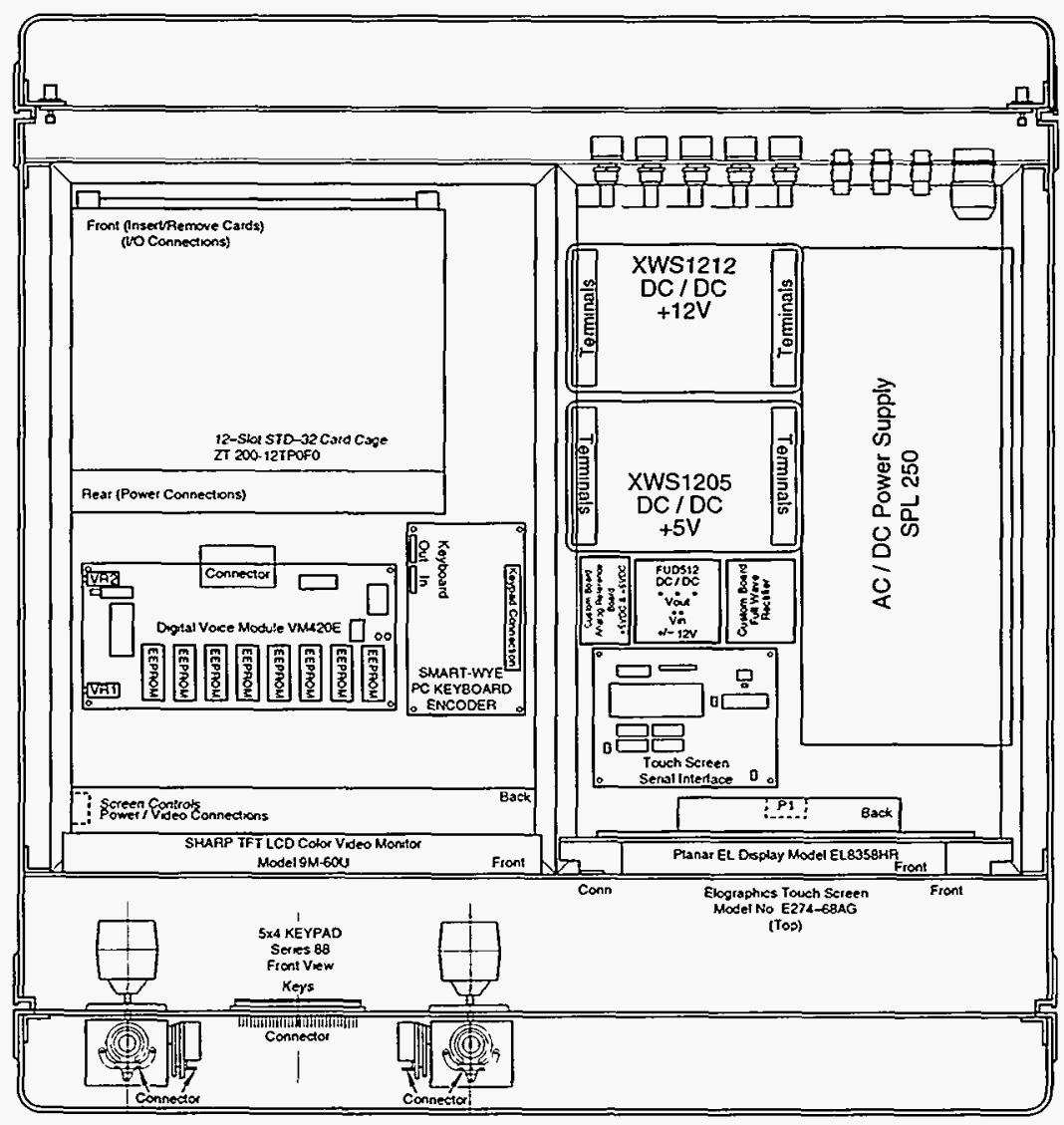

Figure 23. CDS Enclosure (Top View).

For maximum configuration flexibility, the video receiver and RF modem (Figure 24) were packaged in separate enclosures and are connected to the CDS via 100-foot cables. There are several advantages to this method compared to having these internal to the CDS enclosure. The main benefit is the ability to reconfigure or connect different RF frequencies without disassembling the CDS. There is also a signal strength advantage by keeping the antenna 


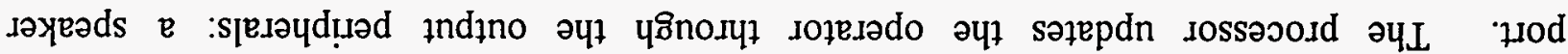

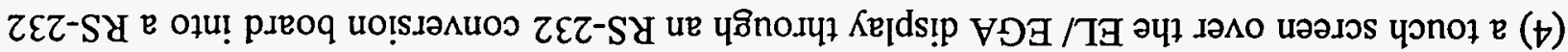

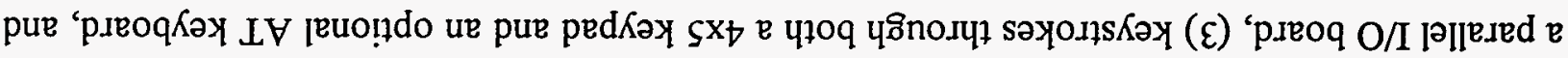

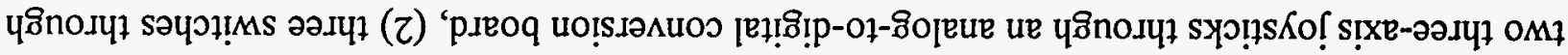

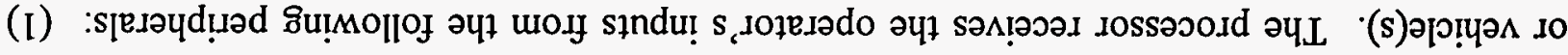

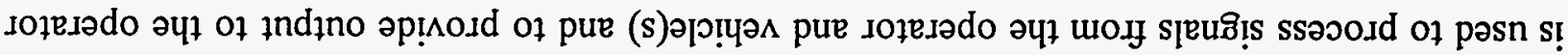

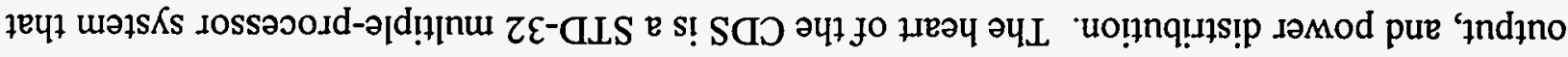

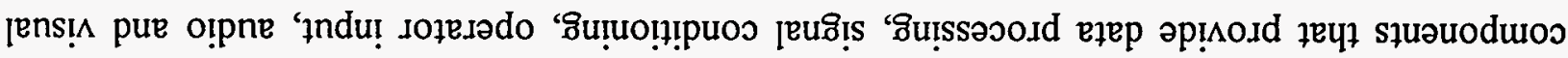

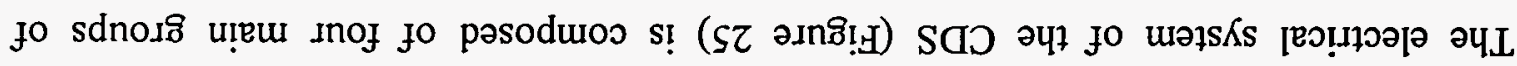

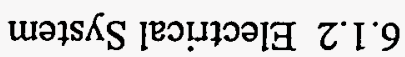

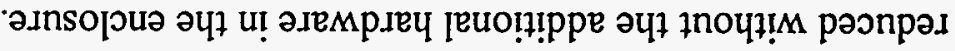

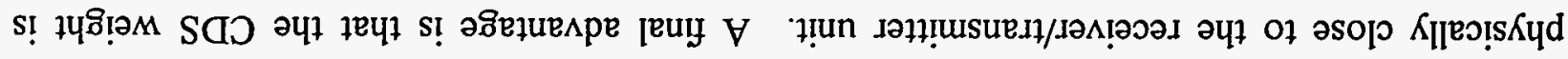

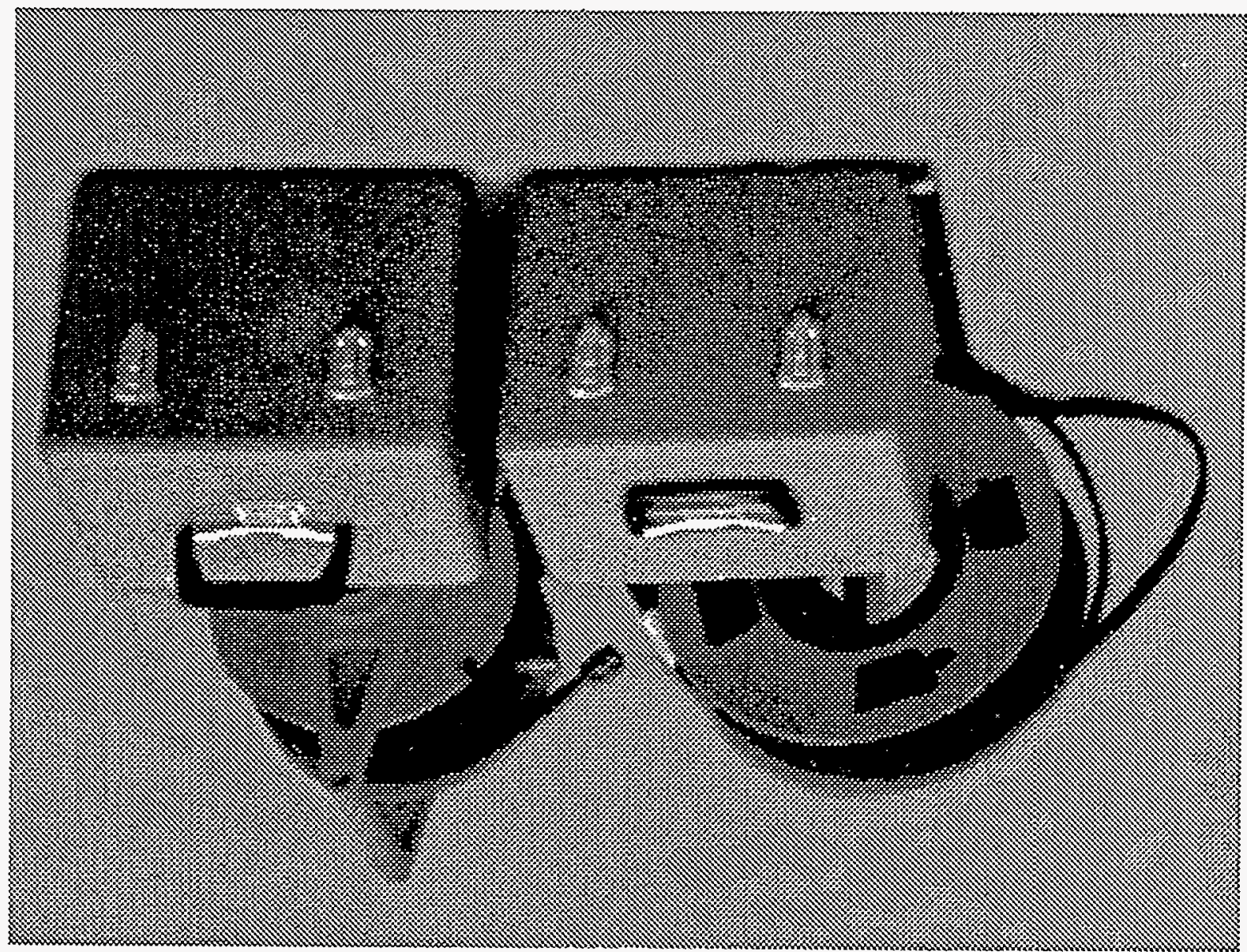




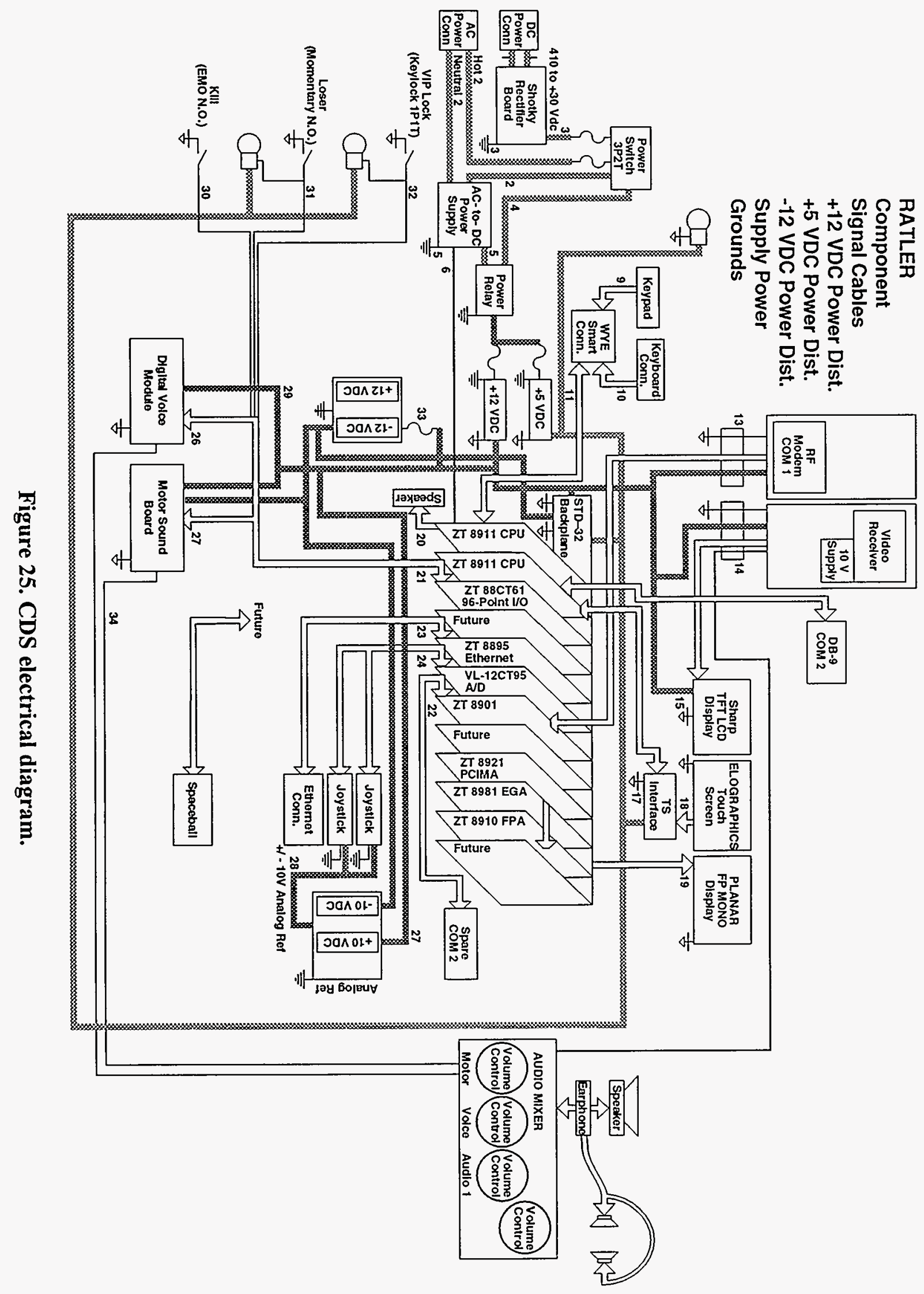


controlled by the processor, the EL/EGA monitor, and digital voice prompts that are stored on EPROMs.

Two sets of power supplies for operation from both $\mathrm{AC}$ and $\mathrm{DC}$ sources are provided in the $\mathrm{CDS}$. The $\mathrm{AC}$ power supply will produce $250 \mathrm{~W}$ at $12 \mathrm{~V}$ with connection to either a $50 \mathrm{~Hz}$ or $60 \mathrm{~Hz}$ and $110 \mathrm{VAC}$ or $220 \mathrm{VAC}$ source. When connected to an AC source, the AC-to-DC power converter will supply the DC-to-DC power converters. The main DC-to-DC power converters will supply $120 \mathrm{~W}$ at $12 \mathrm{~V}$ and $100 \mathrm{~W}$ at $5 \mathrm{~V}$ with an input from any $\mathrm{DC}$ source ranging from 10 to $30 \mathrm{VDC}$.

The power requirements were calculated using the manufacturers' specifications for all the equipment that is powered by the CDS. Table 6 shows the power requirements for the CDS and the estimated operating time using a lead-acid 60Ah battery.

Table 6. CDS Power Usage

\begin{tabular}{|c|c|c|c|}
\hline & $\begin{array}{c}\text { Maximum } \\
\text { Overrated } 30 \% \\
\text { Power } \\
\end{array}$ & $\begin{array}{c}\text { Maximum } \\
\text { Calculated } \\
\text { Power } \\
\end{array}$ & $\begin{array}{c}\text { Measured } \\
\text { Power }\end{array}$ \\
\hline TOTAL POWER (W) & 193.49 & 148.84 & 96.00 \\
\hline Components (A) & 16.12 & 12.40 & 6.67 \\
\hline DC/DC Converter Loss (A) & 3.22 & 2.48 & 1.33 \\
\hline TOTAL CURRENT (A) & 19.35 & 14.88 & 8.00 \\
\hline Battery Amp. Hours (Ah) & 48.00 & 60.00 & 54.00 \\
\hline Min. Operating Time (h) & 2.3 & 3.2 & 6.50 \\
\hline
\end{tabular}

\subsection{Software}

The RATLER II CDS software operates on a STD-32 dual-processor system identical to that on the RATLER II vehicle. The software that controls the serial communications with the vehicle runs on the slave V53 processor, while the operator interface software runs on the master 80486 processor. The processors communicate via shared memory and interprocessor messages provided under the Ziatech Star System. As with the vehicle, the software is composed of Clanguage modules augmented by a real time multi-tasking executive and a locally developed communications protocol library. By using similar architectures on both the vehicle and CDS, key software can be shared, thus saving development and testing time. 
The master processor handles all aspects of the operator interface, including reading the operator input hardware (switches, keypad, joysticks, touchscreen) and displaying vehicle status and other information. Operator commands are put in a standard format and placed into common memory for the slave processor to access. Similarly, vehicle information received via serial link is placed by the slave processor into common memory in the standard format. Synchronization between the CPUs is accomplished via the Ziatech Star System message passing and semaphore facilities.

Following the initial operational capability demonstration of teleoperation in the Fall of 1993, the CDS software will be enhanced as needed in the following areas: touchscreen support, autonomous navigation support, multi-vehicle control, serial communication error detection, scientific payload customization, and manipulator control. Additional work will also be done on the communications protocol to support these new functions. 


\subsection{FUTURE WORK}

A major focus of the project team's efforts in FY94 will be field trials with the RATLER II and its CDS. A payload bay area has been allotted to carry scientific instruments weighing up to $18 \mathrm{~kg}$ and requiring up to $100 \mathrm{~W}$ of power. The RATLER II program is intended to be a testbed for robotic lunar exploration; and as such, it provides mobility for the true focus of such a mission, i.e., the science package. Although SNL/RVR is not developing any science packages for lunar exploration, we are essentially offering a "free ride" during our on-going field trials to developers of such instruments. We will provide the appropriate interface information to qualified instrument developers to allow them access to RATLER II's support systems. With proper planning and coordination between the developer and the RATLER II project team, integrating the science package should be a relatively straightforward "strap-down" process and should allow several different science packages to be operated on board the RATLER II during field operations over the course of FY94 (through September 1994). Each proposed payload will be evaluated on an individual basis, and support funding (if any) will be negotiated as required between SNL/RVR and the instrument developer. As long as no significant modifications to the RATLER II hardware or software are required to support the instrument, no support funding to SNL/RVR will be required from the instrument developer.

As noted above, one of the major efforts beginning in October of 1993 will be the extension of the RATLER II's navigation capabilities to include some autonomous features. Current plans call for a subsumption-like architecture ${ }^{19,20}$ that will also necessitate the addition of obstacle detection sensors. Various configuration options are under consideration, and it is hoped that at least two different implementations will be developed and evaluated over the course of the RATLER II program.

A six-degree-of-freedom manipulator is planned for FY94, and its development will be among the first tasks undertaken beginning in October 1993. A dedicated slave CPU will allow coordinated motion of the manipulator while the vehicle is in motion, with virtually no impact on other on board processing tasks taking place. This capability will allow the entire system to act as a multi-degree-of-freedom (redundant) mobile manipulator, as well as provide a useful platform for field trials and testing of planetary exploration mission scenarios. An initial payload lift capacity of approximately two $\mathrm{kg}$ at full arm extension is planned, along with a small suite of interchangeable end effectors. 
The current video RF transmitter incorporates two sideband audio channels that may be used to bring back stereo audio from the RATLER II to the CDS. Since the Moon has no atmosphere, sound does not travel beyond the surface (however, it does travel through the lunar interior). Potential terrestrial applications for the RATLER II could make use of such a feature, and we plan to incorporate it. In addition, a set of stereo video cameras will be installed along with a duplexing system to allow stereo vision over a single RF transmitter. The use of a duplexer has been implemented previously at SNL/RVR for this purpose and has proven to be quite effective in improving perception without the penalty of doubling the bandwidth required for transmission of the real-time images.

Another item of interest for future work in the RATLER II program will be multi-vehicle control. A second RATLER II prototype will be constructed (essentially a twin of the first unit), and it will be used to explore the advantages and disadvantages of simultaneously controlling more than one rover from a common control station by a single operator. This issue is relevant to the argument that the use of multiple robotic rover vehicles for lunar exploration makes sense, both economically and technically.

Obviously the wheels, solar panels, computers, and batteries being used on the RATLER II are not types that would be suitable for a space-qualified system. Conceptual designs for lunartype wheels will be explored to the extent that at least one set of wheels will be constructed and evaluated, but a comprehensive program of wheel design is not currently planned. The subject of wheel design for lunar roving machines has been explored in some detail, ${ }^{15}$ and if incorporated in this development program, such an effort might easily consume the entire budget. Trade studies may be done with regard to batteries, solar cells, and computing technologies to identify spacequalified (or qualifiable) systems, but the RATLER II prototype currently under development will remain Earthbound. A space-qualified, flight-ready system could be developed based on the RATLER II, if such a program was determined to be in the national interest, but that type of effort is beyond the scope of the RATLER II program as it is currently defined. 


\subsection{REFERENCES}

1. NASA. 1989. 90-Day Study Data Book. NASA internal report.

2. Stafford, T. 1991. America At The Threshold: Report of the Synthesis Group On America's Space Exploration Iniliative. Washington, DC: Superintendent of Documents, U.S. Government Printing Office.

3. Purvis, J.W., and P.R. Klarer. 1993. "RATLER: Robotic All Terrain Lunar Exploration Rover," Sixth Annual Workshop on Space Operations, Applications and Research (SOAR 1992). Houston, TX: Lyndon B. Johnson Space Center. 174-79.

4. Klarer, P., and J. Purvis. 1993. "A Highly Agile Mobility Chassis Design For A Robotic All Terrain Lunar Exploration Rover," American Nuclear Society's Fifth Topical Meeting on Robotics and Remote Systems, Knoxville, TN.

5. Alexandrov, A.K., et. al. 1992. "Investigations of Mobility of LUNOKHOD I," Space Research XII. Berlin: Akademie-Verlag.

6. Florensky, C.P., A.T. Basilevsky, N.N. Bobina, G.A. Burba, N.N. Grebennik, R.O. Kuzmin, B.P. Polosukhin, V.D. Popovich, A.A. Pronin, and L.B. Ronca. 1978. "The Floor of Crater Le Monier: A Study of Lunokhad 2 Data," Proceedings of the Ninth Lunar and Planetary Science Conference, Volume 2: Lunar and Planetary Surfaces, Houston, TX, March 13-17, 1978. Ed. R. B. Merrill. Vol. 9, 1449-58.

7. Hoffman, S.J., and D.B. Weaver. 1992. Results and Proceedings of the Lunar Rover/Mobility Systems Workshop. EXPO-T2-920003-EXPO. Houston, TX: NASA Johnson Space Center.

8. Meyer, C. "Goals and Requirements for Scientific Lunar Rovers," Proceedings of Robotics for Challenging Environments, Amer. Soc. of Civil Engineers, Feb 26-Mar 3, 1994. 166-74.

9. NASA. 1992. ARTEMIS Program for Robotic Lunar Surface Exploration. Exploration Programs Office. Houston, TX: NASA Johnson Space Center. 
10. Purvis, J. 1992. Early Lunar Return Robotic Rover Mission. Civil Space Programs Department 9204. Albuquerque, NM: Sandia National Laboratories.

11. Heiken, G., D. Vaniman, and B.M. French. 1991. Lunar Source Book: A User's Guide to the Moon. Cambridge: Cambridge University Press. 32-3.

12. Heiken, G., D. Vaniman, and B.M. French. 1991. Lunar Source Book: A User's Guide to the Moon. Cambridge: Cambridge University Press. 61-6.

13. Gault, D.E. 1970. "Saturation and Equilibrium Conditions for Impact Cratering on the Lunar Surface: Criteria and Implications," Radio Science. Vol. 5, no. 2. 273-91.

14. Heiken, G., D. Vaniman, and B.M. French. 1991. Lunar SourceBook: A User's Guide to the Moon. Cambridge: Cambridge University Press. 522-29.

15. Costes, N.C., J.E. Farmer, and E.B. George. 1972. Mobility Performance of the Lunar Roving Vehicle: Terrestrial Studies-APOLLO 15 Results. NASA-TR-R-401. Huntsville, AL: NASA, Marshall Space Flight Center.

16. Bekker, M.G. 1969. Introduction To Terrain-Vehicle Systems. Ann Arbor: University of Michigan Press.

17. Lunar Geotechnical Institute. "ROVER.EXE analysis software, version 2.0 for MSDOS." Available from David Carrier, POB 5056, Lakeland, FL 33807, (813) 644-5920.

18. Carrier, D. 1992. "Lessons Learned from the Lunokhod \& Lunar Roving Vehicle," Presentations from the Lunar Rover/Mobility Systems Workshop. Exploration Programs Office Document \#EXPO-T2-920004-EXPO. Houston, TX: NASA Johnson Space Center.

19. Brooks, R.A. 1986. "A Robust Layered Control System for a Mobile Robot," IEEE Journal of Robotics and Automatom. Vol. RA-2, no. 1. 14-23.

20. Miller, D.P. 1990. "Rover Navigation Through Behavior Modification," Fourth Annual Space Operations, Applications, and Research Symposium. Houston, TX: NASA Johnson Space Center. 


\section{APPENDIX A: RATLER TECHNICAL INFORMATION}

This appendix contains the following information:

RATLER Block Diagram (Figure A-1) ........................... A2

RATLER Kill Circuit Diagram (Figure A-2) ........................ A3

RATLER External Connectors ....................................... A4

RATLER I/O Assignments........................................... A6 


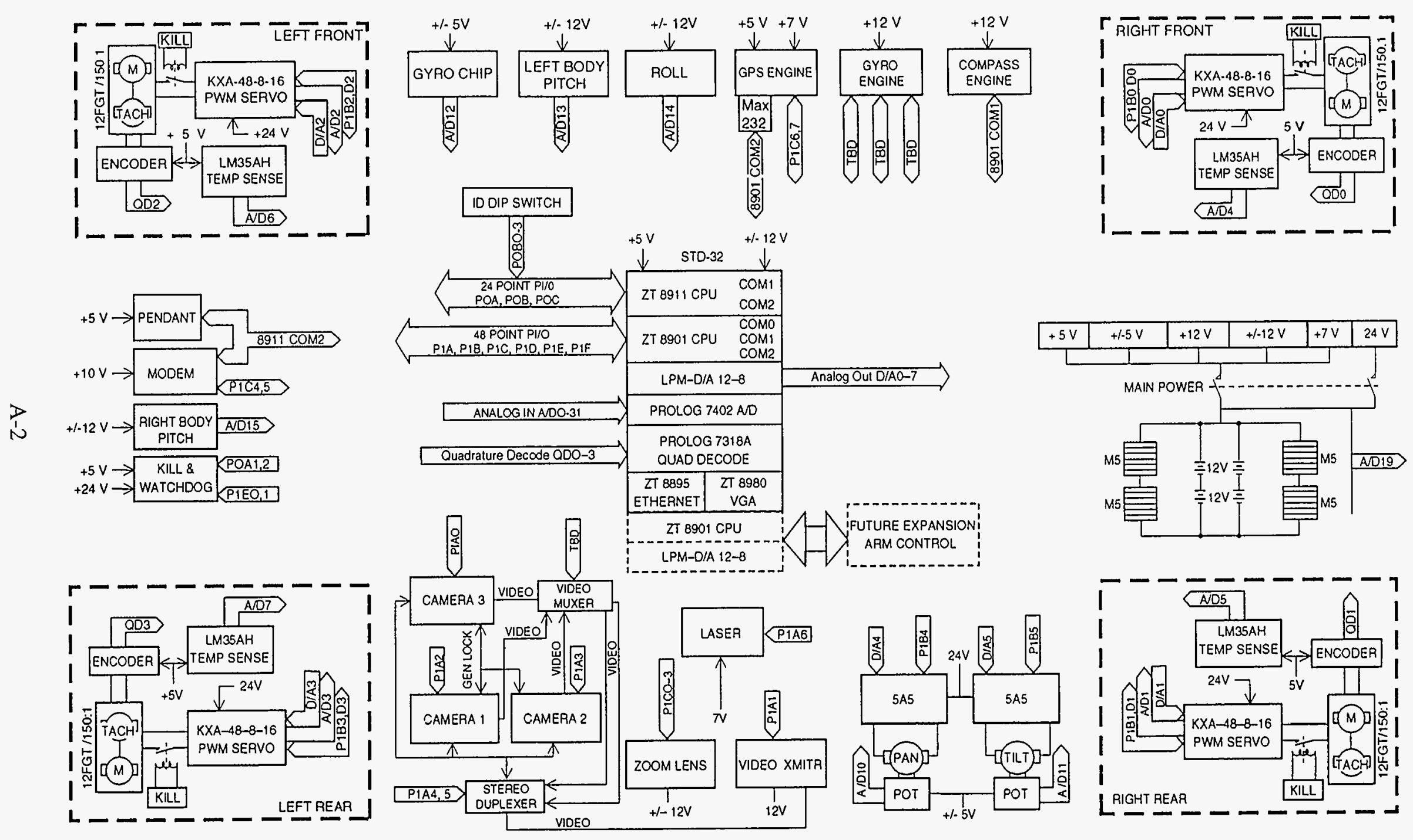

Figure A-1. RATLER Block Diagram. 


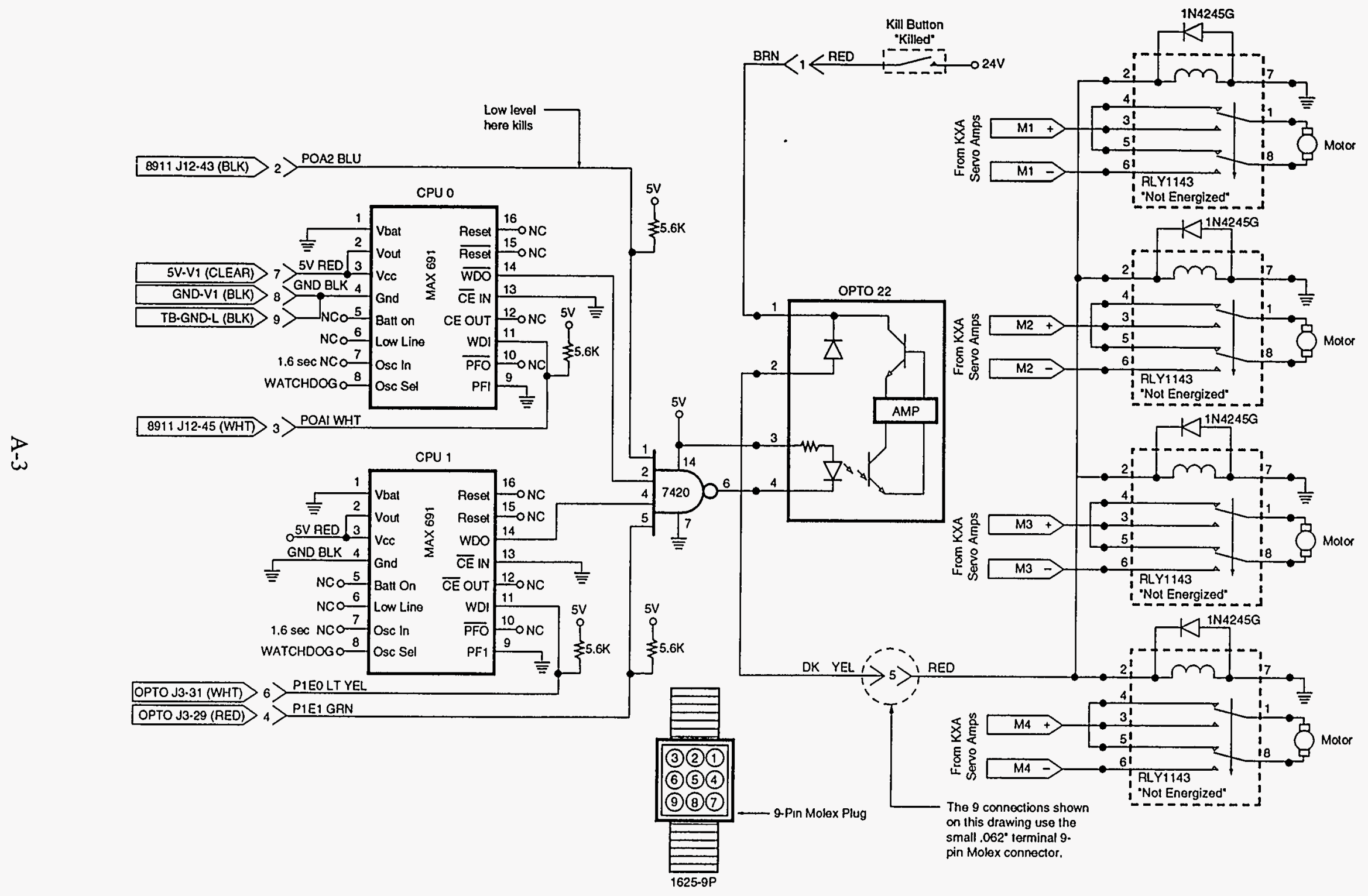

Figure A-2. RATLER Kill Circuit Diagram. 
RATLER External Connectors

\begin{tabular}{|c|l|}
\hline \multicolumn{2}{|c|}{ Charge Plug } \\
\hline $\begin{array}{c}\text { Bulkhead Connector: } \\
\text { Pigtail Connector: }\end{array} \quad$ ITT Canon KPT00P12-3S \\
\hline Pin & \multicolumn{1}{|c|}{ Function } \\
\hline A & +24 Volts DC (charging voltage: 27.6V DC @4.0 amps MAX) \\
B & Not Used \\
C & Ground \\
\hline
\end{tabular}

\section{Camera \& Laser Power}

Bulkhead Connector: ITT Canon KPT00P12-10S

Pigtail Connector: ITT Canon KPT08P12-10P

\begin{tabular}{|c|l|}
\hline Pin & \\
\hline A & Zoom + \\
B & Zoom - \\
C & Camera \#3 Power V+ \\
D & Camera \#1 Power V+ \\
E & Camera Power Ground \\
F & Camera \#2 Power V+ \\
G & Focus + \\
H & Focus - \\
J & Camera Shield \\
K & Zoom/Focus Shield \\
\hline
\end{tabular}




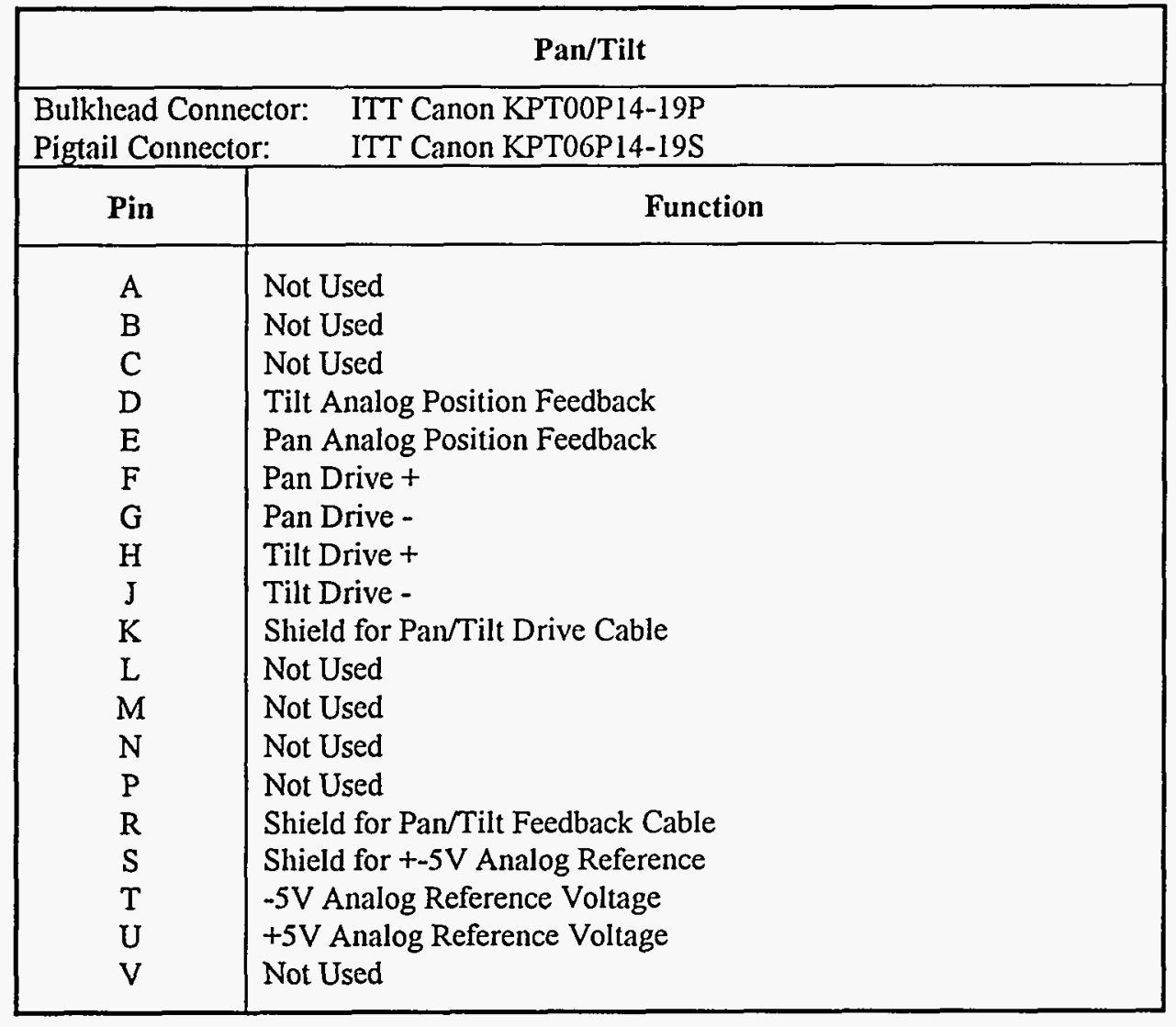




\section{RATLER I/O Assignments}

Ail I/O levels described below are logical levels. These are actually inverted at the output port so that the voltage level corresponding to logic 0 is $5 \mathrm{VDC}$ and to logic 1 is $0 \mathrm{VDC}$.

\section{ZT 8911 Master Processor}

\section{Serial Communications}

\begin{tabular}{|c|l|c|}
\hline Port & \multicolumn{1}{|c|}{ Function } & \multicolumn{1}{c|}{ Settings } \\
\hline COM1 & Not Used & \\
COM2 & RF Modem & 4800 baud, 1 stop, 1 start, no parity, 8 chars \\
\hline
\end{tabular}

Parallel I/O

\begin{tabular}{|c|l|l|}
\hline \multicolumn{3}{|c|}{ CPU 0, Port A - I/O Address 0×00E0 } \\
\hline Bit & \multicolumn{1}{|c|}{ Function } & \multicolumn{1}{c|}{ Description } \\
\hline & Not Used & \\
P0A0 & Kill Signal & Output, 1 = kill \\
P0A1 & 8911 watchdog signal & Output, toggle both ways $<1.6 \mathrm{sec}$ \\
P0A2 & Not Used & \\
P0A3 & Not Used & \\
P0A4 & Not Used & \\
P0A5 & Not Used & \\
P0A6 & Not Used & \\
P0A7 & & \\
\hline
\end{tabular}

\section{CPU 0, Port B - I/O Address 0x00E1}

\begin{tabular}{|c|l|l|}
\hline Bit & \multicolumn{1}{|c|}{ Function } & \multicolumn{1}{|c|}{ Description } \\
\hline & & \\
P0B0 & RATLER ID bit 0 & Input, inverted \\
P0B1 & RATLER ID bit 1 & Input, inverted \\
P0B2 & RATLER ID bit 2 & Input, inverted \\
P0B3 & RATLER ID bit 3 & Input, inverted \\
P0B4 & Not Used & \\
P0B5 & Not Used & \\
P0B6 & Not Used & \\
P0B7 & Not Used & \\
\hline
\end{tabular}




\begin{tabular}{|c|l|l|}
\hline \multicolumn{3}{|c|}{ CPU 0, Port C - I/O Address 0x00E2 } \\
\hline Bit & \multicolumn{1}{|c|}{ Function } & Description \\
\hline P0C0 & Not Used & \\
P0C1 & Not Used & \\
P0C2 & Not Used & \\
P0C3 & Not Used & \\
P0C4 & Not Used & \\
P0C5 & Not Used & \\
P0C6 & Not Used & \\
P0C7 & Not Used & \\
\hline
\end{tabular}




\section{ZT 8901 Vehicle Control Processor}

Serial Communications

\begin{tabular}{|c|l|l|}
\hline Port & \multicolumn{1}{|c|}{ Function } & \multicolumn{1}{|c|}{ Settings } \\
\hline COM0 & Not Used & \\
COM1 & KVH Compass Engine & 9600 baud, 1 start, 1 stop, no parity, 8 chars \\
COM2 & GPS Engine & 4800 baud, 1 start, 1 stop, no parity, 8 chars \\
\hline
\end{tabular}

Parallel I/O

(Note: 1 written to port turns on opto modules)

CPU 1, Port A - Opto Isolated, I/O Address 0x01F8

\begin{tabular}{|c|l|l|l|}
\hline Bit & \multicolumn{1}{|c|}{$\begin{array}{c}\text { Opto22 } \\
\text { Module }\end{array}$} & \multicolumn{1}{|c|}{ Function } & \multicolumn{1}{|c|}{ Description } \\
\hline P1A0 & MOD0 & Camera \#3 power switch & Output, 1 = power on \\
P1A1 & MOD1 & Video transmitter power switch & $\begin{array}{l}\text { Output, 1 = power on } \\
\text { Output, 1 = power on }\end{array}$ \\
P1A2 & MOD2 & Camera 1 power switch & Camera 2 power switch \\
P1A3 & MOD3 & Output, 1 = power on \\
P1A4 & MOD4 & Stereo video duplexer power & Output, 1 = power on \\
P1A5 & MOD5 & Duplexer control & To be determined \\
P1A6 & MOD6 & Laser power switch & Output, 1 = power on \\
P1A7 & MOD7 & Not Used & \\
\hline
\end{tabular}

\begin{tabular}{|c|l|l|l|}
\hline \multicolumn{4}{|c|}{ CPU 1, Port B - Opto Isolated, I/O Address 0x01F9 } \\
\hline Bit & \multicolumn{1}{|c|}{$\begin{array}{c}\text { Opto22 } \\
\text { Module }\end{array}$} & \multicolumn{1}{|c|}{ Function } & \multicolumn{1}{|c|}{ Description } \\
\hline & MOD8 & Right Front Servo Amp inhibit & Output, $0=$ inhibit \\
P1B1 & MOD9 & Right Rear Servo Amp inhibit & Output, $0=$ inhibit \\
P1B1 & MOD10 & Left Front Servo Amp inhibit & Output, 0 = inhibit \\
P1B2 & MOD11 & Left Rear Servo Amp inhibit & Output, $0=$ inhibit \\
P1B3 & MOD12 & Pan Servo Amp inhibit & Output, $0=$ inhibit \\
P1B4 & MOD13 & Tilt Servo Amp inhibit & Output, $0=$ inhibit \\
P1B5 & MOD14 & Not Used & \\
P1B6 & MOD15 & Not Used & \\
P1B7 & & & \\
\end{tabular}




\begin{tabular}{|c|l|l|l|}
\hline \multicolumn{5}{|c|}{ CPU 1, Port C - Opto Isolated, I/O Address 0x01FA } \\
\hline Bit & $\begin{array}{c}\text { Opto22 } \\
\text { Module }\end{array}$ & \multicolumn{1}{|c|}{ Function } & \multicolumn{1}{|c|}{ Description } \\
\hline & MOD16 & Zoom Drive & Output \\
P1C1 & MOD17 & Zoom Drive & Output \\
P1C1 & MOD18 & Focus Drive & Output \\
P1C2 & MOD19 & Focus Drive & Output \\
P1C3 & ROD20 & RF Modem power switch & Output, 1 = power on \\
P1C4 & MOD21 & RF Modem Tx key line & Output, 1 = Transmitter keyed \\
P1C5 & GPS Engine 7V power switch & Output, 1 = power on \\
P1C6 & MOD22 & GPS Engine 5V power switch & Output, 1 = power on \\
P1C7 & MOD23 & & \\
\hline
\end{tabular}

Note: $7 \mathrm{~V}$ supply must be removed before or at the same time as $5 \mathrm{~V}$ supply on GPS Engine

\begin{tabular}{|c|l|l|}
\hline \multicolumn{3}{|c|}{ CPU 1, Port D - I/O Address 0x01FB } \\
\hline Bit & \multicolumn{1}{|c|}{ Function } & \multicolumn{1}{|c|}{ Description } \\
\hline & & \\
P1D0 & Right Front Servo Amp fault & Input, $1=$ fault \\
P1D1 & Right Rear Servo Amp fault & Input, $1=$ fault \\
P1D2 & Left Front Servo Amp fault & Input, $1=$ fault \\
P1D3 & Left Rear Servo Amp fault & Input, $1=$ fault \\
P1D4 & Not Used & \\
P1D5 & Not Used & \\
P1D6 & Not Used & \\
P1D7 & Not Used & \\
\hline
\end{tabular}

\begin{tabular}{|c|l|l|}
\hline \multicolumn{3}{|c|}{ CPU 1, Port E - I/O Address 0x01FC } \\
\hline Bit & \multicolumn{1}{|c|}{ Function } & \multicolumn{1}{c|}{ Description } \\
\hline P1E0 & 8901 watchdog signal & Output, toggle both ways $<1.6 \mathrm{sec}$ \\
P1E1 & Kill signal used for 8901 faults & Output, 1 = kill \\
P1E2 & Not Used & \\
P1E3 & Not Used & \\
P1E4 & Not Used & \\
P1E5 & Not Used & \\
P1E6 & Not Used & \\
P1E7 & Not Used & \\
\hline
\end{tabular}




\begin{tabular}{|c|l|l|}
\hline \multicolumn{3}{|c|}{ CPU 1, Port F - I/O Address 0x01FD } \\
\hline Bit & \multicolumn{1}{|c|}{ Function } & Description \\
\hline & Not Used & \\
P1F0 & Not Used & \\
P1F1 & Not Used & \\
P1F2 & Not Used & \\
P1F3 & Not Used & \\
P1F4 & Not Used & \\
P1F5 & Not Used & \\
P1F6 & Not Used & \\
P1F7 & & \\
\hline
\end{tabular}




\begin{tabular}{|c|c|c|}
\hline \multicolumn{3}{|c|}{ ProLog 7402 A/D - I/O Address 0x0108 - 0x0128 } \\
\hline \multicolumn{3}{|c|}{ Board is set up for 32 single ended inputs } \\
\hline Bit & Function & Description \\
\hline $\mathrm{A} / \mathrm{D} 0$ & Right Front Drive Motor Current Sense & Scaling is $4.26 \mathrm{~A} / \mathrm{V}$. Range is $0-2.814 \mathrm{~V}$ \\
\hline $\mathrm{A} / \mathrm{DI}$ & Right Rear Drive Motor Current Sense & Scaling is $4.26 \mathrm{~A} / \mathrm{V}$, Range is $0-2.814 \mathrm{~V}$ \\
\hline $\mathrm{A} / \mathrm{D} 2$ & Left Front Drive Motor Current Sense & Scaling is $4.26 \mathrm{~A} / \mathrm{V}$, Range is $0-2.814 \mathrm{~V}$ \\
\hline A/D3 & Left Rear Drive Motor Current Sense & Scaling is $4.26 \mathrm{~A} / \mathrm{V}$, Range is $0-2.814 \mathrm{~V}$ \\
\hline $\mathrm{A} / \mathrm{D} 4$ & Right Front Drive Motor Temp & Scaling is $10 \mathrm{mV} / \mathrm{deg} \mathrm{C}$, Range is $-0.55 \mathrm{~V}$ to $1.5 \mathrm{~V}$ \\
\hline $\mathrm{A} / \mathrm{D} 5$ & Right Rear Drive Motor Temp & Scaling is $10 \mathrm{mV} / \mathrm{deg} \mathrm{C}$, Range is $-0.55 \mathrm{~V}$ to $1.5 \mathrm{~V}$ \\
\hline A/D6 & Left Front Drive Motor Temp & Scaling is $10 \mathrm{mV} / \mathrm{deg} \mathrm{C}$, Range is $-0.55 \mathrm{~V}$ to $1.5 \mathrm{~V}$ \\
\hline A/D7 & Left Rear Drive Motor Temp & Scaling is $10 \mathrm{mV} / \mathrm{deg} \mathrm{C}$, Range is $-0.55 \mathrm{~V}$ to $1.5 \mathrm{~V}$ \\
\hline A/D8 & CPU Temp & Scaling is $10 \mathrm{mV} / \mathrm{deg} \mathrm{C}$, Range is $-0.55 \mathrm{~V}$ to $1.5 \mathrm{~V}$ \\
\hline A/D9 & Not Used & \\
\hline $\mathrm{A} / \mathrm{D} 10$ & Pan Axis Position Feedback & Full Scale Output is +/-5 VDC \\
\hline $\mathrm{A} / \mathrm{D} 11$ & Tilt Axis Position Feedback & Full Scale Output is $+/-5$ VDC \\
\hline $\mathrm{A} / \mathrm{D} 12$ & Gyro Chip & $+/-2.5$ VDC Full Scale Output \\
\hline A/D13 & Left Body Half Pitch Inclinometer & +/- 3.6 VDC Full Scale Output \\
\hline A/D14 & Roll Inclinometer & +/- 3.6 VDC Full Scale Output \\
\hline $\mathrm{A} / \mathrm{D} 15$ & Right Body Half Pitch Inclinometer & +/- 3.6 VDC Full Scale Output \\
\hline $\mathrm{A} / \mathrm{D} 16$ & Not Used & \\
\hline $\mathrm{A} / \mathrm{D} 17$ & Not Used & \\
\hline A/D18 & Not Used & \\
\hline $\mathrm{A} / \mathrm{D} 19$ & Battery Voltage & Scaling is 6 battery volts/input volt, Range is 0 to $5 \mathrm{~V}$ \\
\hline $\mathrm{A} / \mathrm{D} 20$ & Not Used & \\
\hline A/D21 & Not Used & \\
\hline $\mathrm{A} / \mathrm{D} 22$ & Not Used & \\
\hline A/D23 & Not Used & \\
\hline $\mathrm{A} / \mathrm{D} 24$ & Not Used & \\
\hline $\mathrm{A} / \mathrm{D} 25$ & Not Used & \\
\hline A/D26 & Not Used & \\
\hline A/D27 & Not Used & \\
\hline A/D28 & Not Used & \\
\hline A/D29 & Not Used & \\
\hline A/D30 & Not Used & \\
\hline A/D31 & Not Used & \\
\hline
\end{tabular}




\begin{tabular}{|c|l|l|}
\hline \multicolumn{3}{|c|}{ WinSystems LPM-D/A 12-8 - I/O Address 0xFCF0 - 0xFCFF } \\
\hline Bit & \multicolumn{1}{|c|}{ Function } & \multicolumn{1}{|c|}{ Description } \\
\hline & & \\
D/A0 & Right Front Drive Motor Speed Command & Full Scale $+/-10$ VDC \\
D/A1 & Right Rear Drive Motor Speed Command & Full Scale +/-10 VDC \\
D/A2 & Left Front Drive Motor Speed Command & Full Scale +/- 10 VDC \\
D/A3 & Left Rear Drive Motor Speed Command & Full Scale $+/-10$ VDC \\
D/A4 & Pan Motor Speed Command & Full Scale +/-10 VDC \\
D/A5 & Tilt Motor Speed Command & Full Scale +/- 10 VDC \\
A/D6 & Not Used & \\
D/A7 & Not Used & \\
\hline
\end{tabular}

\begin{tabular}{|c|c|c|}
\hline \multicolumn{3}{|c|}{ ProLog 7318 Quad Decoder - I/O Address 0x0400 - 0x041F } \\
\hline Bit & Function & Description \\
\hline QD0 & Right Front Odometer & 300,000 counts per revolution \\
\hline QD1 & Right Rear Odometer & 300,000 counts per revolution \\
\hline QD2 & Left Front Odometer & 300,000 counts per revolution \\
\hline QD3 & Left Rear Odometer & 300,000 counts per revolution \\
\hline
\end{tabular}




\section{DISTRIBUTION}

\section{Federal Agencies}

US Department of Energy

Albuquerque Operations Office

PO Box 5400

Albuquerque, NM 87185

US Department of Energy (2)

Office of environmental restoration and Waste

Management

Attn: EM-1

$$
\text { C. Frank, EM-50 }
$$

Washington, DC 20585

US Department of Energy (3)

Office of Environmental Restoration and Waste Management

Attn: $\quad$ M. Frei, EM-34, Trevion II

Director, Waste Management Projects

Washington, DC 20585-0002

US Department of Energy

Office of Environmental Restoration and Waste Management

Attn: J. Lytle, EM-30, Trevion II

Washington, DC 20585-0002

US Department of Energy

Office of Environmental Restoration and Waste Management

Attn: $\quad$ S. Schneider, EM-342, Trevion II

Washington, DC 20585-0002

US Department of Energy (4)

Office of Environment, Safety and Health

Attn: R. P. Berube, EH-20

C. Borgstrum, EH-25

R. Pelletier, EH-231

K. Taimi, EH-232

Washington, DC 20585

US Department of Energy

Technical Information Center

PO Box 62

Oak Ridge, TN 37831

US Department of Energy

Chicago Operations Office

Attn: J.C. Haugen

9800 South Cass Avenue

Argonne, ILL 60439
US Department of Energy

Los Alamos Area Office

528 35th Street

Los Alamos, NM 87544

US Environmental Protection Agency (2)

Altn: Radiation Protection Programs

Attn: $\quad M$. Oge

ANR-460

Washington, DC 20460

National Aeronautics and Space Administration 600 Independence Ave,

Telerobotics Program Manager

Attn: D. Lavery

Washington, DC 20546

National Aeronautics and Space Administration Langley Research Center

Attn: V. Gillespie

Hampton, VA 23665

National Aeronautics and Space Administration Johnson Space Center

Office of ARTEMIS Program Manager

Attn: D. Sancier

C. Meyer

Houston, TX 77058

National Aeronautics and Space Administration Ames Research Center

Artificial Intelligence Laboratory

Attn: B. Hine

G. Briggs

J. Steele

Moffett Field, CA 94035

Lt. Col. Mark Swinson

USMC

UGV/JPO

U.S. Army Missile Command (MICOM)

Attn: AMSMI-RD-UG (AMC-PM-UG)

Redstone Arsenal, BIdg. 5410

Huntsville, AL 35898

US Bureau of Land Management

New Mexico State Office

PO Box 1449

Santa Fe, NM 87507 
Energy and Science Division

Office of Management and Budget

Attn: K. Yuracko

725 17th Street NW

Washington, DC 20503

NASA HQ

MFPE

Code SX

Attn: Steven Brody

600 Independence Ave.

Washington, DC 20546

US Bureau of Mines

Pittsburgh Research Center

Attn: J. Sammarco

Cochrans Mill Rd.

PO Box 18070

Pittsburgh, PA 15236

\section{State Agencies}

Alamogordo Space Museum

Attn: Director

Alamogordo, NM 88310

New Mexico Bureau of Mines and Mineral

Resources

Attn: Director

Socorro, NM 87801

\section{National Laboratories}

Oak Ridge National Laboratory

Attn: J. Herndon

R. Mann

PO Box 2008

Oak Ridge, TN 37831

Los Alamos National Laboratory

Attn: D. Vaniman

D. Petit

J. Blacic

PO Box 1663

Los Alamos, NM 87545

\section{Corporations/Members of the Public}

Martin Marietta Astronautics

Robotics Division

PO Box 179

Attn: P. Shattuck

Denver, CO 80201
MITRE Corporation

Mobile Robotics Dept.

Attn: D. Miller

7525 Coldshire Dr.

McLean, VA 22102

Boeing Defense and Space Group

499 Boeing Blvd.

PO Box 240002

Attn: B. Griffin

Huntsville, AL 35824

Tech Reps, Inc. (2)

5000 Marble Avenue, NE \#222

Albuquerque, NM 87110-6343

Attn: T. Cameron

F. Puffer

Ziatech Corporation

Attn: D. Rennie

3433 Roberto Court

San Luis Obispo, CA 93401

Walt Disney World Co.

Attn: Dr. H. Robitaille, Director Science \& Technology EPCOT Center

PO Box 10,000

Lake Buena Vista, FL 32830-1000

\section{Universities}

\author{
Carnegie-Mellon University \\ 5000 Forbes Ave. \\ Field Robotics Center \\ Attn: K. Dowling \\ E. Krotkov \\ W. Whittaker
}

Pittsburgh, PA 15213

Georgia Institute of Technology

Civil Engineering Dept.

Attn: J. Brazell

Atlanta, GA 30332

Colorado School of Mines

Center for Space Mining

Attn: R. Miller

Golden, CO 80401 
Texas A\&M University

Civil Engineering Dept.

Attn: W. Boles

D. Maxwell

College Station, TX 77843

North Carolina State University

Civil Engineering Dept.

Attn: L. Bernold

Raleigh, NC 27607

University of California-Berkeley

Civil Engineering Dept.

Attn: L. Demsetz

Berkeley, CA 94720

University of Hawaii

Planetary Geosciences Div.

2525 Corret Rd.

Attn: J. Taylor

Honolulu, HI 96822

University of Houston

Lunar and Planetary Institute

3600 Bayaret Blvd.

Attn: P. Spudis

Houston, TX 77058

International Space University

International Space Power Program

Attn: Gregg Maryniak

6 Newel Place

Hopewell, NJ 08525

National Institute of Standards and Technology

Dept of Commerce

Attn: Dr. J. Albus

Robotics Division

Gaithersburg, MD 20899

University of Pittsburgh

School of Health \& Rehabilitation Sciences

Attn: Dr. D. Brienza

915 William Pitt Way

Pittsburgh, PA 15238

\section{Libraries}

New Mexico State Library

Attn: N. McCallan

325 Don Gaspar

Santa Fe, NM 87503
New Mexico Tech

Martin Speere Memorial Library

Campus Street

Socorro, NM 87810

University of New Mexico

Zimmerman Library

Government Publications Department

Albuquerque, NM 87131

\section{Individuals}

Ms. Bonnie Cooper

1620 Oakridge

Dickenson, TX 77539

Mr. W. Ferster

c/o Phillips Publishing

1925 N. Lynn St., Suite 1000

Arlington, VA 22209

R. J. Webb

NAVEODTECHDIV

USATECHDET

2008 Stump Neck Rd.

Indian Head, MD 20640

D. E. Koch

Det-63 ASC (USAF)

NAVEODTECHCEN

2008 Stump Neck Rd.

Indian Head, MD 20640

\section{Sandia Internal}

$\begin{array}{ll}\text { MS0103 } & \text { V.L. Dugan (12100) } \\ \text { MS0490 } & \text { S.D. Spray (12331) } \\ \text { MS0167 } & \text { K. Frazier (12630) } \\ \text { MS0320 } & \text { C.E. Meyer (1011) } \\ \text { MS0949 } & \text { R.W. Harrigan (2102) } \\ \text { MS1007 } & \text { A.T. Jones (2172) } \\ \text { MS0131 } & \text { J. Weiss (4500) } \\ \text { MS0872 } & \text { P.A. Longmire (5407) } \\ \text { MS0769 } & \text { R.W. Moya (5800) } \\ \text { MS0768 } & \text { J.W. Kane (5806) } \\ \text { MS0765 } & \text { D.E. McGovern (5821) } \\ \text { MS0776 } & \text { I.G. Waddoups (5845) } \\ \text { MS0304 } & \text { C.M. Hart (9100) } \\ \text { MS0860 } & \text { E.G. Kadlec (9122) } \\ \text { MS0970 } & \text { T.A. Sellers (9200) } \\ \text { MS0979 } & \text { L.S. Walker (9204) } \\ \text { MS0766 } & \text { J.R. Kelsey (9600) } \\ \text { MS0767 } & \text { E.R. Hoover (9603) } \\ \text { MS0767 } & \text { S.C. Roehrig (9604) }\end{array}$




$\begin{array}{ll}\text { MS0783 } & \text { S.H. Scott (9611) } \\ \text { MS0790 } & \text { H.J. Abeyta (9612) } \\ \text { MS0790 } & \text { J.J. Roesch (9613) } \\ \text { MS0763 } & \text { L.D. Scott (9614) } \\ \text { MS0764 } & \text { S.J. Wiessman (9615) } \\ \text { MS0763 } & \text { J.W. Williams (9621) } \\ \text { MS1125 } & \text { B.C. Caskey (9616) } \\ \text { MS1125 } & \text { P.R. Klarer (9616) (12) } \\ \text { MS0303 } & \text { M.M. Newsom (9700) } \\ \text { MS9018 } & \text { Central Technical Files (8523-2) } \\ \text { MS0619 } & \text { Technical Publications (13416) } \\ \text { MS0100 } & \text { Document Processing for DOE/OSTI } \\ & \text { (7613-2) (10) } \\ \text { MS0899 } & \text { Technical Library (13414) (5) } \\ \text { MS1125 } & \text { File (9616) } \\ \text { MS0357 } & \text { R.B. Asher (9835) }\end{array}$

